NBER WORKING PAPER SERIES

\title{
REORGANIZATION OR LIQUIDATION: BANKRUPTCY CHOICE AND FIRM DYNAMICS
}

\author{
Dean Corbae \\ Pablo D'Erasmo \\ Working Paper 23515 \\ http://www.nber.org/papers/w23515 \\ NATIONAL BUREAU OF ECONOMIC RESEARCH \\ 1050 Massachusetts Avenue \\ Cambridge, MA 02138 \\ June 2017
}

We thank Gian Luca Clementi, Hulya Eraslan, and Vincenzo Quadrini as well as seminar participants at Carnegie Mellon, Rice University, University College London, Ohio State University, BI Norwegian Business School, Bank of Canada, Konstanz University, Macro Finance Society, Society for Economic Dynamics Meetings, and the Econometric Society Summer Meetings for helpful comments. The views expressed in this paper are those of the authors and do not necessarily reflect those of the Federal Reserve Bank of Philadelphia, the Federal Reserve System, or the National Bureau of Economic Research.

NBER working papers are circulated for discussion and comment purposes. They have not been peer-reviewed or been subject to the review by the NBER Board of Directors that accompanies official NBER publications.

(C) 2017 by Dean Corbae and Pablo D'Erasmo. All rights reserved. Short sections of text, not to exceed two paragraphs, may be quoted without explicit permission provided that full credit, including $(\odot$ notice, is given to the source. 
Reorganization or Liquidation: Bankruptcy Choice and Firm Dynamics

Dean Corbae and Pablo D'Erasmo

NBER Working Paper No. 23515

June 2017

JEL No. E22,G32,G33

\begin{abstract}
$\underline{\text { ABSTRACT }}$
In this paper, we ask how bankruptcy law affects the financial decisions of corporations and its implications for firm dynamics. According to current U.S. law, firms have two bankruptcy options: Chapter 7 liquidation and Chapter 11 reorganization. Using Compustat data, we first document capital structure and investment decisions of non-bankrupt, Chapter 11, and Chapter 7 firms. Using those data moments, we then estimate parameters of a firm dynamics model with endogenous entry and exit to include both bankruptcy options in a general equilibrium environment. Finally, we evaluate a bankruptcy policy change recommended by the American Bankruptcy Institute that amounts to a "fresh start" for bankrupt firms. We find that changes to the law can have sizable consequences for borrowing costs and capital structure which via selection affects productivity (allocative efficiency rises by $2.58 \%$ ) and welfare (rises by $0.54 \%$ ).
\end{abstract}

\author{
Dean Corbae \\ Department of Economics \\ University of Wisconsin, Madison \\ 1180 Observatory Drive \\ Madison, WI 53706 \\ and NBER \\ corbae@ssc.wisc.edu \\ Pablo D'Erasmo \\ Federal Reserve Bank of Philadelphia \\ Research Department \\ Ten Independence Mall \\ Philadelphia PA 19106 \\ pabloderasmo@gmail.com
}




\section{Introduction}

According to Aghion, Hart, and Moore [2] (p. 524), Western bankruptcy procedures "are thought either to cause the liquidation of healthy firms (as in Chapter 7 of the U.S. Bankruptcy Code) or to be inefficient and biased toward reorganization under incumbent management (as in Chapter 11 in the United States)." Aghion, et. al. [2] go on to propose a bankruptcy policy similar to a recent proposal by the American Bankruptcy Institute that amounts to a "fresh start" for the firm (existing debt is forgiven, and the new all-equity firm is allocated to former claim holders using the priority rule). ${ }^{1}$ To evaluate the implications of bankruptcy procedures for firm value, industry dynamics, and household welfare, we estimate a structural corporate finance model with both Chapter 7 and Chapter 11 bankruptcy options using Compustat data and then consider the above mentioned policy counterfactual.

We find that the reform results in a considerable reduction of the bankruptcy rate (by $51.1 \%$ ) and a shift toward reorganization (away from inefficient liquidation) with a modest contraction of the exit rate. There is a significant increase in the investment rate $(+19.1 \%)$ at the firm level due, in most part, to a large reduction in the fraction of firms that operate in the "inaction" region (i.e., firms operating with investment rates close to $0 \%$ ). Prior to the reform, incentives to hold capital as collateral are stronger and induce firms to operate at an inefficient scale. Better credit terms after the reform result in a change in the firm size distribution (the average size of incumbent decreases, and the average size of the entrant increases), reduce the fraction of firms with investment bursts (by more than 5\%), improve allocative efficiency, and increase output weighted productivity by close to $0.5 \%$ (measured total factor productivity (TFP) increases by a similar percentage). The combination of these effects results in a reduction in aggregate adjustment and bankruptcy costs that induce an increase in aggregate consumption $(+0.54 \%){ }^{2}$

Besides evaluating an important policy counterfactual, our paper makes two further contributions to the literature. First, using Compustat data from 1980 to 2014, we document capital structure and investment differences between non-bankrupt, Chapter 11 and Chapter 7 firms. $^{3}$ Our paper thus complements several studies that document heterogeneity among firms that choose Chapter 7 and Chapter 11 bankruptcy. One of the most recent papers is by Bris, Welch, and Zhu [10] who provide a comprehensive study of the costs of Chapter 7 versus Chapter 11 in a sample of 300 public and private firms in Arizona and New York from 1995 to 2001. Reorganization by Chapter 11 comprises $80 \%$ of their sample. Chapter 11 firms are

\footnotetext{
${ }^{1}$ A Chapter 7 bankruptcy policy that gives consumers a "fresh start" has been in practice since 1978. For an analysis of the policy, see Livshits, MacGee and Tertilt [30] and Chatterjee, et. al. [12].

${ }^{2}$ The idea that policies that affect the cost of exit can have important implications for entry, the firm size distribution, and welfare is not new. For instance, Hopenhayn and Rogerson [26] (see Table 3) find that firing costs can have a significant impact on hiring, the firm size distribution, and welfare.

${ }^{3}$ We complement Compustat with information from the UCLA-LoPucki Bankruptcy Research Database.
} 
substantially larger in terms of assets, have a larger fraction of secured debt, and have roughly similar debt-to-asset ratios to Chapter 7 (see their Table 1). Importantly, their paper documents substantial differences in recovery rates. In particular, Table 13 documents the median (mean) recovery rate (as a percentage of the initial claim) as 5.8\% (27.4\%) for Chapter 7 , while it is $79.2 \%(69.4 \%)$ for Chapter 11 . Further, the fraction of firms that have $0 \%$ recovery is $79 \%$ for Chapter 7 and $0 \%$ for Chapter 11 . These means are similar to those by Acharya, Barath, and Srinivasan [1], who document (Table 8) that the mean recovery rate for Chapter 7 is $26.38 \%$ and for Chapter 11 is $68.43 \%{ }^{4}$

As Bris, et. al. [10] point out, whether a corporation files for Chapter 7 or 11 is endogenous, and self-selection can contaminate the estimation of bankruptcy costs. In particular, if firms self-select, then it could be misleading to compare the cost of procedures without controlling for endogeneity of chapter choice. The authors carefully attempt to control for self-selection into bankruptcy chapter (Chapter 7 or 11) in their regressions. Endogeneity issues lead us to consider a structural framework. Our second contribution is to extend the basic structural corporate finance models of Cooley and Quadrini [13], Gomes [20], and Hennessy and Whited [23] to incorporate a non-trivial bankruptcy choice. ${ }^{5,6,7}$ Adding a non-trivial bankruptcy choice to an environment where cash flows can turn negative (due to fixed costs, as in Hopenhayn [24]) has important implications beyond the selection issues raised above. For instance, it implies that liquidation arises in equilibrium for a subset of firms in our model, while it does not in Cooley and Quadrini [13] or Hennessy and Whited [23]. It even shows up methodologically since, with liquidation costs that depend on the amount of collateral, here we must expand the state space and cannot simply use net worth. Further, these papers only consider take-itor-leave-it bargaining in renegotiation. ${ }^{8}$

Our paper proceeds as follows. In Section 2, we document bankruptcy facts in the Compustat dataset. In Section 3, we propose a general equilibrium environment with firm dynamics where there are Chapter 7 and Chapter 11 bankruptcy choices. Section 4 defines an equilibrium, and Section 5 estimates model parameters for that environment. Section 6 presents equilibrium capital structure and investment decision rules in the presence of competitive debt

\footnotetext{
${ }^{4}$ These values are themselves averages between no industry distress and industry distress states.

${ }^{5}$ In an important corporate finance paper, Broadie, Chernov, and Sundaresan [11] study Chapter 7 versus Chapter 11 decision problem but in a much simpler model with exogenous cash flows and initial bond finance of fixed investment. Also related are Peri [35], who in a model with fixed capital, focuses on labor contract renegotiations during Chapter 11 reorganization, and Tamayo [40], who studies the effects of eliminating Chapter 11 reorganization in a partial equilibrium model with private information where default can lead to liquidation or reorganization but debt is constant over the life of the firm.

${ }^{6}$ Other closely related papers that incorporate liquidation include Arellano, Bai and Zhang [6]; D'Erasmo and Moscoso Boedo [16]; Khan, Senga, and Thomas [28]; Meh and Terajima [32]; and Cooper and Ejarque [14].

${ }^{7}$ Our paper also contributes to the literature on firm dynamics and misallocation pioneered by Restuccia and Rogerson [36] and Hsieh and Klenow [27], with important contributions by Guner, Ventura, and Xu [21]; Midrigan and Xu [31]; and Moll [33]. See Hopenhayn [25] for a recent review of the literature.

${ }^{8}$ Eraslan [18] studies Chapter 11 in a more general bargaining environment.
} 
pricing, as well as Chapter 7 versus Chapter 11 event analyses. Section 7 evaluates the positive and normative consequences of the policy counterfactual based on the "fresh start" proposal by the American Bankruptcy Institute. Section 8 concludes.

\section{Bankruptcy Facts from Compustat}

Given the fact that the vast majority of empirical corporate finance papers use data from Compustat, we organize bankruptcy facts using Compustat data from 1980 to 2014. This is obviously a different sample than that in Bris, et. al. [10]. Some of our facts are similar to those in Bris, et. al. [10] (e.g., the fraction of Chapter 11 bankruptcies relative to the total number of bankruptcies), while other facts differ (firms are more highly levered in their sample). We note, however, that there can be substantial differences in reported bankruptcy facts across datasets. For instance, bankruptcy statistics on all business filings from the U.S. Courts (www.uscourts.gov/Statistics/BankruptcyStatistics.aspx) suggest that the Bris, et. al. [10] sample as well as ours overstates the proportion of Chapter 11 business bankruptcies. For instance, in the U.S. Courts dataset (which includes smaller firms), the fraction of Chapter 11 business bankruptcies out of total business bankruptcies was roughly $25 \%$ for the year ending in December 2013.

Besides simply comparing characteristics of firms in the state of bankruptcy as in [10] or the U.S. Courts dataset, here we also compare characteristics of firms that are not bankrupt with those that are bankrupt. Table 1 displays a summary of some key differences between Chapter 7, Chapter 11, and non-bankrupt firm variables, which have analogues in our model (see Appendix A1 for a detailed description of the data). Since there can be substantial differences between the median and mean of these variables, the table provides both. In Figures 1 and 2, we graph the conditional distributions of some of the key variables in the model. Further, we test whether the means differ between Chapter 7, Chapter 11, and non-bankrupt.

We follow the classification of Chapter 7 and Chapter 11 bankruptcy used by Duffie, Saita, and Wang [17]. Chapter 7 in Table 1 corresponds to values for the final observation of a firm that exits via a Chapter 7 bankruptcy. Chapter 11 refers to an observation in the initial period of a Chapter 11 bankruptcy. Non-bankrupt identifies annual observations of firms that are not in the state of bankruptcy (i.e., firms that never declare bankruptcy) as well as observations of firms before they declare bankruptcy, excluding the above. To be consistent with the way that the U.S. Census Bureau constructs its exit statistics, a deleted firm (i.e., a firm that disappears from our sample) is counted as a firm that exits if its deletion code is not 01 (mergers and acquisitions), 02 (bankruptcy which we associate with Chapter 11), 04 (reverse acquisition), 09 (going private), or 07 and 10 (other). For example, this means that firms that are acquired or go from public to private are not counted as exiting. Code 03 is defined as liquidation, 
which we associate with Chapter 7. In the Appendix, we provide more information about the frequencies of those events.

Table 1: Balance Sheet and Corporate Bankruptcies 1980 to 2014

\begin{tabular}{|c|c|c|c|c|c|c|}
\hline \multicolumn{7}{|l|}{ Moment } \\
\hline Frequency of Exit (\%) & \multicolumn{6}{|c|}{1.10} \\
\hline Fraction of Exit by Chapter $7(\%)$ & \multicolumn{6}{|c|}{19.83} \\
\hline Frequency of (All) Bankruptcy (\%) & \multicolumn{6}{|c|}{0.96} \\
\hline Fraction of Chapter 11 Bankruptcy (\%) & \multicolumn{6}{|c|}{79.15} \\
\hline & \multicolumn{2}{|c|}{ Non-Bankrupt } & \multicolumn{2}{|c|}{ Chapter 11} & \multicolumn{2}{|c|}{ Chapter 7} \\
\hline & Avg. & Median & Avg. & Median & Avg. & Median \\
\hline Capital (millions 1983\$) & 953.18 & 35.61 & $408.78^{*, * * *}$ & 70.05 & $88.02^{* *}$ & 24.58 \\
\hline Cash (millions 1983\$) & 125.77 & 9.87 & $52.84^{*, * * *}$ & 5.78 & $14.70^{* *}$ & 3.74 \\
\hline Assets (millions 1983\$) & 1371.17 & 95.59 & $503.79^{*, * * *}$ & 97.49 & $139.16^{* *}$ & 53.57 \\
\hline Op. Income (EBITDA) / Assets (\%) & 5.49 & 10.90 & $-8.34^{*}$ & -1.18 & -12.36 & -5.34 \\
\hline Net Debt / Assets (\%) & 9.11 & 11.30 & $29.61^{*, * * *}$ & 25.25 & $21.80^{* *}$ & 20.28 \\
\hline Total Debt / Assets (\%) & 28.31 & 24.45 & $41.99^{*, * * *}$ & 36.81 & $39.74^{* *}$ & 34.12 \\
\hline Frac. Firms with Negative Net Debt (\%) & 36.07 & - & $21.88^{*}$ & - & $29.30^{* *}$ & - \\
\hline Secured Debt / Total Debt (\%) & 43.90 & 40.77 & $47.63^{*}$ & 43.91 & $49.67^{* *}$ & 48.59 \\
\hline Interest Coverage (EBITDA/Interest) & 14.01 & 4.89 & $-0.22^{*}$ & -0.22 & $-6.42^{* *}$ & -0.32 \\
\hline Equity Issuance / Assets (\%) & 4.70 & 0.06 & $2.84^{*}$ & 0.01 & $2.64^{* *}$ & 0.01 \\
\hline Fraction Firms Issuing Equity (\%) & 22.04 & - & $13.14^{*}$ & - & $15.61^{* *}$ & - \\
\hline Net Investment / Assets (\%) & 1.16 & 0.34 & $-2.94^{*}$ & -3.09 & $-2.24^{* *}$ & -2.30 \\
\hline Dividend / Assets (\%) & 3.49 & 2.03 & $1.80^{*}$ & 0.87 & $2.31^{* *}$ & 1.19 \\
\hline Z-score & 3.74 & 3.20 & $-1.36^{*, * * *}$ & -0.05 & $-1.42^{* *}$ & 0.14 \\
\hline DD Prob. of Default (\%) & 2.13 & 0.01 & $3.60^{*}$ & 1.24 & $3.71^{* *}$ & 1.07 \\
\hline
\end{tabular}

Note: See Appendix A1 for a detailed definition of variables and the construction of bankruptcy and exit

indicators. Medians (average) reported in the table correspond to the time series average of the cross-sectional median (mean) obtained for every year in our sample. Test for differences in means at

10\% level of significance: ${ }^{*}$ denotes Chapter 11 different from non-bankrupt, ${ }^{* *}$ denotes Chapter 7 different from Non-bankrupt, ${ }^{* * *}$ denotes Chapter 11 different from Chapter 7. DD, distance to default,

EBITDA, earnings before interest, tax, depreciation and authorization

Table 1 documents that exit rates (fraction of firms that exit out of all firms in a given year) are small $(1.10 \%)$ in our sample and, $20 \%$ of exits are by Chapter 7 liquidation. ${ }^{9}$ The fraction

\footnotetext{
${ }^{9}$ Note that in a stationary environment (or period by period if working with a time series), the frequency of exit, the fraction of exit by Chapter 7, the frequency of (all) bankruptcy, and the fraction of Chapter 11 bankruptcy are not independent moments. In particular, it is possible to write one of these moments as a function of the other three. For example, let $f^{x}, f^{b}, f^{b, 11}$ denote the frequency of exit, the frequency of (all) bankruptcy, and the fraction of Chapter 11 bankruptcy, respectively. Then, the fraction of exit by Chapter 7 equals $\frac{f^{b}\left(1-f^{b, 11}\right)}{f^{x}}$. The moments shown in Table 1 correspond to the time series average with the exception of the fraction of exit by Chapter 7 that
} 
of all firms declaring bankruptcy is also small (0.96\%) in our sample; $79 \%$ of bankruptcies are by Chapter 11 (as in [10]).

Since firms in our model choose physical capital and net debt (total debt minus cash), we examine differences in size measured by total assets. Non-bankrupt firms are bigger than Chapter 11 firms, which in turn are bigger than Chapter 7 firms. In all cases, the differences in mean are statistically significant (at the 10\% level).

Earnings before interest, taxes, depreciation, and amortization (EBITDA) measure a firm's profitability. Negative values generally indicate a firm has fundamental profitability issues, while a positive value does not necessarily mean it is profitable since it generally ignores changes in working capital as well as the other terms described above. The median and mean ratio of EBITDA to assets is negative for both Chapter 11 and Chapter 7 firms, while it is positive for non-bankrupt firms. Differences in mean between non-bankrupt versus Chapter 11 and Chapter 7 are statistically significant, but not statistically significant between Chapter 11 versus Chapter 7 . These statistics accord well with the idea that bankrupt firms have profitability problems.

We provide several measures of leverage. Net debt is measured as debt minus cash, where negative values imply that the firm is highly liquid. We find that both median and mean net debt or total debt to assets are highest for Chapter 11 and lowest for non-bankrupt firms. Statistical significance of differences in mean leverage exists across all types. The time average of the fraction of firms with negative net debt (i.e., liquid firms) is higher for non-bankrupt than bankrupt firms. There is a statistically significant difference in means between bankrupt and non-bankrupt, as well as between Chapter 11 and Chapter 7. The ratio of secured to total debt is highest for Chapter 7 and lowest for non-bankrupt firms. There is a statistically significant difference in means between non-bankrupt versus Chapter 11 and Chapter 7, but not between Chapter 11 and Chapter 7. Interest coverage is measured as the ratio of EBITDA to interest expenses. It is generally thought that a ratio less than one is not sustainable for long. Here we see that both mean and median interest coverage is positive and large for non-bankrupt firms, while it is in general negative for bankrupt firms. There are insignificant statistical differences in mean between the two bankruptcy choices, but the differences are statistically significant between bankrupt and non-bankrupt.

presents the value consistent with the other three in a stationary environment. Since there is significant variation in the value of this moment over time (the maximum observed is $100 \%$ and the minimum is $1.6 \%$ ), the time series average of this moment is different from the value consistent with the other three moments and reported in the table (59.88 versus 19.83$)$. 
Figure 1: Distribution of Debt/Assets and EBITDA/Assets
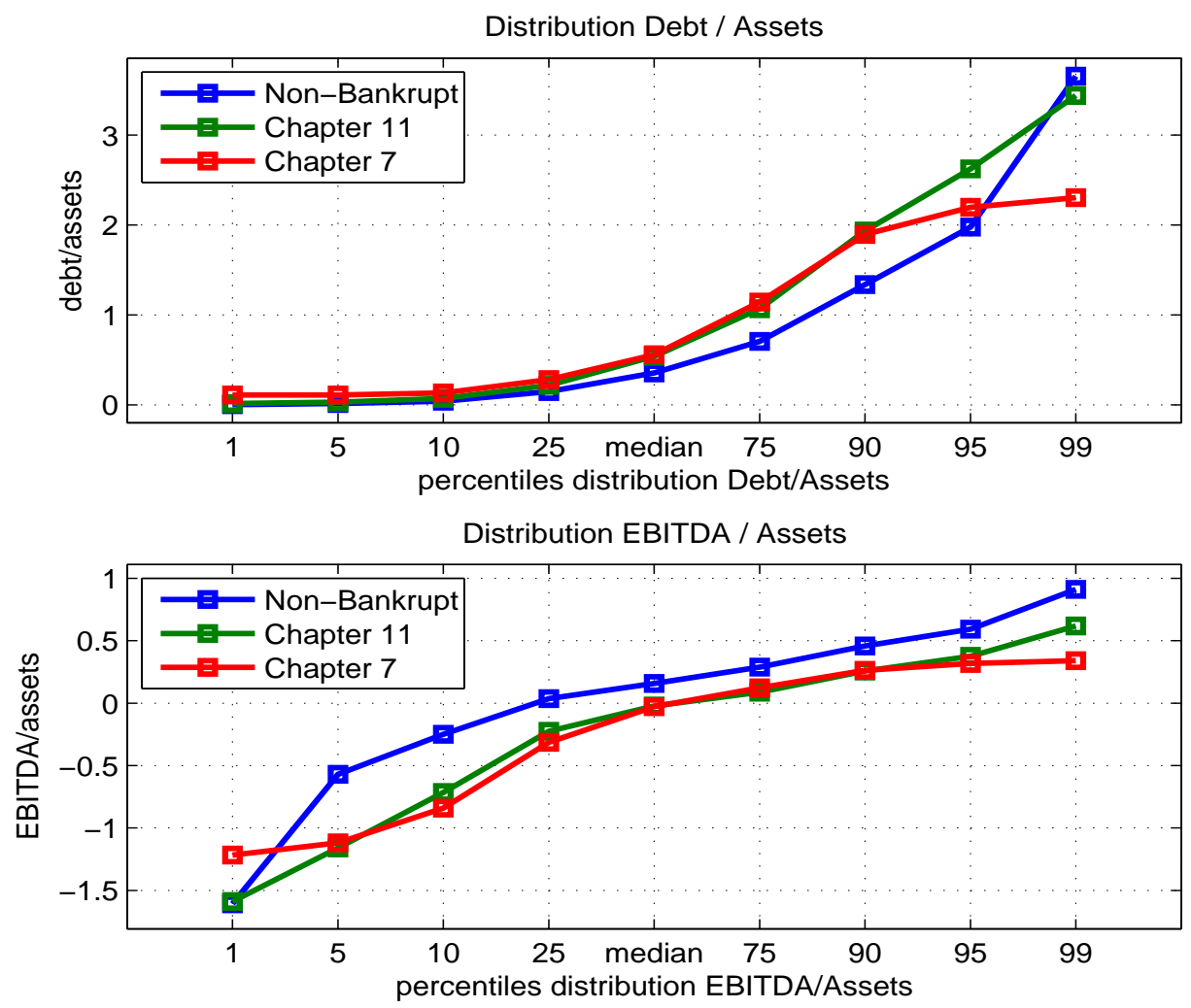

Equity issuance is highest for non-bankrupt firms, and it is statistically significant relative to bankrupt firms but statistically insignificant between bankruptcy choices. The time average of the fraction of firms issuing equity in any given period is highest for Chapter 11 and lowest for Chapter 7, though the differences are only statistically significant between non-bankrupt and bankrupt.

Median and average net investment (gross investment minus depreciation) is positive for non-bankrupt firms and negative for bankrupt firms. The differences between non-bankrupt and bankrupt are statistically significant but not statistically significant between Chapter 11 and Chapter 7. Dividend payouts are highest for non-bankrupt firms and lowest for Chapter 11 firms. In terms of means, there is a statistically significant difference between Chapter 11 and other types of firms.

We also consider two well accepted measures of corporate default probabilities from the finance literature: z-scores and distance-to-default (DD). The Altman [3] z-score is a linear combination of five common firm-level ratios: working capital to assets, retained earnings to assets, earnings before interest and taxes, market value of equity to book value of total liabilities, and sales to total assets. While simplistic, Altman's z-score is widely used by 
practitioners as a predictor of default within the next two years, with values greater than 2.9 deemed safe while values less than 1 are indicative of distress. Table 1 documents that both the median and average z-scores for non-bankrupt firms exceed 3, while z-scores for both Chapter 7 and Chapter 11 are generally below 1. All differences in mean are statistically significant. The DD measure is based upon an estimate of the asset value and volatility of a firm using an option pricing model, along with the observed book value of debt and market value of equity. To compute estimates of asset value and volatility, we use an iterative procedure as in Duffie, et. al. [17] (see Appendix for a full description of the construction of DD). Table 1 documents that the average DD is significantly higher for firms we classify as bankrupt than non-bankrupt.

Figure 2: Distribution of Net Investment/Assets and z-scores
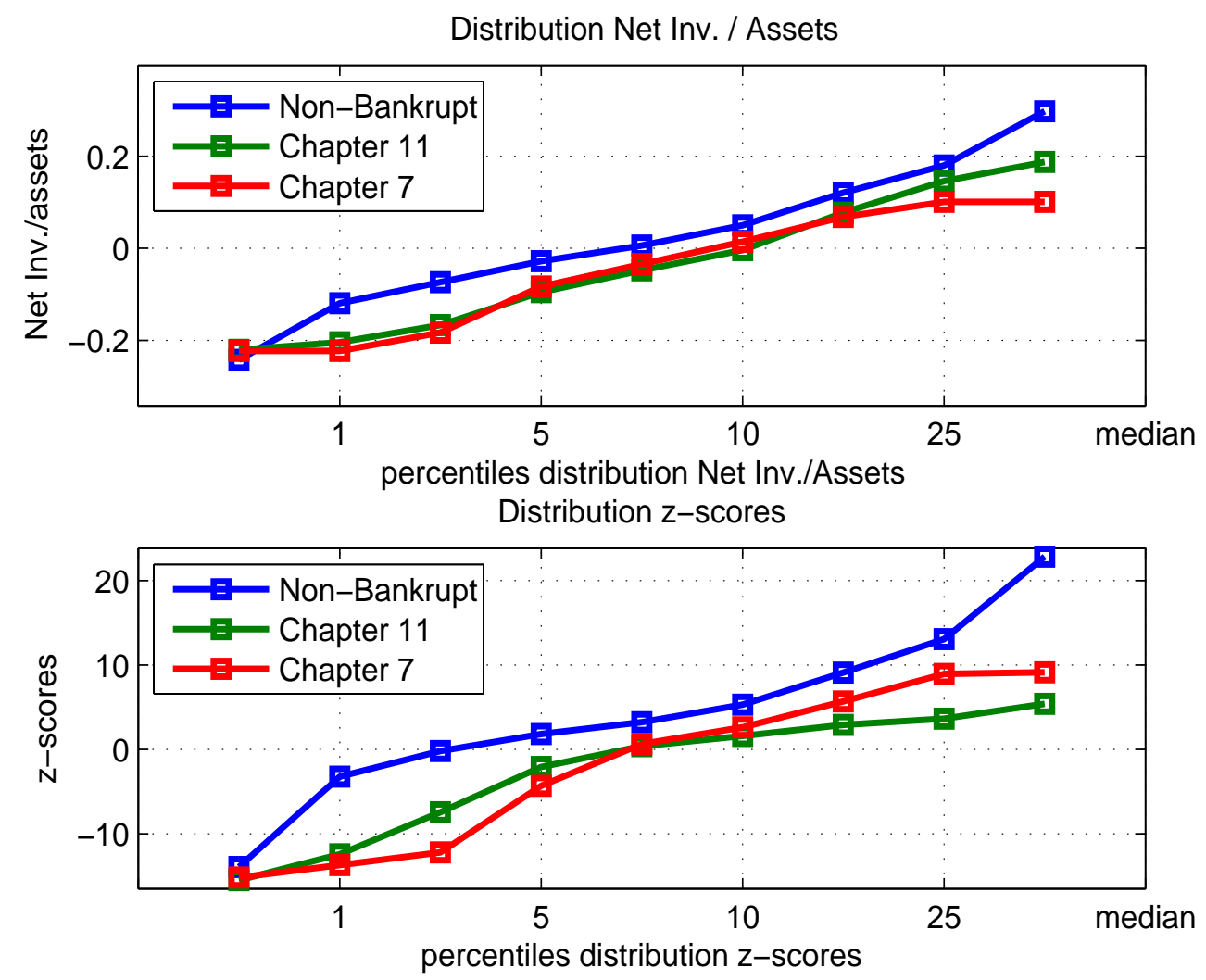

In summary, non-bankrupt firms: (i) are bigger than bankrupt firms; (ii) are profitable while bankrupt firms are not; (iii) have lower leverage than bankrupt firms; (iv) have lower interest expenses relative to their cash flow; (v) do not have statistically significant differences in equity issuance; (vi) have positive net investment as opposed to negative net investment for bankrupt firms; (vii) have higher dividend payouts than bankrupt firms; and (viii) have lower likelihoods of default as measured by practitioners "models" of default. Further, in terms 
of statistical significance, there is resounding support for differences between bankrupt and non-bankrupt firms but slightly less so between firms that choose Chapter 11 versus Chapter 7. This latter result could be due to the small sample size of bankrupt firms.

\section{Environment}

We consider a discrete time, general equilibrium model where heterogeneous firms produce a homogeneous good and issue short-term defaultable debt and costly equity to undertake investment and dividend choices. Since firms can choose Chapter 7 or Chapter 11 bankruptcy, competitive lenders must attempt to predict default decisions of the firms they are lending to when determining the price of debt. There is a representative household that maximizes lifetime utility and whose income comes from wages and dividends on the shares that the representative household holds in every firm. We will focus our attention on a stationary equilibrium characterized by a measure of firms endogenously distributed across productivity, capital, and net debt.

\subsection{Firms and Technology}

Competitive firms produce a homogeneous good that can be consumed by households or can be used as capital. Firm $j$ maximizes the expected discounted value of dividends:

$$
E_{0} \sum_{t=0}^{\infty}(1+r)^{-t} d_{j t}
$$

where $d_{j t}$ denotes dividends in period $t$ and $(1+r)^{-1}$ is the discount rate of the firm. ${ }^{10}$ Firms have access to a decreasing returns to scale production technology:

$$
y_{j t}=z_{j t}\left(k_{j t}^{\alpha} n_{j t}^{1-\alpha}\right)^{\nu}, \quad \alpha \in(0,1), \nu \in(0,1),
$$

where $z_{j t} \in Z \equiv\left\{z^{1}, \ldots, z^{n}\right\}$ is an idiosyncratic productivity shock, i.i.d. across firms, that follows a first-order Markov process with transition matrix $G\left(z_{j t+1} \mid z_{j t}\right) ; n_{j t} \in \mathbb{R}_{+}$is labor input; and $k_{j t} \in K \subset \mathbb{R}_{+}$is capital input. There is a fixed cost of production $c_{f}$, measured in units of output. Firms must pay this fixed cost in order to produce. Active firms own their capital and decide the optimal level of gross investment: $i_{j t}^{g}=k_{j t+1}-(1-\delta) k_{j t}=i_{j t}^{n}+\delta k_{j t}$,

\footnotetext{
${ }^{10}$ Since there are no aggregate shocks in this model, to conserve on notation here we define the objective using a constant discount rate, which is consistent in equilibrium.
} 
where $i_{j t}^{n}$ is net investment. Firms pay capital adjustment costs:

$$
\Psi\left(k_{j t+1}, k_{j t}\right) \equiv \frac{\psi}{2}\left(\frac{i_{j t}^{g}}{k_{j t}}\right)^{2} k_{j t} .
$$

In any given period, firm $j$ 's operating income (EBITDA) is given by:

$$
\pi_{j t}=y_{j t}-w_{t} n_{j t}-c_{f},
$$

where $w_{t}$ is the competitively determined real wage. Inputs can be financed from three sources: $(i)$ one-period non-contingent debt $b_{j t+1} \in B \subset \mathbb{R}$ at discounted price $q_{j t} ;$ (ii) current cash flow and internal savings; and (iii) external equity at cost $\lambda$ to raise funds (so with our assumptions on taxes, firms will never find it optimal to simultaneously pay dividends and issue equity). Taxable income is $\Upsilon_{j t}=\pi_{j t}-\delta k_{j t}-\left(\frac{1}{q_{j t}}-1\right) \frac{b_{j t+1}}{(1+r)}$ (i.e., operating profits less economic depreciation less discounted interest expense) and corporate taxes are:

$$
T_{j t}^{c}=\mathbf{1}_{\left\{\Upsilon_{j t} \geq 0\right\}} \tau_{c} \cdot \Upsilon_{j t},
$$

where $\mathbf{1}_{\{\cdot\}}$ is the indicator function that takes value one if the condition in brackets holds and zero otherwise. ${ }^{11}$

The after-tax net cash flow to equity holders is given by:

$$
d_{j t}=\left\{\begin{array}{cc}
\left(1-\tau_{d}\right) e_{j t} & \text { if } e_{j t} \geq 0 \\
e_{j t}-\lambda\left(e_{j t}\right) & \text { if } e_{j t}<0
\end{array}\right.
$$

where:

$$
e_{j t}=\pi_{j t}-T_{j t}^{c}-i_{j t}^{g}-b_{j t}+q_{j t} b_{j t+1}-\Psi\left(k_{j t+1}, k_{j t}\right) .
$$

In particular, firms pay dividends if $e_{j t} \geq 0$, which incurs dividend taxes $\tau_{d}$. If $e_{j t}<0$, firms pay external finance costs $\lambda\left(e_{j t}\right)$. Provided taxable income is positive, the tax benefit of a unit of debt is given by $\left(1-\tau_{d}\right) \cdot \tau_{c}\left(\frac{1}{q_{j t}}-1\right) /(1+r)>0$.

Firms can enter by paying a cost $\kappa .{ }^{12}$ After paying this cost, which is financed by either equity or debt issue, firms observe their initial level of productivity $z_{j 0}$ drawn from the stationary distribution $\bar{G}(z)$ derived from $G\left(z_{j t+1} \mid z_{j t}\right)$. We denote the mass of new entrants as $M$.

\footnotetext{
${ }^{11}$ As in Strebulaev and Whited [38], we assume the firm takes the present value of the interest tax deduction in the period in which it issues debt. This allows us to avoid adding another state variable. Further, for simplicity, unlike Hennessy and Whited [23], we assume there are no loss limitations.

${ }^{12}$ In our benchmark, we set $\kappa$ as a resource cost. In Appendix A3.1, we analyze a different version of the model where $\kappa$ is denominated in labor units. The main results of our paper are robust to changes in the treatment of the entry cost.
} 


\subsection{Financial Markets}

Firms finance operations either through debt or equity. Equity issuance costs are an increasing function $\lambda\left(e_{j t}\right)$ of the amount of equity issued, and we normalize the number of shares per firm to 1 . A share is a divisible claim on the dividends of the firm.

Competitive lenders have access to one-period, risk-free, discount bonds at after-tax price $q_{t}^{B}$. Loans mature each period, and their price $q_{j t}$ depends on how much the firm borrows $b_{j t+1}$ as well as other characteristics such as firm capital holdings $k_{j t+1}$ (since this affects liquidation value) and current productivity $z_{j t}$. Debt is non-contingent in the sense that it does not depend on future $z_{j t+1}{ }^{13}$

Firms can default on their debt, triggering a bankruptcy procedure. To resemble U.S. law, we allow for two default options:

1. Chapter 7 liquidation: Firm $j$ liquidates its assets at firesale discount $s_{7}<1$, which it uses to pay debts; incurs a bankruptcy $\operatorname{cost} c_{7}$; and exits. Shareholders obtain (pre-tax) $\max \left\{s_{7} k_{j t}-b_{j t}-c_{7}, 0\right\}$. Lenders obtain $\min \left\{b_{j t}, \max \left\{s_{7} k_{j t}-c_{7}, 0\right\}\right\}$.

2. Chapter 11 reorganization: Firm $j$ and lenders renegotiate the defaulted debt, bargain over the repayment fraction $\phi_{j t}$ (where the firm's bargaining weight is given by $\theta$ ); the firm pays bankruptcy cost $c_{11}$, reduces its debt to $\phi_{j t} b_{j t}$ (where $\phi_{j t} \in[0,1]$ ), and faces equity finance costs $\lambda_{11}\left(e_{j t}\right)$, debt finance costs $\lambda_{11}^{b} \leq 1$, and a discount in its capital sales $s_{11}<1$ (i.e., $\mathbf{1}_{\left\{i_{j t}^{g}<0\right\}} s_{11} i_{j t}^{g}$ ); it is not allowed to pay dividends and continues operating (i.e., does not exit). ${ }^{14}$

When making a loan to a firm, lenders take into account that in the case of default they can recover up to a fraction of the original loan. As described above, the recovery rate of a loan depends on the bankruptcy procedure chosen by the firm. In the case of a Chapter 7 liquidation, when making a loan of size $b_{j t}$ in period $t$, lenders can expect to recover in period $t+1 \min \left\{b_{j t+1}, \max \left\{s_{7} k_{j t+1}-c_{7}, 0\right\}\right\}$, where $s_{7}$ is the scrap price of the firm's capital (which serves as collateral). ${ }^{15}$ If the firm chooses to reorganize (i.e., Chapter 11 ), the recovery rate in period $t+1$ will be $\phi_{j t+1}$. That is, lenders will recover a fraction of debt that they agree upon during the reorganization process. We assume the negotiation over recovery rate solves a Nash bargaining problem, where the firm's weight is $\theta$ and the lender's weight is $1-\theta$.

Of course, a firm can choose to exit without defaulting at any point in time. In this case, the firm liquidates its assets (at value $s_{x} \in\left(s_{7}, 1\right]$ ) and pays its debts in full.

\footnotetext{
${ }^{13}$ Our use of equilibrium price menus, which depend on agent characteristics in the presence of default in a quantitative model, is similar to that in Chatterjee, et. al. [12] and Hennessy and Whited [23].

${ }^{14}$ Bankruptcy laws do not allow firms to divert funds by distributing dividends. See Bharath, Panchapagesan, and Werner [9], who provide evidence that new financing under Chapter 11 comes with much more stringent restrictions from creditors.

${ }^{15}$ Hennesy and Whited [22] make a similar assumption. Stromberg [39] finds that asset fire sales and resales to management can lead to low salvage values and striking inefficiencies in the Chapter 7 procedure.
} 


\subsection{Households}

In any period $t$, households choose a stream of consumption $C_{t}$, shares $\left\{S_{j t+1}\right\}_{j}$ of incumbent and entrant firms, and risk-free bonds $B_{t+1}$ to maximize the expected present discounted value of utility given by:

$$
\max E_{0}\left[\sum_{t=0}^{\infty} \beta^{t} U\left(C_{t}\right)\right]
$$

subject to:

$$
C_{t}+\int p_{j t} S_{j t+1} d j+q_{t}^{B} B_{t+1}=w_{t}\left(1-\tau_{i}\right)+\int\left(p_{j t}+d_{j t}\right) S_{j t} d j+B_{t}+T_{t}^{h}
$$

where $p_{j t}$ is the after-dividend stock price of firm $j, q_{t}^{B}$ is the after-tax price of the risk-free discount bond, and $T_{t}^{h}$ are lump sum taxes/transfers for households. The marginal income $\operatorname{tax} \tau_{i}$ applied to wage and interest earnings is rebated back to households in $T_{t}^{h}$. It should be understood that the stock price of a firm that exits is taken to be zero and that, since preferences do not include leisure, households supply their unit of labor inelastically.

\subsection{Timing}

In this section, we describe the timing of the model. At the beginning of period $t$ :

1. Productivity $z_{j t}$ is realized. The state space for incumbent firm $j$ is given by $\left\{z_{j t}, k_{j t}, b_{j t}\right\}$.

2. Bankrupty decision for incumbent firms:

- If the firm chooses to declare bankruptcy, it chooses whether to exit by Chapter 7 liquidation or to continue via Chapter 11 reorganization.

- If the firm chooses Chapter 7 , it incurs costs $\left(c_{7}, s_{7}\right)$, pays "final dividends" $d_{j t}=\left(1-\tau_{d}\right) \max \left\{s_{7} k_{j t}-b_{j t}-c_{7}, 0\right\}$, and exits. ${ }^{16}$

- If the firm chooses Chapter 11, it bargains with lenders over a recovery rate $\phi_{j t}$ and incurs costs $c_{11}, s_{11}$. Once the firm and lenders agree on a recovery rate, the firm repays $\phi_{j t} b_{j t}$ and continues operating. Dividend payments are not allowed during the bankruptcy period. It chooses an amount of capital $k_{j t+1}$ and finances it via internal funds, new debt $b_{j t+1}$ at price $\lambda_{11}^{b} q\left(k_{j t+1}, b_{j t+1}, z_{j t}\right)$, and/or equity issuance with costs $\lambda_{11}\left(e_{j t}\right)$.

- If the firm chooses not to declare bankruptcy, it repays in full and chooses whether to continue or to exit.

\footnotetext{
${ }^{16}$ Note that because of our timing assumptions, the taxation issues about applying net operating losses in Chapter 7 are absent.
} 
- If firm $j$ chooses to continue after repaying $b_{j t}$, it chooses the amount of capital $k_{j t+1}$ and finances it via internal funds, debt $b_{j t+1}$ at price $q\left(k_{j t+1}, b_{j t+1}, z_{j t}\right)$, and/or equity issuance at cost $\lambda(e)$.

- If firm $j$ chooses to exit after repaying $b_{j t}$, it pays "final dividends" $d_{j t}=(1-$ $\left.\tau_{d}\right)\left(s_{x} k_{j t}-b_{j t}\right)$ if $c_{x} k_{j t} \geq b_{j t}$ and $d_{j t}=\left(c_{x} k_{j t}-b_{j t}\right)-\lambda\left(s_{x} k_{j t}-b_{j t}\right)$ otherwise. Note that repayment avoids both bankruptcy $\operatorname{costs} c_{7}$ as well as salvage value $s_{7}$.

3. Entry decision: Potential entrants decide whether to start a firm or not. If they enter, they pay the entry cost $\kappa$ and choose their initial level of capital by issuing equity at cost $\lambda_{E}\left(e_{j t}\right)$ or debt. The initial productivity shock is drawn from $\bar{G}(z)$.

4. Households choose shares and bonds, which given earnings and taxes determines their consumption. If the household chooses to purchase the stock of an entrant, then $S_{j t+1}=$ $S_{j t}$ and $d_{j t}=-k_{j t+1}+q\left(k_{j t+1}, b_{j t+1}\right) b_{j t+1}-\kappa-\lambda_{E}\left(-k_{j t+1}+q\left(k_{j t+1}, b_{j t+1}\right) b_{j t+1}-\kappa\right)$.

\section{Equilibrium}

We consider only stationary equilibria of the model. In what follows, we use the notation that $x_{t}=x$ and $x_{t+1}=x^{\prime}$. Rather than refer to a given firm by its name $j$, it will be named by its place in the cross-sectional distribution of firms $\Gamma(z, k, b)$. To save on notation, we avoid making the dependence of decision rules on prices explicit.

\subsection{Recursive Representation of the Firm's Problem}

An incumbent firm starts the period with productivity $z$, capital $k$, and debt $b$. First, it makes its bankruptcy decision. The value of the firm $V(z, k, b)$ is defined as follows:

$$
V(z, k, b)=\max _{\Delta \in\{0,1\}} V_{\Delta}(z, k, b)
$$

where $\Delta=0$ denotes the decision not to declare bankruptcy while $\Delta=1$ corresponds to the decision to declare bankruptcy.

Conditional on the bankruptcy choice, the firm must choose whether it wants to exit $x=1$ or not $x=0$. In particular:

$$
V_{\Delta}(z, k, b)=\max _{x \in\{0,1\}} V_{\Delta}^{x}(z, k, b)
$$

Note that a firm that chooses not to declare bankruptcy $(\Delta=0)$ still must choose whether it wants to exit $x=1$ or not $x=0$. On the other hand, a decision to declare bankruptcy and 
choose exit (i.e., $(\Delta=1, x=1))$ implies a Chapter 7 liquidation, while a decision to declare bankruptcy and not exit (i.e., $(\Delta=1, x=0))$ implies a Chapter 11 reorganization.

If the firm chooses not to declare bankruptcy and not to exit (i.e., $(\Delta=0, x=0)$ ), then:

$$
V_{0}^{0}(z, k, b)=\max _{n \geq 0, k^{\prime} \geq 0, b^{\prime}}\left\{d+(1+r)^{-1} E_{z^{\prime} \mid z}\left[V\left(z^{\prime}, k^{\prime}, b^{\prime}\right)\right]\right\}
$$

s.t.

$$
\begin{gathered}
e=\pi-T^{c}\left(k, z, k^{\prime}, b^{\prime}\right)-i^{g}-b+q\left(b^{\prime}, k^{\prime}, z\right) b^{\prime}-\Psi\left(k^{\prime}, k\right) \\
d=\left\{\begin{array}{cc}
\left(1-\tau_{d}\right) e & \text { if } e \geq 0 \\
e-\lambda(e) & \text { if } e<0
\end{array} .\right.
\end{gathered}
$$

We denote the optimal labor, capital, debt, and dividend decision rules by $n=h_{0}^{n}(z, k, b)$, $k^{\prime}=h_{0}^{k}(z, k, b), b^{\prime}=h_{0}^{b}(z, k, b)$, and $d=h_{0}^{d}(z, k, b)$, respectively.

If the firm chooses not to declare bankruptcy and to exit (i.e., $(\Delta=0, x=1))$, the dividend policy implies

$$
V_{0}^{1}(z, k, b)=\left\{\begin{array}{cc}
\left(1-\tau_{d}\right)\left(s_{x} k-b\right) & \text { if } s_{x} k \geq b \\
s_{x} k-b-\lambda\left(s_{x} k-b\right) & \text { if } s_{x} k<b
\end{array} .\right.
$$

That is, if the firm wishes to exit without using the limited liability benefit that Chapter 7 provides in the event of $s_{x} k<b$, it must pay off its debt by an equity infusion. ${ }^{17}$

If the firm chooses to declare bankruptcy but not to exit (i.e., a Chapter 11 reorganization $(\Delta=1, x=0))$, we can define payoffs, taking as given the recovery rate $\phi(z, k, b)$ which will be determined by Nash bargaining in subsection 4.4 below as:

$$
V_{1}^{0}(z, k, b)=\max _{n \geq 0, k^{\prime} \geq 0, b^{\prime}, d \leq 0}\left\{d+(1+r)^{-1} E_{z^{\prime} \mid z}\left[V\left(z^{\prime}, k^{\prime}, b^{\prime}\right)\right]\right\}
$$

s.t.

$e=\pi-T^{c}\left(k, z, k^{\prime}, b^{\prime}\right)-\mathbf{1}_{\left\{i^{g} \geq 0\right\}} i^{g}-\mathbf{1}_{\left\{i^{g}<0\right\}} s_{11} i^{g}-\phi(z, k, b) b+q\left(k^{\prime}, b^{\prime}, z\right) \lambda_{11}^{b} b^{\prime}-\Psi\left(k^{\prime}, k\right)-c_{11}$, $d=e-\lambda_{11}(e)$.

We allow the external finance $\operatorname{costs} \lambda_{11}^{b}$ and $\lambda_{11}(e)$ to differ for a firm under reorganization.

We denote the optimal labor, capital, debt, and dividend decision rules by $n=h_{1}^{n}(z, k, b)$, $k^{\prime}=h_{1}^{k}(z, k, b), b^{\prime}=h_{1}^{b}(z, k, b)$, and $d=h_{1}^{d}(z, k, b)$, respectively.

Finally, if the firm chooses to declare bankruptcy and to exit (i.e., a Chapter 7 liquidation $(\Delta=1, x=1))$, then:

$$
V_{1}^{1}(z, k, b)=\left(1-\tau_{d}\right) \max \left\{s_{7} k-b-c_{7}, 0\right\} .
$$

\footnotetext{
${ }^{17}$ Obviously, this won't happen in equilibrium, but the option must be allowed for completeness.
} 


\subsection{Entrants}

In order to draw an initial productivity $z_{0}$, entrants must pay $\kappa$. New firms are created with an initial value of equity raised by issuing new shares and debt. The value of a potential entrant is given by:

$$
V_{E}=\max _{k^{\prime} \geq 0, b^{\prime}}\left\{d_{E}+(1+r)^{-1} \sum_{z^{\prime}} V\left(z^{\prime}, k^{\prime}, b^{\prime}\right) \bar{G}\left(z^{\prime}\right)\right\}
$$

where:

$$
d_{E}=-k_{E}^{\prime}+q\left(k_{E}^{\prime}, b_{E}^{\prime}\right) b_{E}^{\prime}-\kappa-\lambda_{E}\left(-k_{E}^{\prime}+q\left(k_{E}^{\prime}, b_{E}^{\prime}\right) b_{E}^{\prime}-\kappa\right) .
$$

We denote the optimal capital and borrowing decision rules by $k_{E}^{\prime}$ and $b_{E}^{\prime}$.

\subsection{Lender's Problem}

Lenders pool risky corporate loans and borrow from households in the risk-free market at price $q^{B}$. The profit on a loan of size $b^{\prime}$ has two important components. First, the probability of default $\Lambda\left(b^{\prime}, k^{\prime}, z\right)$ is given by:

$$
\Lambda\left(b^{\prime}, k^{\prime}, z\right)=\sum_{\left\{z^{\prime} \in D_{7}\left(k^{\prime}, b^{\prime}\right)\right\} \cup\left\{z^{\prime} \in D_{11}\left(k^{\prime}, b^{\prime}\right)\right\}} G\left(z^{\prime} \mid z\right),
$$

where $D_{7}(k, b)$ and $D_{11}(k, b)$ denote the Chapter 7 and Chapter 11 default sets, respectively defined as:

$$
\begin{aligned}
D_{7}(k, b) & =\{z \in Z: \Delta(z, k, b)=1 \& x(z, k, b)=1\}, \text { and } \\
D_{11}(k, b) & =\{z \in Z: \Delta(z, k, b)=1 \& x(z, k, b)=0\} .
\end{aligned}
$$

The second important component of a lender's profit is the expected recovery rate. If the firm chooses to file for Chapter 7 bankruptcy, the lender recovers $\min \left\{b^{\prime}, \max \left\{s k^{\prime}-c_{7}, 0\right\}\right\}$. If the firm chooses to reorganize under Chapter 11 , the lender will recover $\phi\left(z^{\prime}, k^{\prime}, b^{\prime}\right) b^{\prime}$, which is the solution to a bargaining game between the firm and the lender. Thus, we can write the lender's profit function as follows:

$$
\begin{aligned}
\Omega\left(b^{\prime}, k^{\prime}, z\right)= & -q\left(b^{\prime}, k^{\prime}, z\right) b^{\prime}+q^{B}\left[1-\Lambda\left(b^{\prime}, k^{\prime}, z\right)\right] b^{\prime} \\
& +q^{B} \sum_{z^{\prime} \in D_{7}\left(k^{\prime}, b^{\prime}\right)} \min \left\{b^{\prime}, \max \left\{s 7 k^{\prime}-c_{7}, 0\right\}\right\} G\left(z^{\prime} \mid z\right) \\
& +q^{B} \sum_{z^{\prime} \in D_{11}\left(k^{\prime}, b^{\prime}\right)} \phi\left(z^{\prime}, k^{\prime}, b^{\prime}\right) b^{\prime} G\left(z^{\prime} \mid z\right) .
\end{aligned}
$$




\subsection{Reorganization}

Upon reaching a bargaining agreement, the value of defaulted debt is reduced to a fraction $\varphi$ of the unpaid debt $b$. The value of an agreement of size $\varphi$ to the firm is:

$$
V^{R}(z, k, b ; \varphi)=\max _{n, b^{\prime}, k^{\prime}, d \leq 0}\left\{d+(1+r)^{-1} E_{z^{\prime} \mid z}\left[V\left(k^{\prime}, b^{\prime}, z^{\prime}\right)\right]\right\}
$$

s.t.

$$
\begin{aligned}
e & =\pi-T^{c}\left(k, z, k^{\prime}, b^{\prime}\right)-\mathbf{1}_{\left\{i^{g} \geq 0\right\}} i^{g}-\mathbf{1}_{\left\{i^{g}<0\right\}} s_{11} i^{g}-\varphi b+q\left(k^{\prime}, b^{\prime}, z\right) \lambda_{11}^{b} b^{\prime}-\Psi\left(k^{\prime}, k\right)-c_{11}, \\
d & =e-\lambda_{11}(e) .
\end{aligned}
$$

After the repayment of a fraction $\varphi$ of debt, the firm chooses the optimal level of investment; can issue debt or equity, which may cost a different amount during renegotiation; and continues operating.

Since either the borrower or lender in the renegotiation phase of Chapter 11 has a right to declare Chapter 7 bankruptcy, we assume that the threat points are equal to the payoffs associated with Chapter 7 liquidation. ${ }^{18}$ In that case, the surplus for the firm is:

$$
W^{R}(z, k, b ; \varphi)=V^{R}(z, k, b ; \varphi)-\left(1-\tau_{d}\right) \max \left\{s_{7} k-b-c_{7}, 0\right\}
$$

Since the value of an agreement for the lender is $\varphi b$ (i.e., the recovery on defaulted debt), the surplus for the lender is:

$$
W^{L}(z, k, b ; \varphi)=\varphi b-\min \left\{b, \max \left\{s_{7} k-c_{7}, 0\right\}\right\}
$$

The recovery rate is then the solution to the following Nash bargaining problem:

$$
\phi(z, k, b) \equiv \arg \max _{\varphi \in[0,1]}\left[W^{R}(z, k, b ; \varphi)\right]^{\theta}\left[W^{L}(z, k, b ; \varphi)\right]^{1-\theta}
$$

s.t.

$$
\begin{aligned}
& W^{R}(z, k, b ; \varphi) \geq 0, \\
& W^{L}(z, k, b ; \varphi) \geq 0 .
\end{aligned}
$$

Due to the general equilibrium nature of our problem, it is difficult to sign the effect of changes of firm bargaining power $(\theta)$ on the fraction it repays lenders $\phi .{ }^{19}$ Notice further that

\footnotetext{
${ }^{18}$ As stated on p. 663 in Eraslan [18], "If no progress (in Chapter 11) is made toward agreement, then the court can decide to convert the case to Chapter 7." See also "Conversion or Dismissal" at www.uscourts.gov/FederalCourts/Bankruptcy/BankruptcyBasics/Chapter11.aspx.

${ }^{19}$ Appendix A3.4 presents a set of experiments to understand the effects of changes in $\theta$.
} 
if $\theta=1$, then the lender's surplus in (21) will be zero. In that case, an equilibrium with positive debt where $s_{7} k-c_{7}<0$ implies $\phi=0$ (i.e., if a firm with little capital has all the bargaining power, it doesn't repay debt in reorganization). However, if $s_{7} k-c_{7} \geq 0$, then even with $\theta=1$, creditors will receive some repayment (i.e., $\phi>0$ ). Thus, if high capital firms with debt enter reorganization (something which happens in the data and under our parameterization), then even if creditors have no bargaining it is possible that there will be some payment in Chapter 11.

\subsection{Household's Problem}

The first-order conditions for the household's problem (8) and (9) are given by:

$$
\begin{array}{rll}
B_{t+1} & : & q_{t}^{B} U^{\prime}\left(C_{t}\right)=\beta E_{t}\left[U^{\prime}\left(C_{t+1}\right)\right] \\
S_{j t+1}, \forall j & : & p_{j t} U^{\prime}\left(C_{t}\right)=\beta E_{t}\left[U^{\prime}\left(C_{t+1}\right)\left(p_{j t+1}+d_{j t+1}\right)\right] .
\end{array}
$$

In a steady state, this implies:

$$
\begin{aligned}
q_{t}^{B} & =\beta \\
p_{j t} & =\beta E_{t}\left[p_{j t+1}+d_{j t+1}\right] .
\end{aligned}
$$

To characterize stock prices, consider the case of an incumbent firm and let $p(z, k, b)=$ $V(z, k, b)-d(z, k, b)$. Then it is straightforward to show that (24) is equivalent to (10) or:

$$
\begin{aligned}
p(z, k, b) & =\beta E_{z^{\prime} \mid z}\left[p\left(z^{\prime}, k^{\prime}, b^{\prime}\right)+d\left(z^{\prime}, k^{\prime}, b^{\prime}\right)\right] \\
& \Longleftrightarrow V(z, k, b)-d(z, k, b)=(1+r)^{-1} E_{z^{\prime} \mid z}\left[V\left(z^{\prime}, k^{\prime}, b^{\prime}\right)\right] .
\end{aligned}
$$

In the case of purchasing a stock of an entrant, $S_{E}=S^{\prime}=S$, in which case $p_{j} S_{j t+1}$ and $p_{j} S_{j t}$ cancel and the initial equity injection given by $d_{E}$ in (17) is accounted for in the household's budget set (9).

An implication of $(25)$ is that firm optimization in a steady state implies:

$$
(1+r)^{-1}=\beta
$$




\subsection{Cross-Sectional Distribution}

Let $\bar{K} \subset K, \bar{B} \subset B$ and $\bar{Z} \subset Z$. Further, let $(\Delta(z, k, b), x(z, k, b))=\arg \max _{\Delta \in\{0,1\}, x \in\{0,1\}} V_{\Delta}^{x}(z, k, b)$.

The law of motion for the cross-sectional distribution of firms is given by:

$$
\begin{aligned}
\Gamma^{\prime}(\bar{K}, \bar{B}, \bar{Z} ; M, w)= & \int_{\bar{K}, \bar{B}} \sum_{\bar{Z}}\left\{\int _ { K , B } \sum _ { Z } ( 1 - x ( z , k , b ) ) \left[\mathbf{1}_{\{\Delta(k, b, z)=0\}} \mathbf{1}_{\left\{k^{\prime}=h_{0}^{k}(z, k, b), b^{\prime}=h_{0}^{b}(z, k, b)\right\}}\right.\right. \\
& \left.\left.+\mathbf{1}_{\{\Delta(k, b, z)=1\}} \mathbf{1}_{\left\{k^{\prime}=h_{1}^{k}(z, k, b), b^{\prime}=h_{1}^{b}(z, k, b)\right\}}\right] G\left(z^{\prime} \mid z\right) \Gamma(d k, d b, z)\right\} d k^{\prime} d b^{\prime} \\
& +M \sum_{\bar{Z}} \mathbf{1}_{\left\{k_{E}^{\prime}, b_{E}^{\prime}\right\}} \bar{G}(z),
\end{aligned}
$$

where $M$ is the mass of new entrants.

\subsection{Definition of Equilibrium}

A stationary Markov equilibrium is a list $\left\{V^{*}, w^{*}, r^{*}, q^{B *}, q^{*}, \phi^{*}, p^{*}, D_{7}^{*}, D_{11}^{*}, \Lambda^{*}, \Gamma^{*}, M^{*}, C^{*}, B^{* *}, S^{* *}, T^{*}\right\}$ such that:

1. Given $w, r, q$, and $\phi$, the value function $V^{*}$ is consistent with the firm's optimization problem in (12)-(15).

2. Given $V, w, r$, and $q$, the recovery rate $\phi^{*}(k, b, z)$ solves the bargaining problem (22).

3. The probability of default $\Lambda^{*}$ in (18) and the sets $D_{i}^{*}$ for $i=7,11$ are consistent with firm decision rules.

4. The equilibrium loan price schedule is such that lenders earn zero profits in expected value on each contract. That is, at $q^{*}\left(b^{\prime}, k^{\prime}, z\right), \Omega^{*}\left(b^{\prime}, k^{\prime}, z\right)=0$ in (19).

5. The cost of creating a firm is such that $V_{E}^{*}=0$ in (16).

6. $\Gamma^{*}(z, k, b)$ and $M^{*}$ in $(27)$ is a stationary measure of firms consistent with firm decision rules and the law of motion for the stochastic variables.

7. Given $w, q^{B}, p$, and taxes/tansfers $T^{h}$, households solve (8) and (9), and $\left(q^{B *}, p^{*}, r^{*}\right)$ are consistent with (23), (24), and (26).

8. Labor, bond, and stock markets clear at $w^{*}, q^{B *}$, and $p^{*}$ or:

$$
\begin{aligned}
\int_{K, B} \sum_{Z}(1-x(z, k, b))\left[\mathbf{1}_{\{\Delta(k, b, z)=0\}} h_{0}^{n}(z, k, b)+\mathbf{1}_{\{\Delta(k, b, z)=1\}} h_{1}^{n}(z, k, b)\right] \Gamma(d k, d b, z) & =1 \\
\int_{K, B} \sum_{Z}(1-x(z, k, b))\left[\mathbf{1}_{\{\Delta(k, b, z)=0\}} h_{0}^{b}(z, k, b)+\mathbf{1}_{\{\Delta(k, b, z)=1\}} h_{1}^{b}(z, k, b)\right] \Gamma(d k, d b, z) & =B^{\prime *} \\
S^{\prime *} & =1 .
\end{aligned}
$$


9. Taxes/transfers satisfy the government budget constraint:

$$
T^{h}=T^{d}+T^{B}+T^{7}+T^{i}+\mathbf{T}^{c}-T^{L},
$$

where dividend taxes $T^{d}$ are:

$$
T^{d}=\tau_{d} \int_{K \times B} \sum_{z}(1-x(k, b, z)) \mathbf{1}_{\{e(k, b, z) \geq 0\}} e(k, b, z) \Gamma(d k, d b, z) ;
$$

taxes on interest earnings $T^{B}$ are:

$$
T^{B}=\tau_{i} \widetilde{q}^{B}\left(\frac{1}{\widetilde{q}^{B}}-1\right) B^{\prime}
$$

at pre-tax bond price $\widetilde{q}^{B}$; taxes to cover bankruptcy cost of liquidated firms $T^{7}$ are: ${ }^{20}$

$$
T^{7}=\int_{K \times B} \sum_{z} x(k, b, z) \mathbf{1}_{\{\Delta=1\}} c_{7} \Gamma(d k, d b, z),
$$

income taxes on the final distribution by exiting firms $T^{i}$ are:

$$
T^{i}=\tau^{i} \int_{K \times B} \sum_{z} x(k, b, z)\left\{\mathbf{1}_{\{\Delta=0\}}(k-b)+\mathbf{1}_{\{\Delta=1\}} \max \left\{s_{7} k-b-c_{7}, 0\right\}\right\} \Gamma(d k, d b, z)
$$

corporate taxes are:

$$
\begin{array}{r}
\mathbf{T}^{c}=\int_{K, B} \sum_{Z}(1-x(z, k, b))\left[\mathbf{1}_{\{\Delta(k, b, z)=0\}} T^{c}\left(k, z, h_{0}^{k}(z, k, b), h_{0}^{b}(z, k, b)\right)\right. \\
\left.+\mathbf{1}_{\{\Delta(k, b, z)=1\}} T^{c}\left(k, z, h_{1}^{k}(z, k, b), h_{1}^{b}(z, k, b)\right)\right] \Gamma(d k, d b, z) ;
\end{array}
$$

and taxes necessary to cover ex-post losses associated with bankruptcy $T^{L}$ are:

$$
T^{L}=q^{B} \int_{K \times B} \sum_{z}\left\{-\Lambda(z, k, b) b+\min \left\{b, \max \left\{s_{7} k-c_{7}, 0\right\}\right\}+\phi(z, k, b) b\right\} \Gamma(d k, d b, z) .
$$

Of course, by Walras' law the household budget constraint (9) implies the goods market clearing condition is satisfied and aggregate consumption is given by

$$
C=Y-C F-I-\Psi-\Lambda+X-B C^{c}-B C^{s}-E,
$$

\footnotetext{
${ }^{20}$ In general, bankruptcy costs for liquidated firms need to be recovered by taxes only for those firms that go bankrupt and have $s_{7} k-b-c_{7}<0$. However, since this condition always holds in equilibrium, we omitted the corresponding indicator function.
} 
where aggregate output $Y$ is:

$$
Y=\int_{K, B} \sum_{Z}(1-x(z, k, b))\left[\mathbf{1}_{\{\Delta=0\}} z\left(k^{\alpha}\left(h_{0}^{n}\right)^{1-\alpha}\right)^{\nu}+\mathbf{1}_{\{\Delta=1\}} z\left(k^{\alpha}\left(h_{1}^{n}\right)^{1-\alpha}\right)^{\nu}\right] \Gamma(d k, d b, z)
$$

aggregate operating costs are:

$$
C F=\int_{K \times B} \sum_{z}(1-x(k, b, z)) c_{f} \Gamma(d k, d b, z)
$$

aggregate investment $I$ is:

$$
\begin{array}{r}
I=\int_{K, B} \sum_{Z}(1-x(z, k, b))\left[\mathbf{1}_{\{\Delta=0\}}\left[h_{0}^{k}(z, k, b)-(1-\delta) k\right]\right. \\
\left.+\mathbf{1}_{\{\Delta=1\}}\left[h_{1}^{k}(z, k, b)-(1-\delta) k\right]\right] \Gamma(d k, d b, z) ;
\end{array}
$$

capital adjustment costs $\Psi$ are:

$\Psi=\int_{K, B} \sum_{Z}(1-x(z, k, b))\left[\mathbf{1}_{\{\Delta=0\}}\left[\Psi\left(h_{0}^{k}(z, k, b), k\right)\right]+\mathbf{1}_{\{\Delta=1\}}\left[\Psi\left(h_{1}^{k}(z, k, b), k\right)\right]\right] \Gamma(d k, d b, z) ;(33$

aggregate external finance costs are:

$$
\begin{aligned}
\Lambda= & \int_{K \times B} \sum_{z}(1-x(k, b, z))\left\{\mathbf{1}_{\{e(k, b, z)<0\}}\left[\mathbf{1}_{\{\Delta=0\}} \lambda(e)+\mathbf{1}_{\{\Delta=1\}} \lambda_{11}^{e}(e)\right]\right. \\
& \left.+\mathbf{1}_{\{\Delta=1\}}\left(1-\lambda_{b}^{11}\right) q\left(h_{1}^{b}, h_{1}^{k}, z\right) h_{1}^{b}(b, k, z)\right\} \Gamma(d k, d b, z)+M \lambda\left(k_{E}^{\prime}-q\left(k_{E}^{\prime}, b_{E}^{\prime}\right) b_{E}^{\prime}+\kappa\right)
\end{aligned}
$$

capital sales from exiting firms are:

$$
X=\int_{K \times B} \sum_{z} x(k, b, z) s_{x} k \Gamma(d k, d b, z)
$$

aggregate bankruptcy costs due to $c_{7}$ and $c_{11}$ are: ${ }^{21}$

$$
B C^{c}=\int_{K \times B} \sum_{z} \mathbf{1}_{\{\Delta=1\}}\left\{(1-x(k, b, z)) c_{11}+x(k, b, z) c_{7}\right\} \Gamma(d k, d b, z)
$$

\footnotetext{
${ }^{21}$ We assume that bankruptcy $\operatorname{costs} B C^{c}$ are a resource cost that is paid by the consumer even if the liquidation value of capital $\left(s_{7} k\right)$ is not enough to cover them. We analyzed the effects of this assumption on our main results by studying a version of our model where $B C^{c}$ is defined as follows:

$$
\tilde{B C} C^{c}=\int_{K \times B} \sum_{z} \mathbf{1}_{\{\Delta=1\}}\left\{(1-x(k, b, z)) c_{11}+x(k, b, z) \min \left\{c_{7}, s_{7} k\right\}\right\} \Gamma(d k, d b, z) .
$$

In this case, there is an upper bound on bankruptcy $\operatorname{costs} c_{7}$ derived from the value of firm's assets at liquidation. We found no significant changes in firm dynamics or welfare either in the benchmark or in the main counterfactual. For brevity, we omit presenting the results, but they are available upon request.
} 
aggregate bankruptcy costs due to $s_{7}$ and $s_{11}$ are:

$$
\begin{array}{r}
B C^{s}=\int_{K \times B} \sum_{z} \mathbf{1}_{\{\Delta=1\}}\left\{(1-x(k, b, z)) \mathbf{1}_{\left\{i^{g}(k, b, z)<0\right\}}\left(1-s_{11}\right)\left(-i^{g}(k, b, z)\right)\right. \\
\left.+x(k, b, z)\left(s_{x}-s_{7}\right) k\right\} \Gamma(d k, d b, z) ;
\end{array}
$$

and entrants' initial investment and costs are:

$$
E=M\left\{k_{E}^{\prime}+\kappa\right\}
$$

\section{Estimation}

In this section, we present our model parameterization. A summary of the model-implied definitions for key variables we observe in the data is given in Table 2.

Table 2: Model Definitions

\begin{tabular}{l|c}
\hline \hline Variable & Model Expression \\
\hline Book Value Assets & $k+I_{\{b<0\}}(-b)$ \\
Capital & $k$ \\
Net Debt & $b$ \\
Total Debt & $I_{\{b \geq 0\}} b$ \\
Operating Income & $\pi=z k^{\alpha} n^{1-\alpha}-w n-c_{f}$ \\
Taxable Income & $\pi-\delta k-\left(\frac{1}{q}-1\right) \frac{b^{\prime}}{(1+r)}$ \\
Cash Flow & $\pi-\left(\frac{1}{q}-1\right) b^{\prime}-T$ \\
Equity Issuance & $I_{\{e<0\}} e$ \\
Dividends & $I_{\{d \geq 0\}}\left(1-\tau^{d}\right) d$ \\
Gross Investment & $i^{g}=k^{\prime}-(1-\delta) k$ \\
Net Investment & $i^{n}=i^{g}-\delta k$ \\
Market Value Assets & $V(k, b, z)+q b^{\prime}$ \\
\hline \hline
\end{tabular}

A period is set to be one year. Conditional on issuing a positive amount of equity, we parameterize equity issuance costs as a linear function, $\lambda(x)=\lambda_{1}|x|$. We assume that firm productivity follows an $\mathrm{AR}(1)$ process:

$$
\log \left(z_{t}\right)=\rho_{z} \log \left(z_{t-1}\right)+\epsilon,
$$

with $\left|\rho_{z}\right|<1$ and $\epsilon \sim N\left(0, \sigma_{\epsilon}\right)$. We use Tauchen's procedure to discretize this process into an 11-state Markov process $\left\{z_{1}, \ldots, z_{11}\right\}$. 
In summary, our model has 21 parameters, which appear in Table 3. We divide them in two sets. The first set (those above the line in Table 3), are set outside the model using standard values in the literature or independent targets. Note that once we set the pre-tax, risk-free rate $\tilde{r}^{B}=\left(1 / \tilde{q}^{B}-1\right)$, together with the income tax $\tau_{i}$, equilibrium conditions determine $\beta, r$, and $q^{B}$. More specifically, $\beta=q^{B}=(1+r)^{-1}=1 /\left(1+\tilde{r}^{B}\left(1-\tau_{i}\right)\right)$. The production function parameters come from Atkeson and Kehoe [7]. Taxes are set following Hennessy and Whited [22]. To estimate the parameters of the $z$ process, we follow Cooper and Haltiwanger [15]. In particular, taking logs of operating income (evaluated at optimal labor) and quasi-differencing yields:

$$
\pi_{i t}=\rho_{z} \pi_{i t-1}+\eta k_{i t}-\rho_{z} \eta k_{i t-1}+\epsilon_{i t},
$$

where $\eta=\frac{\alpha \nu}{1-(1-\alpha) \nu}$. We estimate this equation for firms outside bankruptcy using a panel fixed effect estimator with a complete set of dummies to capture year fixed-effects. The results provide us with an estimate of $\rho_{z}$ and $\sigma_{\epsilon}{ }^{22}$ Finally, the value of assets during bankruptcy $\left(c_{11}\right.$ and $c_{7}$ ), taken from Bris, et. al. [10], who present information on the value of assets after bankruptcy conditional on whether the firm was liquidated or reorganized.

The parameters below the line in Table 3 are estimated by simulated method of moments (SMM) that, in short, amount to minimizing the distance between model moments and data moments (weighted by the optimal weighting matrix) selected to provide identification of the model parameters. Our data moments come mostly from Compustat, which we presented in Section 2. Specifically, the parameters are chosen to minimize:

$$
Q(\Theta)=\left[\mu^{d}-\mu^{s}(\Theta)\right]^{\prime} W^{*}\left[\mu^{d}-\mu^{s}(\Theta)\right]
$$

with respect to parameters $\Theta$, where $\mu^{d}$ are the moments from the data, $\mu^{s}(\Theta)$, are the moments from the simulated model at parameters $\Theta$ and $W^{*}$ is a positive definite weighting matrix. ${ }^{23}$ The covariance matrix of $\sqrt{N}(\hat{\Theta}-\Theta)$ is given by:

$$
\left(1+\frac{1}{J}\right)\left[\partial \mu^{s}(\Theta) / \partial \Theta\right]^{\prime} W^{*}\left[\partial \mu^{s}(\Theta) / \partial \Theta\right]^{-1}
$$

where the term $\left(1+\frac{1}{J}\right)$ is the adjustment for simulation error.

Table 3 presents the parameter values and its standard errors.

\footnotetext{
${ }^{22}$ Estimates are in line with those presented in the literature. See for example Cooper and Haltiwanger [15] and Khan and Thomas [29].

${ }^{23}$ In a first pass, we set $W^{*}$ to the identity matrix (adjusting the moments by their data means to avoid putting more weight on moments that are large in absolute value). We then estimate the optimal weighting matrix using the inverse of the variance-covariance matrix of the simulated moments. Finally, with the optimal weighting matrix at hand, we minimize (41) to estimate the parameters of the model and compute (42) to obtain their standard errors. See Strebulaev and Whited ([38]) and references there for a comprehensive description of SMM estimation.
} 
Table 3: Parameter Values

\begin{tabular}{l|c|c|c|l}
\hline \hline Parameter & & Value & s.e. & Targets \\
\hline Discount Rate & $\tilde{r}^{B}$ & 0.020 & - & T-Bill Rate \\
Corporate Tax Rate & $\tau_{c}$ & 0.300 & - & Corporate Taxes U.S. (see [22]) \\
Dividend Tax Rate & $\tau_{d}$ & 0.120 & - & Dividend Tax U.S. (see [22]) \\
Income Tax Rate & $\tau_{i}$ & 0.250 & - & Income Tax U.S. (see [22]) \\
Depreciation Rate & $\delta$ & 0.150 & - & Capital Dep. Rate Compustat \\
Capital Share & $\alpha$ & 0.330 & - & standard parameter \\
Return to Scale & $\nu$ & 0.850 & - & standard parameter \\
Autocorrelation $z$ & $\rho_{z}$ & 0.657 & - & Autocorrel Op. Inc. (eq. (40)) \\
Std. Dev. Shock & $\sigma_{\epsilon}$ & 0.199 & - & Autocorrel Op. Inc. (eq. (40)) \\
Price Capital after Liquidation & $s_{7}$ & 0.400 & - & Asset Value Ch. 7see [10]) \\
Price Capital in Ch. 11 & $s_{11}$ & 0.869 & - & Asset Value Ch. 11 (see [10]) \\
\hline & & & & \\
\hline Fixed Cost Production & $c_{f}$ & 0.051 & 0.001 & Exit Rate \\
Chapter 7 Cost & $c_{7}$ & 0.001 & 0.000 & Recovery Rate Ch 7 \\
Chapter 11 Cost & $c_{11}$ & 0.160 & 0.054 & Fraction of Bankrupty Ch. 11 \\
Firm's Bargaining Power & $\theta$ & 0.968 & 0.020 & Recovery Rate Ch. 11 \\
Equity Issuance Cost & $\lambda_{1}$ & 0.010 & 0.092 & Equity Issuance Non-Bankrupt \\
Equity Issuance Cost Ch. 11 & $\lambda_{1}^{11}$ & 0.440 & 0.250 & Equity Issuance Ch. 11 \\
Debt Cost in Chapter 11 & $\lambda_{b}^{11}$ & 0.880 & 0.107 & Debt to Assets Ch. 11 \\
Adjustment Cost & $\psi$ & 0.297 & 0.032 & Net Investment Non-Bankrupt \\
Price of Capital Exit & $s_{x}$ & 0.724 & 0.082 & Bankruptcy Rate \\
Entry Cost & $\kappa$ & 0.174 & - & Debt to Assets Non-Bankrupt \\
& & & & Net Investment Ch. 11 \\
\hline \hline
\end{tabular}

Note: Parameters below the line are set by minimizing the distance between

model moments and target moments. The entry cost $\kappa$ is calibrated so it is consistent with the equilibrium where the wage rate equals 1.

Before presenting the estimation outcome, we discuss the selection of these moments. Since every moment that results from the model is a function of all parameters, there is no one-toone link between parameters and moments. However, we can point to moments that are more informative to pin down a given parameter or set of parameters than others. The value of the fixed operating cost $c_{f}$ is important for matching the exit rate. The cost of filing for Chapter 7 bankruptcy $c_{7}$ is important for matching the recovery rate in Chapter 7 (as estimated in Bris, et. al. [10]). The cost of filing for Chapter $11 c_{11}$ bankruptcy is important for matching the fraction of Chapter 11 bankruptcy. The bargaining power of the firm once in reorganization $\theta$ is important for matching the observed recovery rate in Chapter 11 (as estimated in Bris, et. al. [10]). The equity issuance cost parameters $\lambda_{1}$ and $\lambda_{1}^{11}$ are set to match the median equity issuance by non-bankrupt and Chapter 11 firms, respectively. The differential borrowing cost 
of Chapter 11 firms $\lambda_{b}^{11}$ is selected to match the debt-to-asset ratio of firms in Chapter 11 . The net investment rate provides information on the adjustment cost parameter $\psi$. The scrap value of capital $s_{x}$ is related to the bankruptcy rate. The entry cost $\kappa$ is set so it is consistent with an equilibrium where the wage rate is normalized to $1 .^{24}$ Finally, we study an overidentified model, and we also include the debt-to-asset ratio of non-bankrupt firms as well as the net investment of Chapter 11 firms.

Given these parameter values, the moments we find in the model are given in Table 4 . Above the line, we show moments that were targets. Below the line we present some additional moments.

Table 4: Comparison of Data and Model Moments

\begin{tabular}{l|cc}
\hline \hline & \multicolumn{2}{|c}{ Benchmark } \\
Moments (\%) & Data & Model \\
\hline Exit Rate & 1.10 & 1.19 \\
Frequency of All Bankdruptcy & 0.96 & 0.88 \\
Fraction of Bankruptcy Reorganization & 79.15 & 72.61 \\
Recovery Rate by Liquidation & 5.80 & 4.23 \\
Recovery Rate Reorganization & 49.09 & 57.91 \\
Med. Equity Issuance Non-Bankrupt & 0.06 & 0.00 \\
Med. Equity Issuance Reorganization & 0.01 & 0.01 \\
Debt to Assets Non-Bankrupt & 28.31 & 28.97 \\
Debt to Assets Reorganization & 41.99 & 43.15 \\
Net Investment/Assets Non-Bankrupt & 1.16 & 0.89 \\
Net Investment/Assets Reorganization & -2.94 & -6.22 \\
\hline Fraction of Exit by Liquidation & 19.83 & 20.18 \\
Frac. Firms Issuing Equity Non-Bankrupt & 22.04 & 26.72 \\
Frac. Firms Issuing Equity Reorganization & 13.14 & 9.75 \\
Dividend to Asset Non-Bankrupt & 3.49 & 2.87 \\
Net Debt / Assets Non-Bankrupt & 9.11 & 22.82 \\
Net Debt / Assets Reorganization & 29.61 & 43.15 \\
Spread All firms & 1.30 & 0.50 \\
Spread Non-Bankrupt & & 0.43 \\
Spread Reorganization & & 13.86 \\
\hline \hline
\end{tabular}

In general, the model does a good job approximating the targeted moments. Among those moments that were not targeted, the model generates a much larger net debt to assets and overestimates the fraction of firms that issues equity for firms in reorganization. We do not

\footnotetext{
${ }^{24}$ This normalization is done only in the benchmark economy. In our counterfactual experiments, the value of $\kappa$ remains fixed and the wage rate $w$ adjusts to satisfy the equilibrium conditions.
} 
have access to information on corporate bond prices in our data, but we use the median spread for a sample of firms in Compustat presented in Arellano, Bai, and Kehoe [5]. The spread is defined as $(1 / q)-(1+r)$. Note that, given that credit markets are competitive and lenders are risk-neutral, after matching the bankruptcy rate, the recovery rate in Chapter 7 , and the recovery rate in Chapter 11 there is no room to improve on the average spread generated by the model. ${ }^{25}$

\section{Results}

\subsection{Equilibrium Properties}

Figure 3: Bankruptcy and Exit Decision Rules
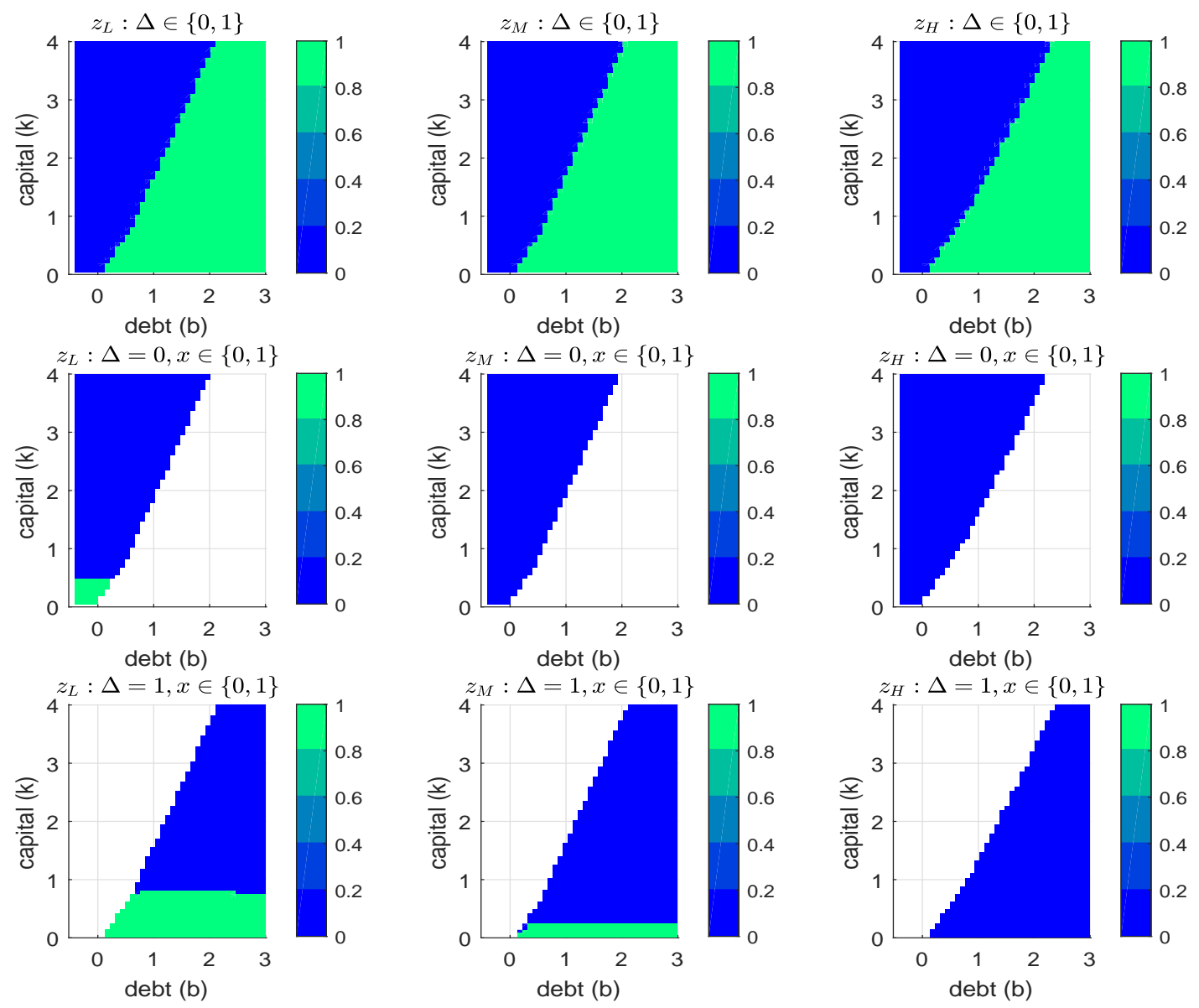

\footnotetext{
${ }^{25}$ The average bond price is well approximated by these three moments (see equation (19)).
} 
We begin by describing decision rules concerning exit and bankruptcy choice. Figure 3 presents the bankruptcy and exit decision rules across capital, debt, and productivity. The leftmost panels present bankruptcy (top), exit conditional on not declaring bankruptcy (middle), and exit conditional on declaring bankruptcy (i.e., whether to continue by reorganizing via Chapter 11 or exit by liquidating via Chapter 7 , bottom) decision rules respectively, for a firm with low productivity $\left(z=z_{L}\right)$. The next two columns present the same decision rules for firms with median and high productivity $\left(z=z_{M}\right.$ and $\left.z=z_{H}\right)$, respectively. The blank regions in the middle and bottom panels occur when the decision rule is not relevant. More specifically, in states where a firm chooses to exit $x(k, b, z)=1$ the decision rule for reorganization is not shown. Similarly, in states where a firm chooses to stay $x(k, b, z)=0$ the decision rule for liquidation is not shown.

As evident in Figure 3, firms with high productivity (the rightmost column) do not exit no matter what their mix of capital and debt. Some firms with high productivity and high debt do however choose Chapter 11. At the other end of the spectrum (the leftmost column), for firms with low productivity, those with (i) negative net debt (cash) and low capital choose to exit without declaring bankruptcy, (ii) high debt and low capital choose Chapter 7, and (iii) medium to high levels of capital choose to continue operating and, depending on their level of debt-to-capital ratio, choose to reorganize or not. Qualitatively, median productivity firms behave more like low productivity firms (since most options are chosen) than high productivity firms (except those with negative net debt and low capital that choose to continue operating as high productivity firms).

We next describe recovery rates under reorganization and bond prices offered to firms conditional on how much they borrow $\left(b^{\prime}\right)$, what collateral they will have next period when they have to repay $\left(k^{\prime}\right)$, and their current productivity $(z)$. Figure 4 graphs equilibrium recovery rates (top panel) and price menus (bottom panel) offered to firms with median productivity. As evident in Figure 4, for a given level of capital (which serves as collateral), the higher a firm's debt the less lenders recover, and, for a given level of debt, the higher a firm's capital the more lenders recover. Thus, firms with high debt to assets face higher real interest rates on their borrowings. While not pictured, we also note that, since firms with low productivity are more likely to go bankrupt (see Figure 3), for a given level of borrowing and collateral $\left(b^{\prime}, k^{\prime}\right)$, bond prices (interest rates) are increasing (decreasing) in firm-level productivity. Finally, note that equilibrium interest rates observed in the economy depend not only on these menus but also the equilibrium cross-sectional distribution of firms. Table 4 makes clear, for instance, that the equilibrium average interest rate that non-bankrupt, non-exiting firms face is lower $(1.93 \%)$ than those faced by firms that are reorganizing $(15.36 \%)$. 
Figure 4: Debt Price Schedules

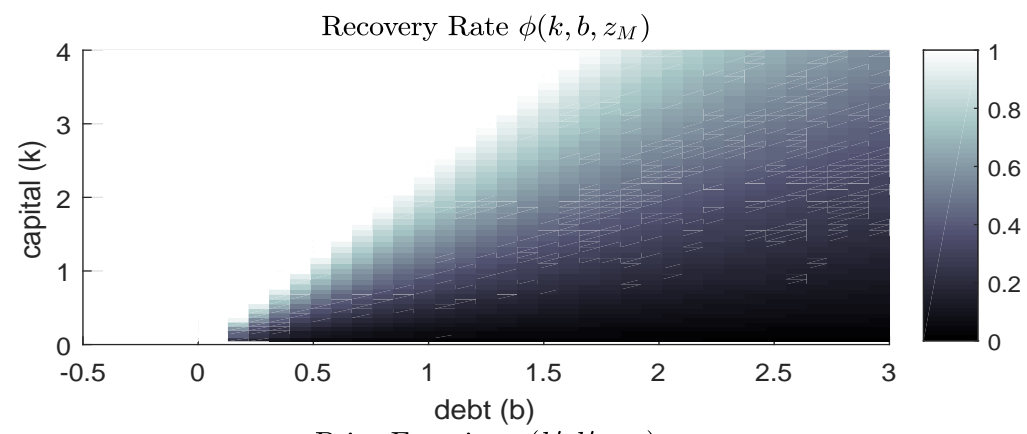

Price Function $q\left(k^{\prime}, b^{\prime}, z_{M}\right)$

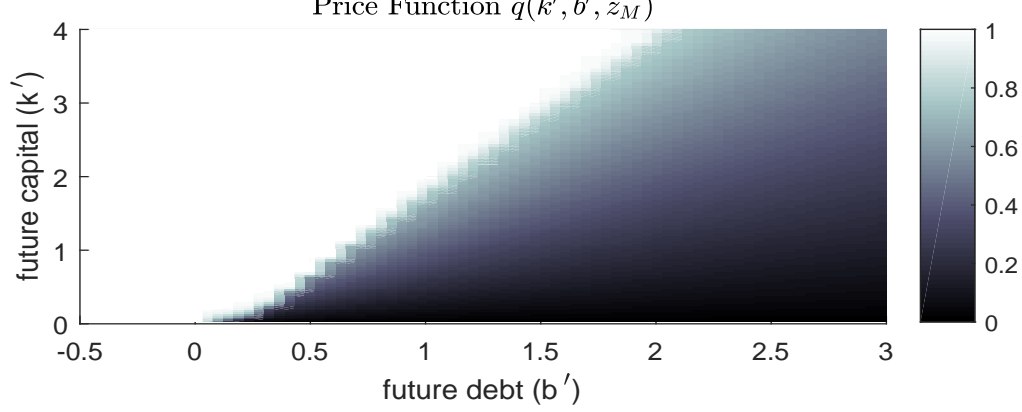

Debt dynamics for non-bankrupt/non-exiting $(\Delta=0, x=0)$ firms are illustrated in Figure 5 (evaluated at the average level of debt $b_{M}$ ) as a function of capital. ${ }^{26}$

Figure 5: Debt Choice $b^{\prime}(k, b, z)$ Non-Bankrupt $\left(\right.$ at $\left.b=b_{M}\right)$

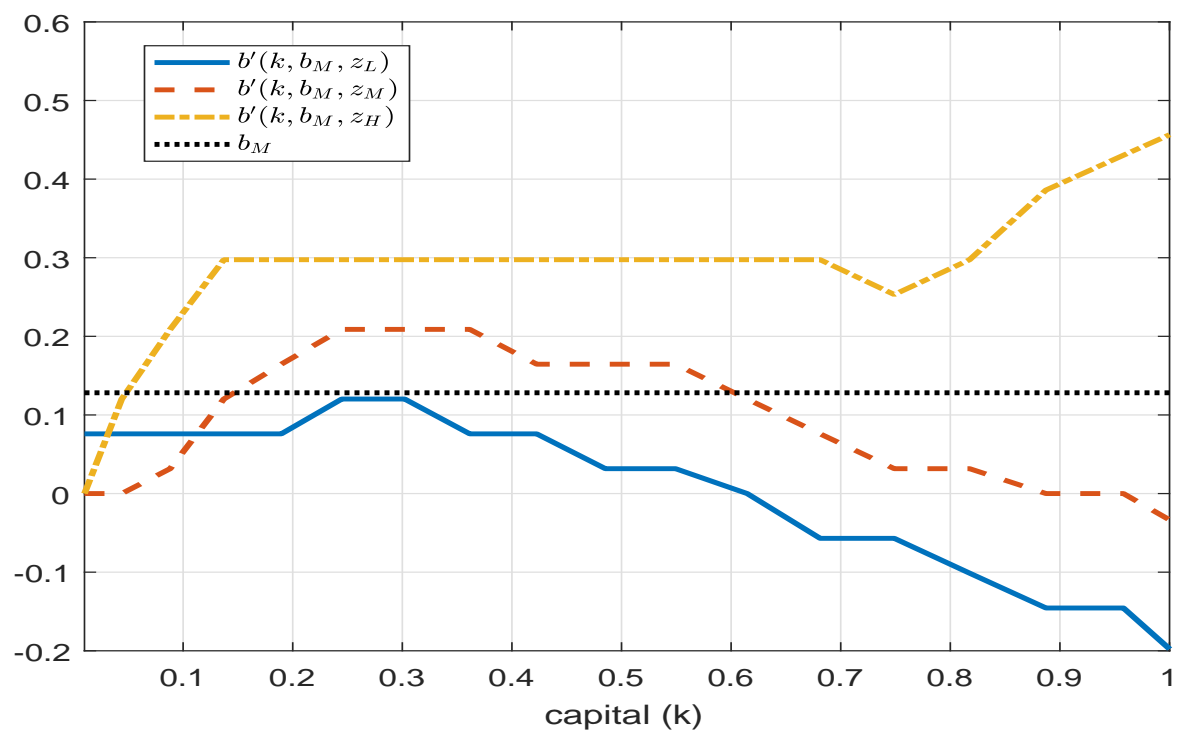

\footnotetext{
${ }^{26}$ The average value of debt $b_{M}$ is derived from the stationary distribution of the model and equals 0.1642 (approximately $37 \%$ of average output).
} 
Low productivity firms that are non-bankrupt/non-exiting choose to reduce their level of debt or accumulate cash whenever they do not exit. On one hand, rolling over debt for these low productivity firms is costly (since interest rates are high due to their elevated default risk). On the other hand, the marginal product of capital is low, so reducing their level of capital to pay off debt is optimal. Median productivity firms with low capital (where adjustment costs reduce the marginal benefit of investment and borrowing costs are relatively high) or relatively high capital (where the marginal product of capital is lower than low levels of capital due to decreasing returns) choose to reduce their debt level as well. However, those with intermediate levels of capital choose to increase their debt level in order to invest. Finally, most firms with high productivity choose to increase their debt level since the high level of productivity makes them less likely to declare bankruptcy and reduces borrowing costs, and the benefit of investment is high.

The net cash flow $e$ over assets of non-bankrupt firms is illustrated in Figure 6 (evaluated at $b=b_{M}>0$, so total assets equal $k$ ). Recall that $e>0$ denotes that the firm is distributing dividends and that $e<0$ denotes that the firm is issuing equity.

Figure 6: Net Cash Flow Over Assets $(e / k)$ Non-Bankrupt $\left(\right.$ at $\left.b=b_{M}\right)$

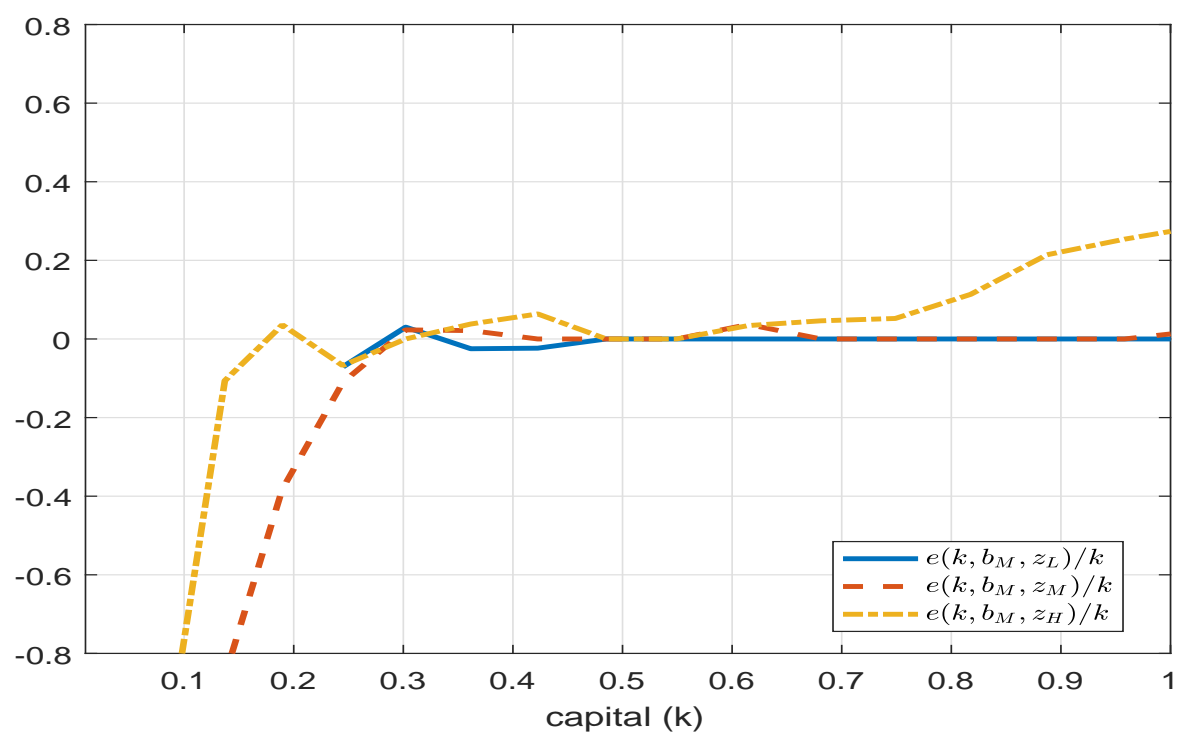

This figure shows that there are three regions that depend on the level of capital and productivity of each firm. Firms with low productivity that do not exit do not find it profitable to issue equity and do not pay dividends. Firms with median and high productivity choose to issue equity when capital is relatively low in order to invest. High-productivity firms choose to pay dividends since they can finance some of those dividend payments out of their positive cash flow and borrowing at low interest rates. 
The equilibrium cumulative distribution function of firms conditional on their productivity is illustrated in Figure 7. It is evident that firms with low productivity are amassed on lower capital and debt levels, while those with high productivity are amassed on higher capital and debt levels.

Figure 7: Distribution of Firms (conditional on $z$ )

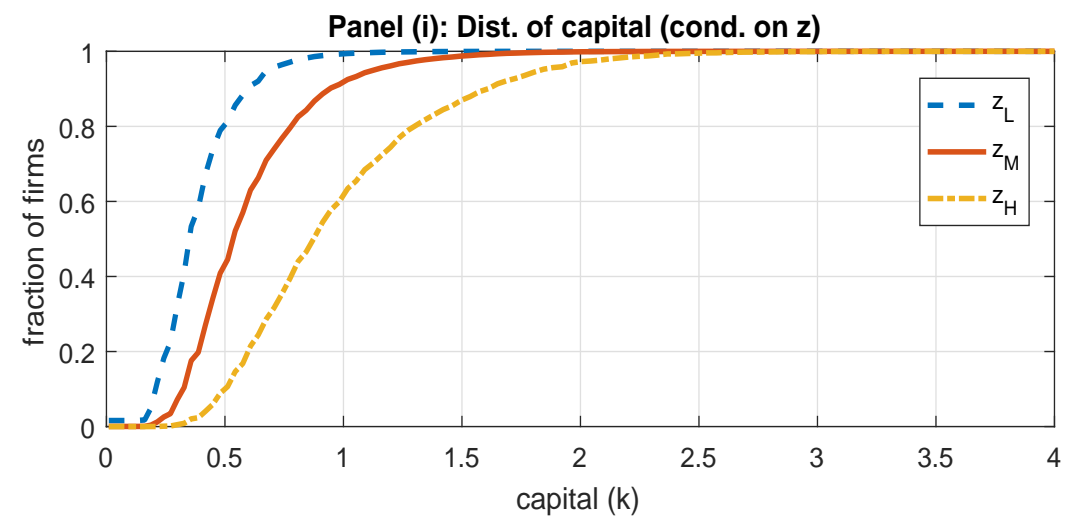

Panel (ii): Dist. of debt (cond. on z)

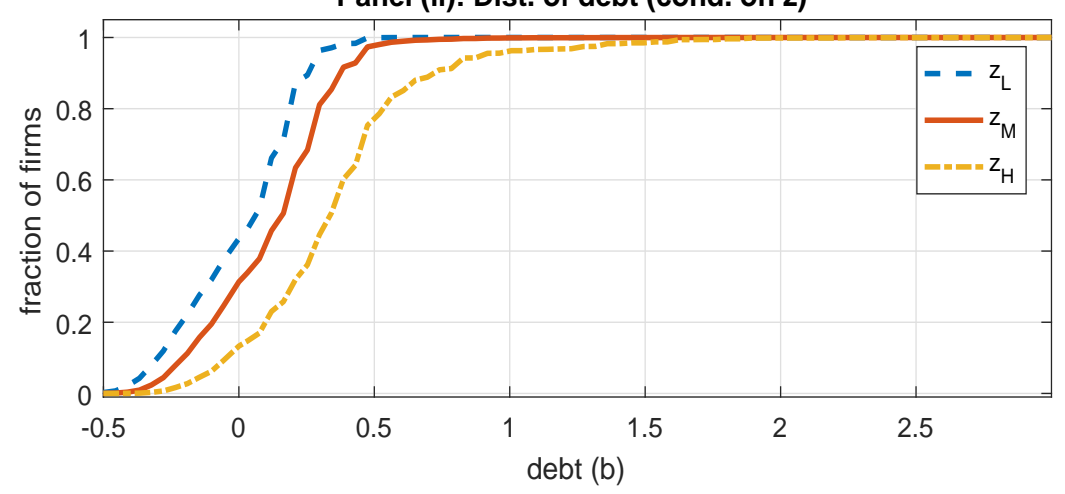

\subsection{Event Analysis: Reorganization}

Next, we study dynamics around bankruptcy events both in the model and the data. This allows us to describe the dynamics of the model and provides a natural "test" of the model since we do not estimate parameters to match the dynamics. We start by depicting the evolution around a bankruptcy that results in reorganization. Figure 8 shows a set of charts based on the simulated data of the model (Panels $(i),(i i i),(v)$, and $(v i i)$ ) and the data (Panels (ii), (iv), (vi), and (viii)). The plots show 11-year event windows (from $t=-5$ to $t=5$ ) centered on the year of bankruptcy $(t=0)$. Solid lines represent the average of the variable in each panel and dotted lines to $\mathrm{a}+/-1$ standard deviation across all firms that went through reorganization. Figure 8, Panels $(i)$ and $(i i)$ show the debt-to-asset ratio, Panels (iii) and (iv) the debt interest rate, Panels $(v)$ and $(v i)$ the sales-to-asset ratio, and Panels (vii) and (viii) 
the net-investment-to-asset ratio. ${ }^{27}$

Figure 8: Reorganization Event Dynamics: Model and Data
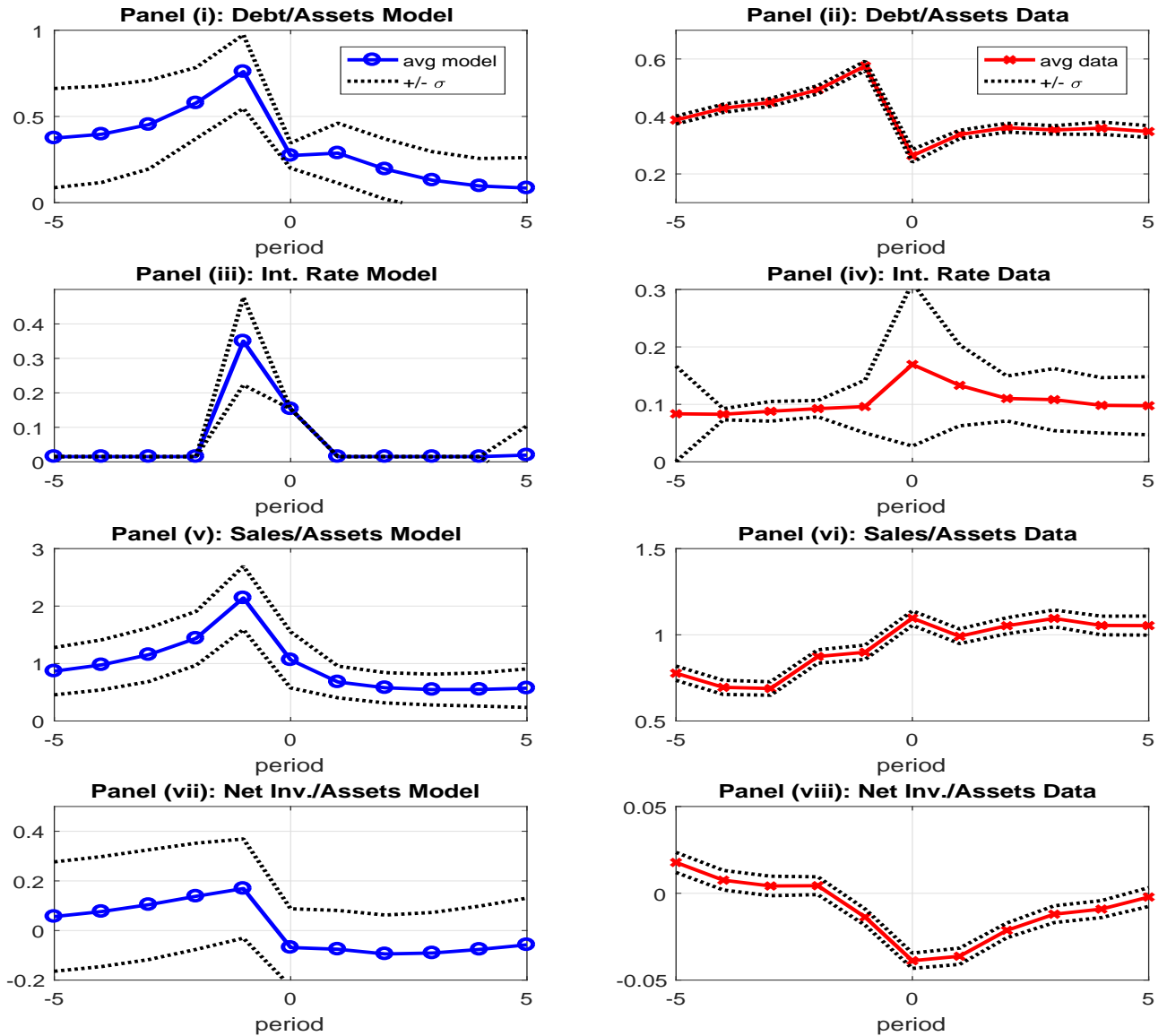

Note: In the data, events are constructed using firms that go through only one reorganization during the duration of the event analysis. Appendix A1 presents a detailed description of the construction of the variables.

Focusing on the model dynamics, we note that the increase in the sales-to-asset ratio (Panel $(v))$ prior to bankruptcy derives from a rapid increase in productivity (that outpaces the growth of assets). Panel ( $i$ ) shows that, pre-bankruptcy, the debt-to-asset ratio also increases sharply. The firm borrows to invest as the marginal product of capital increases. Interest rates (Panel

\footnotetext{
${ }^{27}$ See Appendix A1 for a description of variables and how events are constructed. Compustat does not have available a measure of debt interest rate at the firm level. For that reason, as a proxy, we use the ratio of interest payments to total debt.
} 
(iii)) remain close to the risk-free level $(t=-5,-4,-3)$ while the growth rate of the debtto-assets ratio stays relatively low (since most debt is fully collateralized and the bankruptcy probability is close to zero). However, further increases in the leverage ratio $(t=-2,-1)$ result in a jump in the bankruptcy probability that is reflected in a similar jump in the average interest rate that firms pay. Interest rates do not increase as much as the bankruptcy probability since the expected recovery rate for lenders is positive. Post-bankruptcy, firms reduce their leverage ratio, the sales-to-asset ratio also decreases, and the investment rate remains below the levels observed prior to bankruptcy.

Figure 8 shows that the model is consistent with the dynamics of the debt-to-asset ratio, interest rates, and the investment rate observed in the data (the debt-to-asset ratio increases prior to bankruptcy and declines abruptly during the bankruptcy, the interest rate increases close to bankruptcy, and the investment rate declines sharply when the firm enters bankruptcy). However, the model overpredicts how fast the firm reduces its debt-to-asset ratio after bankruptcy, overestimates the increase in the sales-to-asset ratio prior to bankruptcy and its decline post bankruptcy, and predicts a slower improvement in the investment rate than in the data.

\subsection{Event Analysis: Liquidation}

In this section, we describe a bankruptcy event that results in liquidation. As before, we present the evolution of the variables for the model and the data. Figure 9 show 5 -year event windows that end the year of liquidation at $t=0$. Solid lines represent the average of the variable in each panel and dotted lines to a $+/-1$ standard deviation (across all firms that exit via liquidation). Panels $(i)$ and $(i i)$ show the debt to asset ratio, Panels (iii) and (iv) the debt interest rate, Panels $(v)$ and $(v i)$ the sales-to-asset ratio, and Panels (vii) and (viii) the net-investment-to-asset ratio.

A liquidation event is the result of a slow decline in productivity as is evident from the decline in sales to assets (Panel $(v)$ ). Investment declines (Panel (vii)) to the point where the firm is actually reducing its level of capital. The leverage ratio remains constant for most of the event (Panel $(i)$ ), implying that the level of debt is also diminishing. Interest rates jump the year prior to the bankruptcy, together with a significant increase in debt-to-asset ratio that derives mostly from the fact that during this period the firm deploys its level of capital (the investment rate is close to -1). Note that since the firm is liquidated with a debt level that is above the residual value of capital, limited liability binds and the recovery rate is close to 0 .

When comparing the dynamics of the model and the data, we observe that the model is qualitatively consistent with the evolution of the leverage ratio, sales-to-assets, and net investment. The model overpredicts the increase in the leverage ratio in the final period and the interest rate the year prior to liquidation. 
Figure 9: Liquidation Event Dynamics: Model and Data
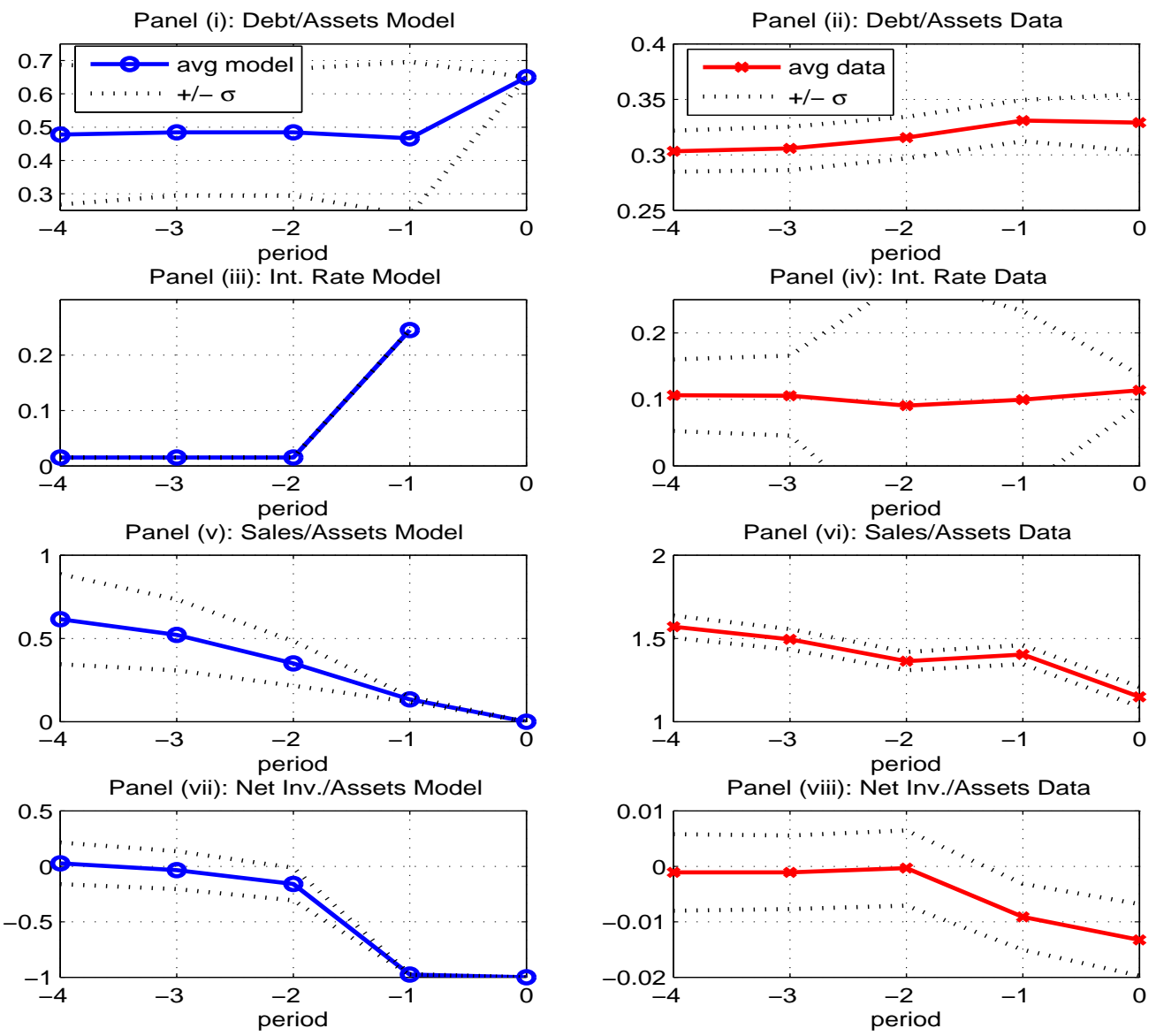

Note: Appendix A1 presents a detailed description of the construction of the variables.

\section{Policy Counterfactual: A Fresh Start for Firms}

In our counterfactual experiment, we analyze a variant of the bankruptcy procedure proposed by Aghion, Hart, and Moore [2], which itself is related to Bebchuk [8]. In particular, their proposal consists of three simple steps: (i) When a firm goes bankrupt, a fraction $(1-\varphi)$ of the firm's existing debts are canceled (Aghion, et. al. take $\varphi=0$ ); (ii) bids are solicited for the "new", all equity firm and rights to the equity in this new firm are allocated among the former claim holders (applying absolute priority rule, first to bond holders, then to former equity 
holders) ${ }^{28}$ (iii) the new shareholders - that is, the former claim holders - decide whether to continue the all equity firm or exit. After these steps, the firm exits from bankruptcy. ${ }^{29} \mathrm{~A}$ similar proposal has recently been suggested by the American Bankruptcy Institute. ${ }^{30}$

At the beginning of the period, the firm decides whether to declare bankruptcy $(\Delta=1)$ or not $(\Delta=0)$. If it decides not to default, the firm repays its debt and decides whether to continue $(x=0)$ or not $(x=1)$. If it decides to default, the procedure described above is triggered.

As before, the value of the firm is given by:

$$
V(z, k, b)=\max _{\Delta \in\{0,1\}} V_{\Delta}(z, k, b)
$$

where as before:

$$
V_{\Delta=0}(z, k, b)=\max _{x \in\{0,1\}} V_{0}^{x}(z, k, b),
$$

but now $V_{\Delta=1}(z, k, b)$ must be consistent with the process outlined in the new bankruptcy procedure.

Specifically, a firm that does not declare bankruptcy and chooses not to exit will decide its optimal level of investment and borrowing as before:

$$
V_{0}^{0}(z, k, b)=\max _{n \geq 0, k^{\prime} \geq 0, b^{\prime}}\left\{d+(1+r)^{-1} E_{z^{\prime} \mid z}\left[V\left(z^{\prime}, k^{\prime}, b^{\prime}\right)\right]\right\}
$$

s.t.

$$
\begin{gathered}
e=\pi-T^{c}\left(k, z, k^{\prime}, b^{\prime}\right)-\left(k^{\prime}-(1-\delta) k\right)-b+q\left(b^{\prime}, k^{\prime}, z\right) b^{\prime}-\Psi\left(k^{\prime}, k\right) \\
d= \begin{cases}\left(1-\tau_{d}\right) e & \text { if } e \geq 0 \\
e-\lambda(e) & \text { if } e<0 .\end{cases}
\end{gathered}
$$

Further, in the event of exiting without default, the dividend policy implies as before:

$$
V_{0}^{1}(z, k, b)=\left\{\begin{array}{cl}
\left(1-\tau_{d}\right)(k-b) & \text { if } k \geq b \\
s_{x} k-b-\lambda(k-b) & \text { if } s_{x} k<b
\end{array}\right. \text {. }
$$

Unlike before, in the event the firm declares bankruptcy, given limited liability its value is

\footnotetext{
${ }^{28}$ The solicitation of bids means the firm is competitively priced in our framework. More generally, multiple bids can help in environments with private information.

${ }^{29}$ To further understand how this reform affects the economy, in Appendix A3.3 we study the normative effects of a reform that gets rid of Chapter 11 and in Appendix A3.4 we describe the results of reforms that affect the estimated bargaining weight by changing $\theta$ to 0.01 and to 0.99 .

${ }^{30}$ Consistent with the policy recommendation in Aghion, et. al. [2], Stech [37] writes about the American Bankruptcy Institute proposal "Under the proposed changes, a bankruptcy judge would estimate the reorganization value of a company once it files for Chapter 11 protection. The bankrupt company could reorganize and leave Chapter 11 by paying that amount to a senior lender, even if that lender's debt has a larger face value." For the full report, see American Bankruptcy Institute [4].
} 
given by:

$$
V_{\Delta=1}(z, k, b)=\max \left\{W(z, k, \varphi b)-(1-\varphi) b-c_{B}, 0\right\},
$$

where $c_{B}$ is the bankruptcy cost and $W(z, k, \varphi b)$ is the value of the "new" firm after a fraction $1-\varphi$ of its original debts have been canceled. This value captures the fact that the new owners of the firm have the option to either continue operating the firm or liquidate it and is given by:

$$
\begin{gathered}
W(z, k, \varphi b)=\max \left\{W^{0}(z, k, \varphi b), s_{B} k-\varphi b\right\} . \\
W^{0}(z, k, \varphi b)=\max _{n \geq 0, k^{\prime} \geq 0, b^{\prime}, d \leq 0}\left\{d+(1+r)^{-1} E_{z^{\prime} \mid z}\left[V\left(z^{\prime}, k^{\prime}, b^{\prime}\right)\right]\right\}
\end{gathered}
$$

s.t.

$$
\begin{aligned}
e & =\pi-T^{c}\left(k, z, k^{\prime}, b^{\prime}\right)-i^{g}-\varphi b+q\left(k^{\prime}, b^{\prime}, z\right) b^{\prime}-\Psi\left(k^{\prime}, k\right), \\
d & =e-\lambda(e) .
\end{aligned}
$$

One important aspect of this counterfactual is the pricing of debt. The bankruptcy set is given by:

$$
D_{1}(k, b)=\{z \in Z: \Delta(z, k, b)=1\} .
$$

In this case, we can write the lender's profit function as follows:

$$
\begin{aligned}
\Omega\left(b^{\prime}, k^{\prime}, z\right)= & -q\left(b^{\prime}, k^{\prime}, z\right) b^{\prime}+q^{B}\left[1-\Lambda\left(b^{\prime}, k^{\prime}, z\right)\right] b^{\prime} \\
& +q^{B} \sum_{z^{\prime} \in D_{1}\left(k^{\prime}, b^{\prime}\right)} \min \left\{b^{\prime}, \max \left\{W\left(z^{\prime}, k^{\prime}, \varphi b^{\prime}\right)-c_{B}, 0\right\}\right\} G\left(z^{\prime} \mid z\right) .
\end{aligned}
$$

In equilibrium, the lender's profits must be zero.

As in our benchmark, we solve for a general equilibrium (i.e., wages adjust to clear the labor market) under the new bankruptcy policy. In Appendix A3.5, we decompose the effects of the reform into those that would arise in a partial equilibrium setting (where the wage rate stays constant and does not adjust to satisfy the free entry condition) to compare the general equilibrium results. While there are not sizeable differences between the two, we find that the partial equilibrium model would overpredict the impact on the bankruptcy rate $(8 \%$ higher under partial equilibrium than under general equilibrium) and spreads ( $12 \%$ higher).

Aggregate consumption in this economy is again given by the resource constraint (29), where $Y, C F$, I, and $E$ are defined as before in (30), (31), (32), and (39) while aggregate 
equity issuance costs are: ${ }^{31}$

$$
\Lambda=\int_{K \times B} \sum_{z}\left[(1-\Delta(k, b, z))\left(\mathbf{1}_{\{e<0\}} \lambda(e)\right)+\Delta(k, b, z)\left(\mathbf{1}_{\{V(z, k, \varphi b)>s k, e<0\}} \lambda(e)\right)\right] \Gamma(d k, d b, z)
$$

final distributions from exiting firms are:

$$
X=\int_{K \times B} \sum_{z} x(k, b, z)\left\{\mathbf{1}_{\{\Delta=0\}}(k-b)+\mathbf{1}_{\{\Delta=1\}} \max \left\{W(z, k, \varphi b)-b-c_{B}, 0\right\}\right\} \Gamma(d k, d b, z)
$$

and aggregate bankruptcy costs are:

$$
\begin{gathered}
B C^{c}=\int_{K \times B} \sum_{z} x(k, b, z) \mathbf{1}_{\{\Delta=1\}} c_{B} \Gamma(d k, d b, z) . \\
B C^{s}=\int_{K \times B} \sum_{z} \mathbf{1}_{\{\Delta=1\}} x(k, b, z)\left(s_{x}-s_{B}\right) k \Gamma(d k, d b, z) .
\end{gathered}
$$

Notice that the key essential difference between the proposed bankruptcy reform and that of the current law is that absolute priority rule is applied in all cases in the proposal while it is only applied in Chapter 7 currently. This can have a big impact on recovery rates and the pricing of debt. In particular, in return for debt forgiveness the creditors receive an all-equity firm without having to go through a bargaining process. This alters recovery rates in (50) and hence interest rate menus that firms face. This will have important implications for capital structure and firm dynamics.

In our main experiment, we set $\varphi=0$ as proposed by Aghion, et. al. [2], the bankruptcy costs and the price of capital equal to those estimated for Chapter 7 bankruptcy in our benchmark economy (i.e., $c_{B}=c_{7}$ and $\left.s_{B}=s_{7}\right){ }^{32}$ Table 5 presents a comparison across the two steady states.

\footnotetext{
${ }^{31}$ To save on notation, the first expression uses the fact that a firm will never pay back debt and issue equity when it exits.

${ }^{32}$ Appendix A3.2 shows the results from experiments where $\left\{c_{B}, s_{B}\right\}=\left\{c_{11}, s_{7}\right\}$ as well as $\left\{c_{B}, s_{B}\right\}=\left\{c_{11}, s_{11}\right\}$. Using different bankruptcy costs affects the resulting bankruptcy rate (decreases with the value of $c_{B}$ ), but the main results of the paper (capital structure of firms and welfare) are robust to the different specifications of bankruptcy costs.
} 
Table 5: Counterfactual New Bankruptcy Procedure

\begin{tabular}{l|c|c|c}
\hline \hline & & Benchmark & Bankruptcy \\
& Data & Model & Reform \\
\hline Exit Rate & 1.10 & 1.19 & 1.14 \\
Frequency of All Bankruptcy & 0.96 & 0.88 & 0.43 \\
Fraction of Bankruptcy Reorganization & 79.15 & 72.61 & 99.99 \\
Recovery Rate by Liquidation & 5.80 & 4.23 & 14.51 \\
Recovery Rate Reorganization & 49.09 & 57.91 & 88.04 \\
Median Equity Issuance Non-Bankrupt & 0.06 & 0.00 & 0.00 \\
Median Equity Issuance Reorganization & 0.01 & 0.01 & 0.65 \\
Debt to Assets Non-Bankrupt & 28.31 & 28.97 & 36.63 \\
Debt to Assets Reorganization & 41.99 & 43.15 & 89.06 \\
Net Investment/Assets Non-Bankrupt & 1.16 & 0.89 & 1.06 \\
Net Investment/Assets Reorganization & -2.94 & -6.22 & -13.55 \\
\hline Fraction of Exit by Liquidation & 19.83 & 20.18 & 0.00 \\
Frac. Firms Issuing Equity Non-Bankrupt & 22.04 & 26.72 & 25.70 \\
Frac. Firms Issuing Equity Reorganization & 13.14 & 9.75 & 50.88 \\
Dividend to Assets Non-Bankrupt & 3.49 & 2.87 & 3.00 \\
Net Debt / Assets Non-Bankrupt & 9.11 & 22.82 & 32.98 \\
Net Debt / Assets Reorganization & 29.61 & 43.15 & 89.06 \\
Spread All firms & 1.300 & 0.50 & 0.051 \\
Spread Non-Bankrupt & & 0.43 & 0.052 \\
Spread Reorganization & & 13.86 & 0.000 \\
\hline Avg Size $(k)$ / Prod. $z$ Non-Bankrupt & & $0.642 / 1.015$ & $0.633 / 1.021$ \\
Avg Size $k$ / Prod. $z$ Ch 11 & & $1.978 / 1.561$ & $0.433 / 0.619$ \\
Avg Size $k$ / Prod. $z$ Ch 7 & & $0.010 / 0.645$ & $0.010 / 0.589$ \\
Avg Size $(k) /$ Debt $b$ Entrant & & & \\
\hline \hline
\end{tabular}

Notes: In the benchmark, liquidation (Chapter 7) refers to $(\Delta=1, x=1)$, while reorganization (Chapter 11) refers to $(\Delta=1, x=0)$. In the reform, liquidation refers to $\Delta=1$ and $V(z, k, 0)<s k$, while reorganization refers to $\Delta=1$ and $V(z, k, 0) \geq s k$.

The reform results in a considerable reduction of the bankruptcy rate and a jump in the fraction of bankruptcy via reorganization (via the new policy) while leaving the exit rate almost unaffected. While the fraction of firms that reorganize after going bankrupt increases, the overall fraction of firms that are reorganized after the reform drops since the reduction in the bankruptcy rate dominates. We also observe an increase in the debt-to-asset ratio for nonbankrupt and bankrupt firms (larger in the case of those firms that reorganize than in those that do not). There is a significant rise of the lender's recovery rate after reorganization that is reflected in the reduction of spreads for firms that decide to continue after going through bankruptcy.

To understand the differences between the benchmark and reform economies, we begin by comparing the interest rate menus in both cases. The reform allows firms to access better 
credit terms and reduces the need for the firm to hold as much capital (collateral against loans). Figure 10 presents the price schedule for both cases (Panel $(i)$ our benchmark and Panel (ii) the counterfactual economy, both evaluated at median productivity $z=z_{M}$ ).

Figure 10: Comparison Equilibrium Price Function

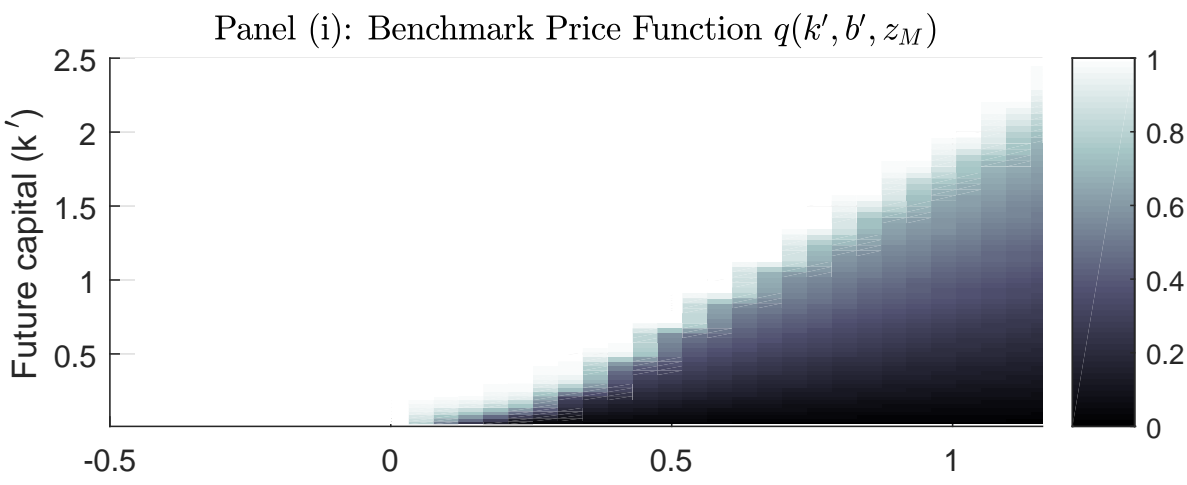

Future debt $\left(b^{\prime}\right)$

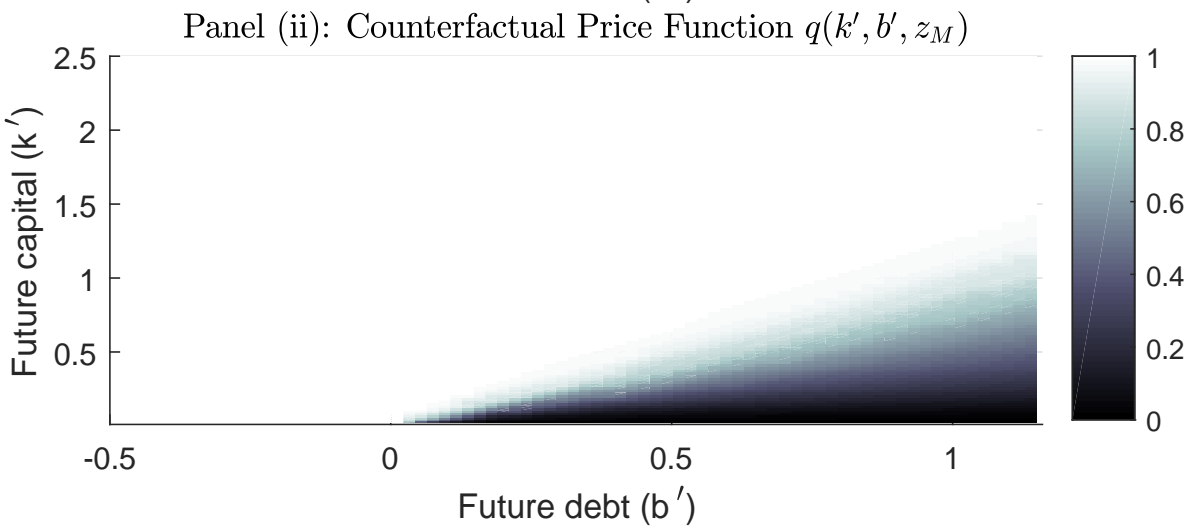

Note: Light colors correspond to high bond prices and dark colors correspond to low bond prices. Bond prices $q\left(k^{\prime}, b^{\prime}, z\right) \in\left[0,(1+r)^{-1}\right]$.

Figure 10 makes clear that, at any given level of $\left(b^{\prime}, k^{\prime}\right)$, prices are higher in the reform economy than in our benchmark. This derives from the fact, with a more "lender" friendly economy, at a given $\frac{b}{k}$, the expected recovery rate goes up (and in fact is increasing in $\frac{b}{k}$ ), allowing the firm to borrow at lower interest rates ceteris paribus.

The resultant shift in the interest rate menu has two effects: (i) firms are willing to borrow more in order to invest (debt-to-asset and net debt-to-asset ratios increase for both nonbankrupt and bankrupt firms); and (ii) they need to hold less collateral in order to sustain a given level of investment (this results in a reduction in the aggregate and average level of capital). These two effects are easily observed in Figure 11, which graph the distribution of debt to assets. 
Figure 11: Distribution of Debt to Assets

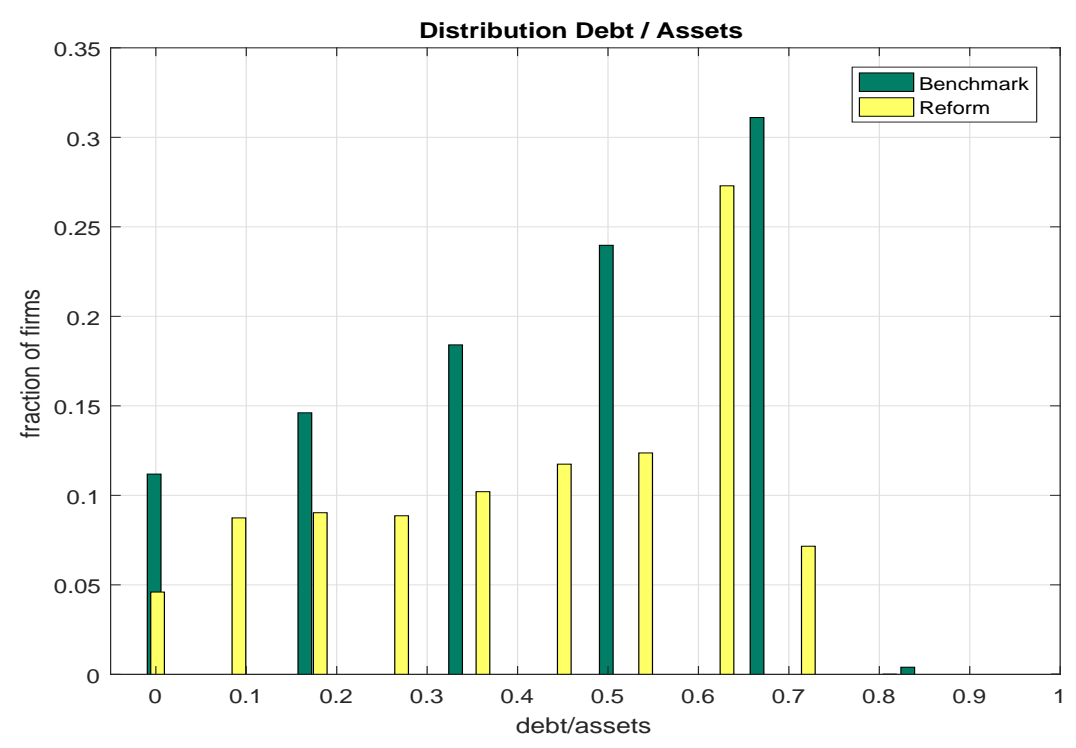

Consistent with Figure 11, Table 5 documents a $26 \%$ increase in borrowing (relative to assets) for non-bankrupt firms. Everything else equal, the shift in the price schedule from the benchmark to the reform economy would imply a sizeable reduction in interest rates. However, the increase in the amount firms borrow actually results in a slight increase in the average interest rate paid by non-bankrupt firms (2.0\% versus $2.01 \%)$. Firms that reorganize under the reform have a "fresh start" since they operate with no debt during the bankruptcy procedure. In equilibrium, the realized recovery rate for lenders when a firm reorganizes increases to $88.04 \%$ (leverage ratios increase by more than $100 \%$ for reorganized firms), and the recovery rate for firms that are liquidated also increases (but this is not as relevant for firm dynamics since almost no firm is liquidated after bankruptcy post-reform). These capital structure decisions impact net investment to assets. There is a $20 \%$ increase in investment rates for non-bankrupt firms and a sharp reduction in investment rates for those firms that are reorganized. Capital levels for non-bankrupt and bankrupt firms decline considerably after the reform as a consequence of changes in firm dynamics to be described below. As Figure 12 shows, after the reform, there is a considerable reduction in the fraction of firms that operate in the "inaction" region (i.e., firms operating with investment rates close to $0 \%$ ). ${ }^{33}$

\footnotetext{
${ }^{33}$ The lower capital levels (which are the main component of assets) also account for some of the rise in investmentto-asset ratios.
} 
Figure 12: Distribution of Investment Rates

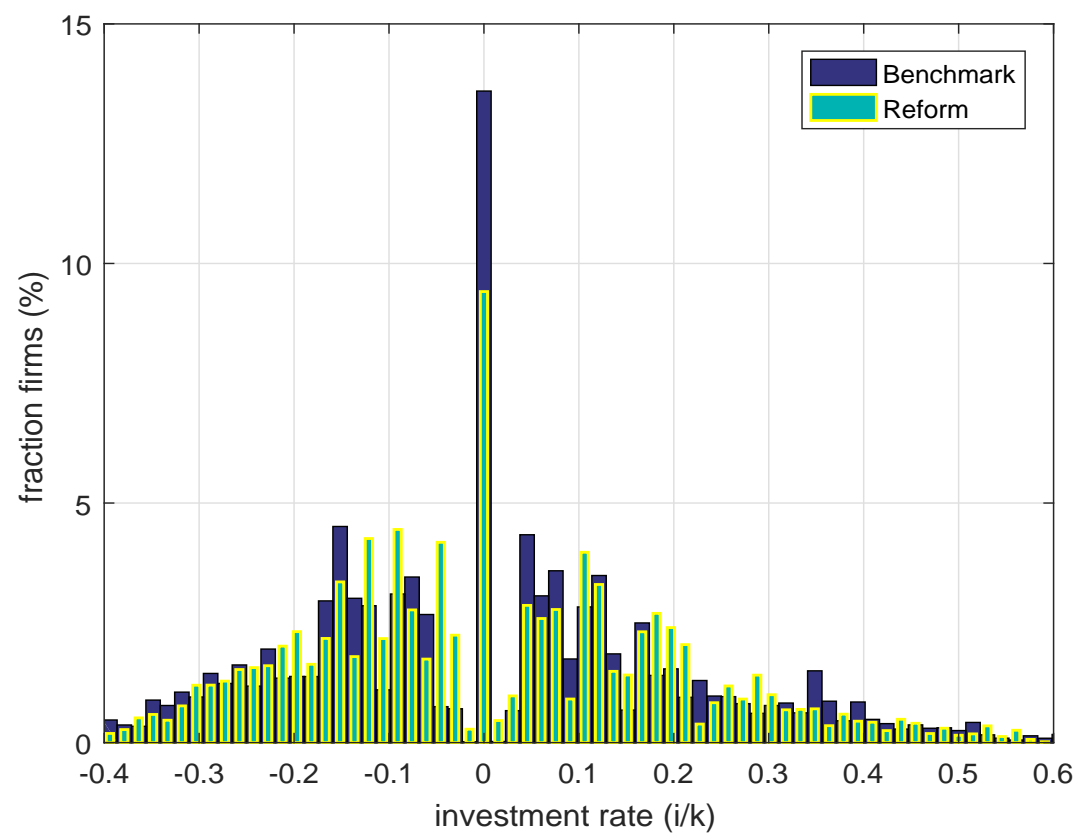

Table 5 also documents that, while the fraction of firms declaring bankruptcy decreases significantly (from $0.88 \%$ to $0.43 \%$ ), the fraction of firms exiting falls much more modestly (-5\% approximately). Firm reorganization conditional on going bankrupt (via ownership change and debt forgiveness) increases considerably (by 55\%). However, the reduction in the bankruptcy rate more than compensates this increase and results in an overall lower fraction of firms being reorganized after the reform. The total mass of firms depends directly on the fraction of entrants that survive over time. The reform economy exhibits a lower mass of entrants $M$ (3\% smaller) but the reduction in exit rates results in a higher total mass of firms after the reform than in the benchmark (an increase of 1.8\%). There are several effects at work here that depend on firm dynamics to be described below. First, for a given mass of entrants, since the exit rate declines the total mass of firms will increase in equilibrium. Second, in the opposite direction, since the average size of the firm declines, average labor demand also declines (which is somewhat offset by a general equilibrium increase in wages). The first of the two effects dominates so aggregate labor demand increases and a lower mass of entrants is needed in equilibrium in order to clear the labor market.

The effects of the reform on the life cycle of firms can be computed for a given cohort of firms. ${ }^{34}$ Figure 13 shows the survival, exit and bankruptcy probabilities for a given cohort of firms under the benchmark and after the bankruptcy reform. This figure makes evident that

\footnotetext{
${ }^{34}$ To track the evolution of a given cohort of firms, we start with a mass of firms $M$ and follow them over time (age) using equation (27) with no entry after the initial period. Statistics presented are conditional on firm age.
} 
a firm is less likely to survive in the benchmark than after the reform. However, a firm is less likely to declare bankruptcy late in its life cycle after the reform. Fewer firms enter (there is $3 \%$ decline in $M$ ) but entrants are bigger in the reform economy (see Figure 14) since they face better credit terms. The reduction in exit rates early in the life cycle of the firm generates a lower average productivity for young firms post-reform. There is less cleansing at the lower end of the productivity distribution after the reform (since firms with lower productivity are able and willing to borrow in order to continue). The increase in the bankruptcy rate in the initial period is the result of the higher debt-to-asset ratio observed in newly created firms (borrowing increases by $36 \%$ and the debt-to-asset ratio by $26 \%$ ). The lower exit rate after the reform implies that in a steady-state average age is higher in the reform economy than in the benchmark.

Figure 13: Survival, Exit, and Bankruptcy by Firm Age
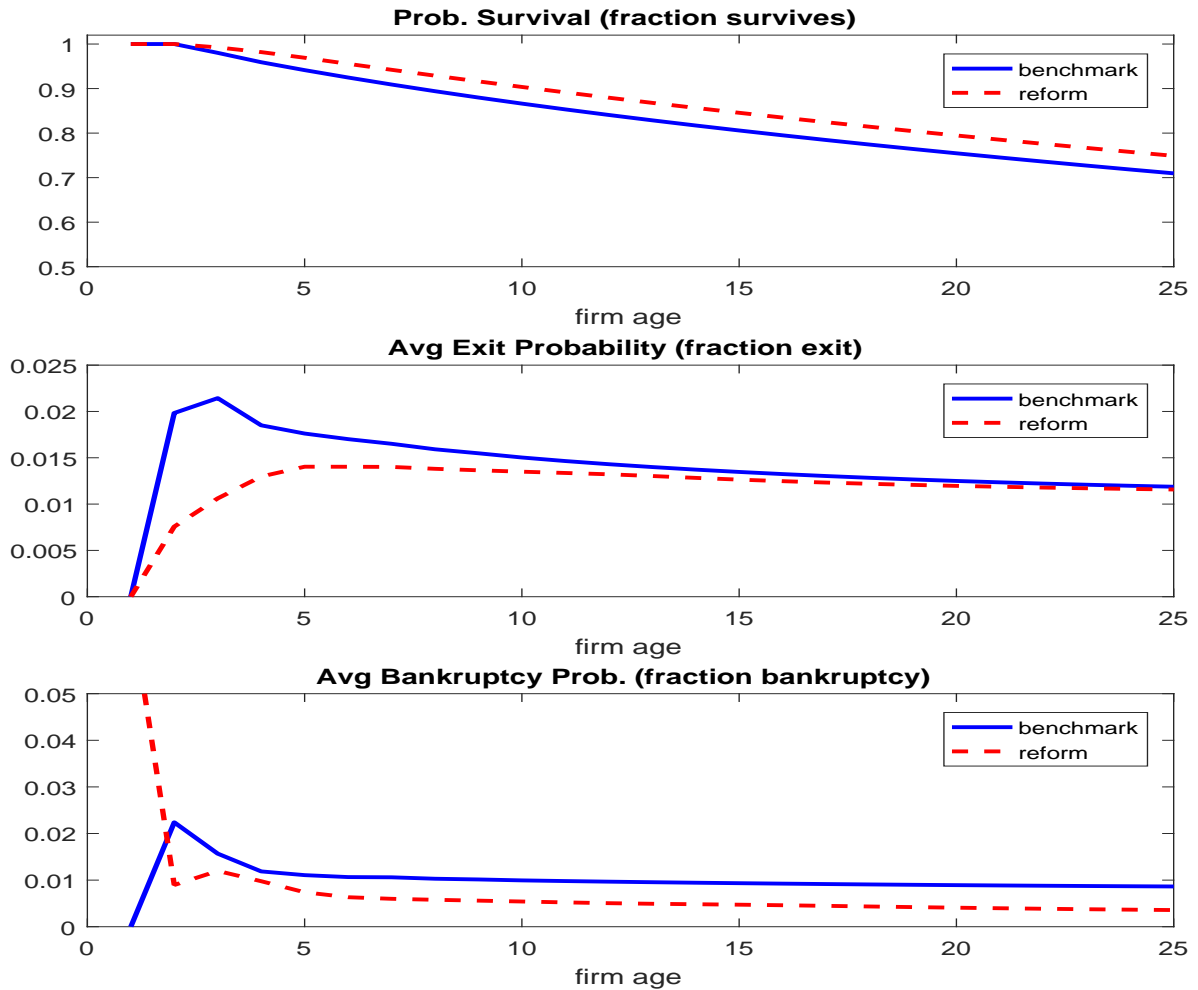

Figure 14 shows the evolution of net investment relative to assets, firm size (capital), and productivity over the firm's life cycle. Entrants' size rises (by 8\%) as the size of young incumbent firms (age $\leq 3$ years). Borrowing levels for young firms also increase (by approximately $36 \%$ ). While the stochastic process for technology shocks does not change across experiments, Figure 14 shows that after entry it is more likely for young, less productive firms to survive 
under the reform. Incentives to exit or go bankrupt are stronger for firms with low productivity in the benchmark economy. Since firms are offered better credit terms after the reform, as we show in Figure 15, firms are able to start larger, sustain higher leverage ratios, and reduce on equity issuance. Selection effects result in lower average productivity for young firms in the economy under the new bankruptcy regime. The productivity differential vanishes as firms aged (at age 18 average productivity is the same before and after the reform, and at age 30 productivity is $0.1 \%$ higher for firms after the reform). However, since firms previous to the reform slowly continue to grow and accumulate capital, the average size of old firms prior to the reform is larger than those after the reform. Moreover, as we discuss next, allocative efficiency improves with the new bankruptcy regime.

Figure 14: Evolution of Net Investment, Firm Size, and Productivity
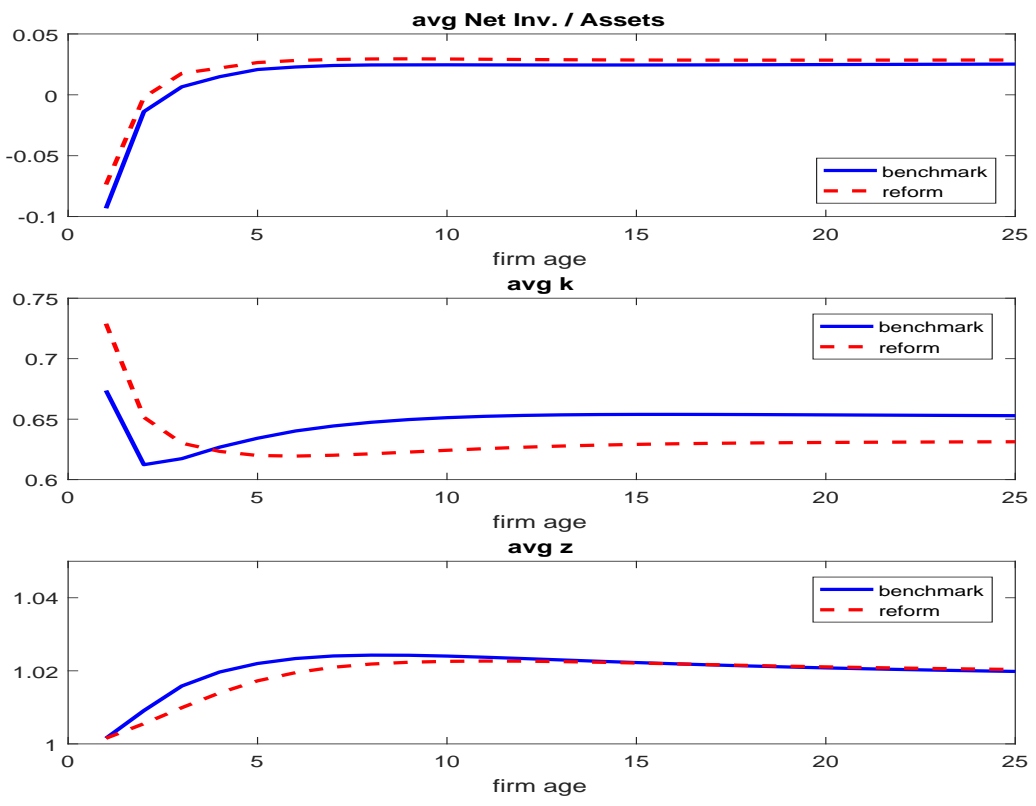

The capital structure decisions that support the above investment choices are given in Figure 15. The figure shows that mature firms sustain a higher debt-to-asset ratio and lower equity-issuance-to-asset ratio. This results in lower equity issuance costs. 
Figure 15: Debt to Assets and Equity Issuance to Assets Over Age
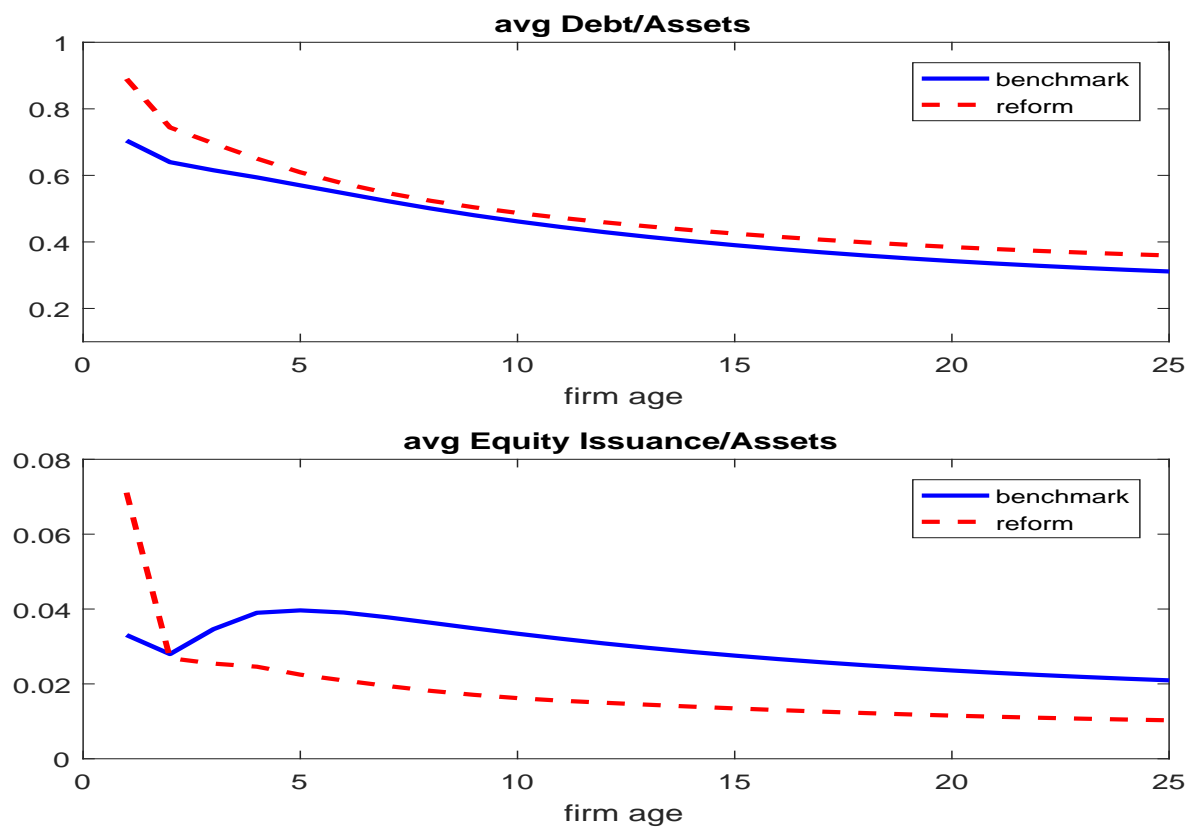

We also explore the implications of the reform for firms of different sizes. Table 6 presents summary statistics conditional on firm size when size is measure by total assets. We focus on the bottom $5 \%$ and the top $5 \%$ of the firm size distribution.

The exit rate decreases modestly after the reform when looking at all firms in the economy. However, there is a very significant reduction in the exit rate for the bottom $5 \%$. Small firms that are liquidated or exit after the reform are much less productive $(-10 \%)$ after the reform than in the benchmark. This reduces the positive impact of the bankruptcy reform on aggregate productivity since relatively low productivity firms are kept alive. Also in the bottom $5 \%$, we uncover a large reduction in the bankruptcy rate and, among the firms that go bankrupt, a large shift from liquidation to reorganization. The reduction in the bankruptcy rate and the shift from liquidation to reorganization (with the corresponding increase in the realized recovery rate for the lender) results in a large drop in spreads (from $5.23 \%$ to $0.34 \%$ ). The reduction in bankruptcy rates is also present at the top of the distribution. In this group, prior to the reform, all bankrupt firms were reorganized. After the reform, since bankruptcy also implies a change in ownership, large and productive firms operate in a region where default risk is absent. Both at the top and at the bottom of the distribution, we observe an increase in the debt-to-asset and net-debt-to-asset ratio after the reform. The increase in allocative efficiency, as measured by the covariance between productivity and share of output, increases by $12 \%$ at the bottom of the distribution and by $8 \%$ at the top. This is also reflected in an increase in output weighted productivity that is more significant at the bottom than at the 
top $(+1.8 \%$ and $+0.4 \%$, respectively).

Table 6: Bankruptcy Reform: Firm Dynamics (conditional on size)

\begin{tabular}{l|c|c||c|c||c|c}
\hline \hline & \multicolumn{2}{|c||}{ All Firms } & \multicolumn{2}{c||}{ Bottom 5\% } & \multicolumn{2}{c}{ Top 5\% } \\
\hline Moments (\%) & Benchmark & Reform & Benchmark & Reform & Benchmark & Reform \\
\hline Exit Rate & 1.19 & 1.14 & 19.44 & 12.36 & 0.00 & 0.00 \\
Freq. of All Bankruptcy & 0.88 & 0.43 & 5.07 & 1.54 & 11.93 & 0.00 \\
Frac. of Bankruptcy Reorg. & 72.61 & 99.99 & 0.00 & 99.98 & 100.00 & - \\
Rec. Rate by Liquidation & 4.23 & 14.51 & 4.23 & 14.51 & - & - \\
Rec. Rate Reorganization & 57.91 & 88.04 & - & 87.69 & 58.05 & - \\
Equity Issuance Non-Bankrupt & 0.00 & 0.00 & 1.06 & 1.01 & 0.00 & 0.00 \\
Equity Issuance Reorganization & 0.01 & 0.65 & - & 0.77 & 0.01 & - \\
Debt to Assets Non-Bankrupt & 28.97 & 36.63 & 20.14 & 29.11 & 40.48 & 50.69 \\
Debt to Assets Reorganization & 43.15 & 89.06 & - & 103.41 & 43.13 & - \\
Net Inv./Assets Non-Bankrupt & 0.89 & 1.06 & 10.29 & 10.80 & -6.79 & -6.24 \\
Net Inv./Assets Reorganization & -6.22 & -13.55 & - & -1.76 & -6.91 & - \\
\hline Fraction of Exit by Liquidation & 20.18 & 0.00 & 26.06 & 0.00 & - & - \\
Frac. Firms $e<$ 0 Non-Bankrupt & 26.72 & 25.70 & 75.05 & 53.15 & 0.00 & 0.00 \\
Frac. Firms $e<$ 0 Reorganization & 9.75 & 50.88 & - & 96.32 & 8.85 & - \\
Dividend to Assets Non-Bankrupt & 2.87 & 3.00 & 0.60 & 0.67 & 9.19 & 8.77 \\
Net Debt / Assets Non-Bankrupt & 22.82 & 32.98 & -4.95 & 13.98 & 40.47 & 50.69 \\
Net Debt / Assets Reorganization & 43.15 & 89.06 & - & 103.41 & 43.13 & - \\
Spread All Firms & 0.50 & 0.051 & 5.23 & 0.34 & 5.34 & 0.00 \\
Spread Non-Bankrupt & 0.43 & 0.052 & 5.23 & 0.35 & 4.28 & 0.00 \\
Spread Reorganization & 13.86 & 0.000 & - & 0.00 & 13.86 & - \\
\hline Avg Size $(k)$ Non-Bankrupt & 0.642 & 0.633 & 0.235 & 0.235 & 1.613 & 1.585 \\
Avg Size $k$ Reorganization & 1.978 & 0.433 & - & 0.243 & 2.012 & - \\
Avg Size $(k)$ Liquidation & 0.010 & 0.010 & 0.010 & 0.010 & - & - \\
Avg $z$ Non-Bankrupt & 1.015 & 1.021 & 0.805 & 0.814 & 1.307 & 1.336 \\
Avg $z$ Reorganization & 1.561 & 0.619 & - & 0.699 & 1.558 & - \\
Avg $z$ Liquidation & 0.645 & 0.589 & 0.645 & 0.584 & - & - \\
Avg. Prod. $z$ & 1.020 & 1.019 & 0.805 & 0.812 & 1.337 & 1.336 \\
Avg. (weighted) Prod. $\hat{z}$ & 1.240 & 1.246 & 0.879 & 0.895 & 1.502 & 1.508 \\
Cov $(z, \omega)$ Non-Bankrupt & 0.221 & 0.227 & 0.074 & 0.083 & 0.166 & 0.173 \\
\hline \hline
\end{tabular}

Notes: In the benchmark, liquidation (Chapter 7) refers to $(\Delta=1, x=1)$ while reorganization (Chapter 11) refers to $(\Delta=1, x=0)$. In the reform, liquidation refers to $\Delta=1$ and $V(z, k, 0)<s k$ while reorganization refers to $\Delta=1$ and $V(z, k, 0) \geq s k$. Size bins derived from asset distribution (e.g., bottom $5 \%$ corresponds to firms in the bottom $5 \%$ of the asset distribution). Moments conditional on given group of firms.

The positive effects in Table 5 have implications for household welfare (aggregate consumption), which is presented in Table $7 .{ }^{35}$

\footnotetext{
${ }^{35}$ Because we consider steady-state equilibria and we have a representative household, there are no transition welfare effects.
} 
Table 7: Bankruptcy Reform: Welfare and Aggregates

\begin{tabular}{l|c||c}
\hline \hline & $\begin{array}{c}\text { Benchmark } \\
\text { Model }\end{array}$ & $\begin{array}{c}\text { Bankruptcy } \\
\text { Reform } \\
(\Delta \%)\end{array}$ \\
\hline Aggregate Consumption $C$ & 1.13 & 0.54 \\
Aggregate Output $Y$ & 1.76 & -0.04 \\
Fixed Cost $C F$ & 0.20 & 1.87 \\
Investment $I$ & 0.36 & -0.83 \\
Adjustment Costs $\Psi$ & 0.03 & -5.49 \\
Equity Issuance $\Lambda$ & 0.002 & -84.32 \\
Bankruptcy Costs $B C^{c}$ & 0.004 & -99.75 \\
Bankruptcy Costs $B C^{s}$ & 0.0001 & -100.00 \\
Exit Value $X$ & 0.01 & 26.38 \\
Entry Costs $E$ & 0.04 & 3.52 \\
\hline Equilibrium Wage & 1.00 & 0.02 \\
Capital to Output Ratio $K / Y$ & 1.46 & -1.35 \\
Measured TFP $\left(=Y / K^{1 / 3}\right)$ & 1.28 & 0.43 \\
Avg. Productivity $\bar{z}$ & 1.02 & -0.02 \\
Avg. (output weighted) Prod. $\hat{z}$ & 1.24 & 0.44 \\
Cov( $z$, $\omega)$ & 0.22 & 2.58 \\
\hline Mass Entrants & 0.05 & -2.78 \\
Total Mass Firms & 3.97 & 1.80 \\
\hline \hline
\end{tabular}

Note: Benchmark Model in levels, bankruptcy reform column presents the percent deviation from the benchmark model. $\bar{z}$ is average firm productivity, $\widehat{z}$ is the (output weighted) average firm-level productivity, and $\omega$ is the output share of each firm.

Table 7 shows that, even though output decreases slightly (-0.04\%), consumption increases $(+0.54 \%)$ as the result of the reduction in adjustment costs $(-5.49 \%)$, equity issuance costs $(-$ $84.32 \%)$, and bankruptcy costs $(-100 \%)$ together with the increase in the exit value $(+26.38 \%)$. Better credit terms are also the driver of lower equity issuance (reducing the need to issue equity in order to finance investment); also, since after the reform firms that reorganize change owners, they do not need to either issue debt or equity in order to pay for bankruptcy costs (paid for by the previous owners). The change in the price schedule reduces the need to hold capital as a way to reduce borrowing costs (since it works as collateral), inducing a reduction in the aggregate level of capital and investment. This change at the individual firm is counteracted by the increase in the total mass of firms after the reform $(+1.8 \%)$. However, the first effect dominates. The $3.5 \%$ increase in total entry costs $E$ in Table 7 is all due to the increase in the size of the entrants discussed before. The lower entry rate after the reform results in a reduction in the mass of entrants $(-2.8 \%)$ that is not enough to reverse the changes in initial 
capital. While the aggregate results are relatively modest, they are in line with recent papers that have analyzed the role of financial frictions on aggregate productivity, consumption, and welfare. For example, Midrigan and $\mathrm{Xu}$ [31] find that changes in borrowing limits predict fairly small efficiency losses from capital misallocation (close to $0.4 \%$ ) and negligible changes in consumption. In another related paper, Moll [33] argues that, if shocks are persistent (as in our benchmark calibration), steady-state losses due to financial frictions are small since entrepreneurs can potentially overcome them through the accumulation of internal funds.

An important aspect of the bankruptcy reform is that it improves the allocation of resources in the economy. Table 7 shows that measured aggregate TFP rises by $0.43 \%$. In order to explain this change and to provide a measure that captures how efficiently resources are allocated in the economy, we use a decomposition of weighted average firm-level productivity proposed originally by Olley and Pakes [34]:

$$
\widehat{z} \equiv \int_{K \times B} \sum_{z} z_{j} \omega_{j} d j=[\bar{z}+\operatorname{cov}(z, \omega)]
$$

where $\widehat{z}$ is the average of firm-level productivity weighted by output share, $\omega_{j}$ is the output share of each firm $j$, and $\bar{z}$ is the unweighted mean productivity (i.e., $\int_{K \times B} \sum_{z} z \Gamma(d k, d b, z)$ ). That is, output weighted productivity can be decomposed into two terms: the unweighted average of firm-level productivity and a covariance term between output shares and productivity. A larger value for the covariance term captures an improvement in allocative efficiency. Table 7 shows the values for this decomposition. We observe that while average (unweighted) productivity decreases slightly $(-0.02 \%)$ in the reform economy (this is due to the lower exit rate and weaker selection for young firms), average weighted productivity in the economy increases $(+0.44 \%)$ since the increase in the covariance between output shares and productivity (better allocative efficiency) more than compensates $(+2.58 \%)$ for the reduction in average (unweighted) productivity. ${ }^{36}$ In sum, after the reform, a larger fraction of production is placed with more productive firms. The change in credit terms between the benchmark and the reform economy allows firms to operate at a more efficient scale, so the correlation between capital stock and productivity increases.

\section{Conclusion}

We extend a standard model of firm dynamics to incorporate Chapter 7 and Chapter 11 bankruptcy choices. We find that, if reforms proposed by legal and economic scholars are followed, there can be significant changes in borrowing costs, capital structure, and investment decisions as well as the cross-sectional distribution of firms. The general equilibrium

\footnotetext{
${ }^{36}$ That is, by weaker selection we mean that less (more) low productivity firms exit (survive).
} 
consequences of such reforms can lead to a rise in consumer welfare and allocative efficiency.

\section{References}

[1] Acharya, V., S. Bharath, and A. Srinivasan (2007). "Does Industry-wide distress Affect Defaulted Firms? Evidence from Creditor Recoveries," Journal of Financial Economics, vol. 85 , p. $787-821$.

[2] Aghion, P., O. Hart, and J. Moore (1992). "The Economics of Bankruptcy Reform," Journal of Law, Economics, and Organization, vol. 8, p. 523-546.

[3] Altman, E. (1968). "Financial Ratios, Discriminant Analysis and the Prediction of Corporate Bankruptcy," Journal of Finance, vol. 23, p. 589-609.

[4] American Bankruptcy Institute (2014). "Commission to Study the Reform of Chapter 11," https://commission.abi.org/full-report.

[5] Arellano, C., Y. Bai, and P. Kehoe (2016). "Financial Frictions and Fluctuations in Volatility," Minneapolis Fed Research, Staff Report 466.

[6] Arellano, C., Y. Bai, and J. Zhang (2012). "Firm Dynamics and Financial Development," Journal of Monetary Economics, vol. 59, p. 533-549.

[7] Atkeson, A. and P. J. Kehoe (2005). "Modeling and Measuring Organization Capital," Journal of Political Economy, vol. 113, p. 1026-1053.

[8] Bebchuk, L. (1988). "A New Approach to Corporate Reorganizations," Harvard Law Review, vol. 101, p. 775-804.

[9] Bharath S., V. Panchapegesan, and I. Werner (2010). "The Changing Nature of Chapter $11, "$ mimeo.

[10] Bris, A., I. Welch, and N. Zhu (2006). "The Costs of Bankruptcy: Chapter 7 Liquidation versus Chapter 11 Reorganization, "Journal of Finance, vol. 61, p. 1253-1303.

[11] Broadie M., M. Chernov, and S. Sundaresan (2007). "Optimal Debt and Equity Values in the Presence of Chapter 7 and Chapter 11," Journal of Finance, vol.62, 3, p. 1341-1377.

[12] Chatterjee, S., D. Corbae, M. Nakajima, V. Rios-Rull (2007). "A Quantitative Theory of Unsecured Consumer Credit with Risk of Default," Econometrica, vol. 75, p. 1525-1589.

[13] Cooley, T. and V. Quadrini (2001). "Financial Markets and Firm Dynamics," American Economic Review, vol. 91, p. 1286-1310.

[14] Cooper, R. and J. Ejarque (2003). "Financial Frictions and Investment: Requiem in Q," Review of Economic Dynamics, vol. 6, p. 710-728. 
[15] Cooper, R. and J. Haltiwanger (2006). "On the Nature of Capital Adjustment Costs," Review of Economic Studies, vol. 73, p. 611-633.

[16] D'Erasmo, P. and H. Moscoso Boedo (2012). "Financial Structure, Informality and Development," Journal of Monetary Economics, vol. 59, p. 286-302.

[17] Duffie, D., L. Saita and K. Wang (2007). "Multi-period Corporate Default Prediction with Stochastic Covariates", Journal of Financial Economics, vol. 83, p. 635-665.

[18] Eraslan, H. (2008). "Corporate Bankruptcy Reorganizations: Estimates from a Bargaining Model", International Economic Review, vol. 49, p. 659-681.

[19] Gilchrist S., J. Sim, and E. Zakrajsek (2014) "Uncertainty, Financial Frictions, and Investment Dynamics," mimeo.

[20] Gomes, J. (2001). "Financing Investment," American Economic Review, vol. 91, p. 12631285.

[21] Guner, N., G. Ventura, Y. Xu (2008). "Macroeconomic Implications of Size-Dependent Policies," Review of Economic Dynamics, vol. 11, p. 721-744.

[22] Hennessy, C. and T. Whited (2005). "Debt Dynamics," Journal of Finance, vol. 60, p. 1129-1165.

[23] Hennessy, C. and T. Whited (2007). "How Costly is External Financing? Evidence from a Structural Estimation, "Journal of Finance, vol. 62, p. 1705-1745.

[24] Hopenhayn, H. (1992). "Entry, Exit, and Firm Dynamics in Long-Run Equilibrium," Econometrica, 60, p. 1127-50.

[25] Hopenhayn, H. (2014). "Firms, Misallocation, and Aggregate Productivity: A Review," Annual Review of Economics, vol. 6, p. 735-770

[26] Hopenhayn, H. and R. Rogerson (1993) "Job Turnover and Policy Evaluation: A General Equilibrium Analysis", Journal of Political Economy, vol. 101, p. 915-38.

[27] Hsieh, C. and P. Klenow, P. (2009). "Misallocation and Manufacturing TFP in China and India," Quarterly Journal of Economics, 124, p. 1403-1448.

[28] Khan, A., T. Senga, and J. Thomas (2016). "Default Risk and Aggregate Fluctuations in an Economy with Production Heterogeneity," Society of Economic Dynamics, Meeting Paper.

[29] Khan, A. and J. Thomas (2013). "Credit Shocks and Aggregate Fluctuations in an Economy with Production Heterogeneity," Journal of Political Economy, vol. 121, p. 1055-1107.

[30] Livshits, I., J. MacGee, and M. Tertilt (2007). "Consumer Bankruptcy: A Fresh Start, "American Economic Review, vol. 97, p. 402-418. 
[31] Midrigan, V. and D. Xu (2014). "Finance and Misallocation: Evidence from Plant-Level Data," American Economic Review, vol. 104, p. 422-58.

[32] Meh, C. and Y. Terajima (2008). "Unsecured Debt, Consumer Bankruptcy, and Small Business,"WP2008-5, Bank of Canada.

[33] Moll, B. (2014). "Productivity Losses from Financial Frictions: Can Self-Financing Undo Capital Misallocation?" vol. 104, p. 3186-3221.

[34] Olley, G. S. and A. Pakes (1996). "The Dynamics of Productivity in the Telecommunications Equipment Industry," Econometrica, vol. 64, p. 1263-1297.

[35] Peri, A. (2015). "Bankruptcy Reforms When Workers Extract Rents."

[36] Restuccia, D. and R. Rogerson (2008). "Policy Distortions and Aggregate Productivity with Heterogeneous Establishments," Review of Economic Dynamics, vol. 1124, 707-720.

[37] Stech, K. (2014). "Bankruptcy Law Overhaul Would Mean Big Changes," Wall Street Journal, December 8, http://blogs.wsj.com/bankruptcy/2014/12/08/bankruptcy-lawoverhaul-would-mean-big-changes/.

[38] Strebulaev, A. and T. Whited (2012). Dynamic Models and Structural Estimation in Corporate Finance, Foundations and Trends in Finance, vol. 6, Now Publishers, Inc.

[39] Stromberg, P. (2000). "Conflicts of Interest and Market Illiquidity in Bankruptcy Auctions: Theory and Tests," Journal of Finance, vol. 55, p. 2641-2691.

[40] Tamayo, C. (2016). "Bankruptcy Choice with Endogenous Financial Constraints." 


\section{Appendix}

\section{A1 Data}

We use data from Compustat North America Fundamentals Annual. ${ }^{37}$ Our choice of firm identifier is GVKEY. The sample period for the fundamentals data ranges from 1980 to 2012. Our year variable is extracted from the variable DATADATE. We exclude financial firms with SIC codes between 6000 and 6999, utility firms with SIC codes between 4900 and 4999, and firms with SIC codes greater than 9000 (residual categories). Observations are deleted if they do not have a positive book value of assets or if gross capital stock or sales are zero, negative, or missing. We censorize the top and bottom $2 \%$ of the ratios we construct, as in Henessy and Whited [23]. The final sample is an unbalanced panel with more than 12,000 firms and 117,746 firm/year observations. All nominal variables are deflated using the Consumer Price Index (CPI) index (normalized to 100 in 1983). See Tables A1 and A2.

\footnotetext{
${ }^{37}$ All variable names correspond to the Wharton Research Data Services (WRDS) version of Compustat.
} 
Table A1: Variables

\begin{tabular}{|c|c|c|}
\hline Variable & Item (old definition) & Description \\
\hline GVKEY & & Firm Identifier \\
\hline DATADATE & & Data Date \\
\hline Company Name & & \\
\hline DLDTE & & Research Company Deletion Date \\
\hline DLRSN & & Research Co Reason for Deletion \\
\hline NAICS & & \\
\hline $\mathrm{SIC}$ & & \\
\hline $\mathrm{AT}$ & 6 & Book Assets \\
\hline PPEGT & 7 & Property, Plant and Equipment - Total (Gross) \\
\hline SPPE & 107 & Sale of Property \\
\hline CAPXV & 30 & Capital Expend Property, Plant and Equiment \\
\hline $\mathrm{DP}$ & 14 & Depreciation and Amortization \\
\hline IB & 18 & Income Before Extraordinaty Items \\
\hline SSTK & 108 & Sale of Common and Preferred Stock (equity issuance) \\
\hline DLTT & 9 & Long-Term Debt - Total \\
\hline DLC & 34 & Debt in Current Liabilities \\
\hline DVP & 19 & Dividends Preferred/Preference \\
\hline DVC & 21 & Dividends Common/Ordinary \\
\hline PRSTKC & 115 & Purchase of Common and Preferred Stock \\
\hline $\mathrm{CHE}$ & 1 & Cash and Short-Term Investments \\
\hline SALE & 12 & Sales \\
\hline CEQ & 60 & Common/Ordinary Equity - Total \\
\hline PRCC_F & 199 & Price Close - Annual Fiscal \\
\hline $\mathrm{CSHO}$ & 25 & Common Shares Outstanding \\
\hline $\mathrm{ACT}$ & 4 & Current Assets - Total \\
\hline $\mathrm{LCT}$ & 5 & Current Liabilities - Total \\
\hline OIBDP & 13 & Operating Income Before Depreciation \\
\hline XINT & 15 & Interest and Related Expense - Total \\
\hline INVT & 3 & Inventories - Total \\
\hline RECT & 2 & Receivables - Total \\
\hline BAST & 104 & Short Term Borrowings \\
\hline PPENT & 8 & Property, Plant and Equipment - Total (Net) \\
\hline $\mathrm{DM}$ & 241 & Debt - Mortgages and Other Secured $=$ Secured Debt \\
\hline DD1 & & Long-Term Debt Due in one Year \\
\hline $\mathrm{LT}$ & & Total Liabilities \\
\hline GP & & Gross Profits \\
\hline DT & & Total Debt Including Current \\
\hline TFVA & & Total Fair Value Assets \\
\hline TFVL & & Total Fair Value Liabilities \\
\hline EBIT & & Earnings before Interest and Taxes \\
\hline EBITDA & & Earnings before Interest \\
\hline
\end{tabular}

Source: Compustat Fundamentals (WRDS). 
Table A2: Derived Variables

\begin{tabular}{l|c|l}
\hline \hline Variable & Item (old definition) & Description \\
\hline PPEGT + CHE & $7+1$ & Total Assets = Capital + Cash \\
SSTK / (PPEGT + CHE) & $108 /(7+1)$ & Equity Issuance / Total Assets \\
CAPXV-SPPE & $30-107$ & Gross Investment \\
CAPXV-SPPE-DP & $30-107-18$ & Net Investment \\
CAPXV-SPPE-DP) / (PPEGT + CHE) & $(30-107-18) /(7+1)$ & Net Investment / Total Assets \\
DVP+DVC+PRSTKC & $19+21+115$ & Dividends = Total Cash Distributions \\
& $14+18$ & Cash Flow \\
$($ DVP+DVC+PRSTKC) / PPEGT + CHE) & $(19+21+115) /(7+1)$ & Dividends / Assets \\
DLTT+DLC & $34+9$ & Total debt \\
DLTT+DLC-CHE & $34+9-1$ & Net Debt = Total Debt - Cash \\
DLTT+DLC-CHE $<0$ & & Negative Net Debt \\
EBITDA /XINT & & Interest Coverage Ratio (EBITDA) \\
\hline \hline
\end{tabular}

Source: Compustat Fundamentals (WRDS).

\section{Identifying Exit and Bankruptcies}

We document firm exit, Chapter 11 bankruptcy, and Chapter 7 bankruptcy using a set of different sources. We code a firm/year observation as being in Chapter 11 bankruptcy whenever the following happens:

- Footnote to total assets in period $t+1$ reports code "AG" (reflects adoption of fresh-start accounting upon emerging from Chapter 11 bankruptcy).

- Footnote to total assets in period $t$ reports code "TL" (company in bankruptcy or liquidation) and the bankruptcy event does not lead to firm deletion.

- Footnote to total assets in period $t$ reports code "TL" (company in bankruptcy or liquidation), the bankruptcy event leads to firm deletion, and the variable DLRSN (research company reason for deletion) is equal to codes 01 (acquisition or merger), 02 (BBankruptcy), 04 (reverse acquisition), 07 (other, no longer files with SEC among other possible reasons, but pricing continues), 09 (now a private company) and 10 (other, no longer files with SEC among other possible reasons).

- If the firm/year observation corresponds to the last period of the firm in our sample, the variable DLRSN (research company reason for deletion) is equal to code 02 (bankruptcy), and the footnote to assets does not contain bankruptcy information.

To complement the set of Chapter 11 bankruptcies that we find using Compustat and dates from the footnote of total assets, we use Chapter 11 bankruptcy dates provided for firms with assets worth 100 million or more (in 1980 US\$) available in the UCLA-LoPucki Bankruptcy Research Database. 
We code a firm/year observation as being in Chapter 7 bankruptcy whenever the following happens:

- Footnote to total assets in period $t$ reports code "TL" (company in bankruptcy or liquidation); the bankruptcy event leads to firm deletion and the variable DLRSN (research company reason for deletion) is equal to code 03 (liquidation).

- If the firm/year observation corresponds to the last period of the firm in our sample, the variable DLRSN (research company reason for deletion) is equal to code 03 (Liquidation) and the footnote to assets does not contain bankruptcy information.

The classification into Chapter 11 and Chapter 7 bankruptcy during the last period of the firm in the sample is the same used by Duffie, Saita and Wang [17].

To be consistent with the definition of Chapter 11 bankruptcy, a deleted firm (i.e., a firm that disappears from our sample) is counted as a firm exit if the variable DLRSN is not equal to codes 01, 02, 04, 07, 09, or 10 (i.e., those not identified as continuing firms due to mergers, reorganization or because they go private for example). That implies that we classify a deletion as exit if the code equals code 02 (liquidation) or codes 11 through 14 or if the code is missing. This is consistent with the definition of exit that the U.S. Census Bureau uses to construct its exit statistics. Table A3 provides summary statistics about the frequency of each of the above codes. Using this information, we have 173,617 non-bankrupt firm/year observations, 1,319 Chapter 11 firm/year observations, and 315 Chapter 7 firm/year observations. Table A3 presents a set of summary statistics. Moments in this table are computed as the time series average of the corresponding cross-sectional statistic.

Table A3: Bankruptcy, Deletion and Exit Statistics

\begin{tabular}{l|c}
\hline \hline Moment (\%) & \\
\hline Frequency of Deletion & 8.09 \\
Frequency of Deletion Exit & 1.10 \\
Frequency of Deletion M \& A & 3.58 \\
Frequency of Deletion Going Private & 0.28 \\
Frequency of Deletion Chapter 7 & 0.19 \\
Frequency of all Bankruptcy & 0.96 \\
Fraction of Deletion Exit as Chapter 7 & 59.88 \\
Fraction of Chapter 11 Bankruptcy & 79.15 \\
\hline \hline
\end{tabular}

Note: Moments are computed as time series averages of the cross-sectional statistic. Deletion corresponds to the fraction of firms that disappear from our sample in any given period. M \& A refers to mergers and acquisitions. Source: Compustat Fundamentals (WRDS).

In Table 1 (see Section 2), we include tests of the differences between means. To do so, for 
each variable of interest $x_{t}$ (i.e., variables listed in Table 1), we run the following regressions:

$$
x_{i t}=a_{0}+a_{1} d_{i t}^{c h 11}+a_{2} d_{i t}^{c h 7}+b_{t}+u_{i t},
$$

where $d_{i t}^{c h 11}$ is a dummy variable that takes value 1 if the firm/year observation corresponds to the start of a Chapter 11 bankruptcy and zero otherwise; $d_{i t}^{c h} 7$ is a dummy variable that takes value 1 if the firm/year observation corresponds to a Chapter 7 bankruptcy and zero otherwise; and $b_{t}$ corresponds to a full set of year fixed effects. A significant coefficient $a_{1}$ reflects that average $x_{t}$ is significantly different for firms in Chapter 11 bankruptcy than that of nonbankrupt firms. Similarly, a significant coefficient $a_{2}$ reflects that average $x_{t}$ is significantly different for firms in Chapter 7 bankruptcy than that of non-bankrupt firms. To test whether that average of $x_{t}$ is significantly different for firms in Chapter 7 than for those in Chapter 11, we run a similar regression using only observations in Chapter 7 and Chapter 11 and using as a regressor $d_{i t}^{c h 7}$ and time fixed effects. A significant $d_{i t}^{c h 7}$ coefficient reflects means between these two groups are significantly different.

\section{z-scores and Distance to Default}

The Altman z-score is a commonly used measure of the level of distress of corporations (see Altman [3] for the seminal paper on the subject). The basic idea is to construct an index based on observable variables that helps to predict whether a firm is close to bankruptcy or not. More specifically, the $z$-score is defined as follows:

$$
z=1.2 x_{1}+1.4 x_{2}+3.3 x_{3}+0.6 x_{4}+0.999 x_{5}
$$

where $x_{1}$ is the working-capital-to-total-asset ratio (measured as current assets minus current liabilities over assets), $x_{2}$ is retained earnings over assets, $x_{3}$ corresponds to the earnings before interest and taxes over assets, $x_{4}$ is the market value of equity over the book value of total liabilities and $x_{5}$ is sales over total assets. The coefficients are determined using a multiple discriminant statistical method. Once the $z$-score is constructed, the rule of thumb is to define all firms having a $z$-score greater than 2.99 as "non-distressed" firms and those firms having a $z$-score below 1.81 as "distressed" firms. The area between 1.81 and 2.99 is defined as the "zone of ignorance."

In order to construct a default probability based on the distance-to-default model, we follow Duffie et. al [17]. The default probability is constructed using the number of standard deviations of asset growth by which a firm's market value of assets exceeds a liability measure. That is, for a given firm, the 1-year horizon distance to default is defined as:

$$
D_{t}=\frac{\ln \left(V_{t} / L_{t}\right)+\left(\mu_{A}-1 / 2 \sigma_{A}^{2}\right)}{\sigma_{A}}
$$


where $V_{t}$ is the market value of the firm's assets at time $t$, and $L_{t}$ is the liability measure (calculated as short-term book debt plus $1 / 2$ of long-term book debt), $\mu_{A}$ is the mean rate of asset growth and $\sigma_{A}$ the standard deviation of asset growth.

The market value of the firm is estimated following the theory of Merton (1974) and Black and Scholes (1973). More specifically, we let $W_{t}$ denote the market value of equity which is equal to an option on the value of a firm's assets, currently valued at $V_{t}$, with strike price of $L_{t}$ and one year to expiration. We obtain the asset value $V_{t}$ and the volatility of asset growth by solving the following system of equations iteratively:

$$
\begin{aligned}
W_{t} & =V_{t} \Phi\left(d_{1}\right)-L_{t} e^{r} \Phi\left(d_{2}\right), \\
\sigma_{a} & =\text { Std.Dev. }\left(\ln \left(V_{t}\right)-\ln \left(V_{t-1}\right),\right. \\
d_{1} & =\frac{\ln \left(V_{t} / L_{t}\right)+\left(r+1 / 2 \sigma_{A}^{2}\right)}{\sigma_{A}}, \\
d_{2} & =d_{1}-\sigma_{A},
\end{aligned}
$$

where $\Phi(\cdot)$ is the standard normal cdf, Std. Dev. denotes standard deviation and $r$ is the risk-free rate (that we take to be the real 1-year T-bill rate). The initial guess for $V_{t}$ is the sum of $W_{t}$ (measured as end-of-period real stock price times number of shares outstanding) and the book value of total debt (sum of short-term and long-term book debt). Once $V_{t}$ and $\sigma_{A}$ are estimated, we compute $D_{t}$. The corresponding default probability is

$$
p_{t}^{D}=\Phi\left(-D_{t}\right)
$$

\section{Construction of Bankruptcy Events}

In order to construct bankruptcy events, we restrict the sample to bankruptcies that happened between the years 1985 and 2010, so the entire window of any given event falls within our sample. Our sample contains not only firms with one event during their existence but also firms with more than one bankruptcy. We also found that events that are identified as Chapter 11 bankruptcies sometimes lead to the deletion of the firm from the sample (for example, due to changes in organizational structure or mergers). We proceed as follows:

- We ignore any event of a firm that goes into Chapter 11 the same year that it is removed from the sample (since we do not have information post-bankruptcy and these events are not classified as Chapter 7 bankruptcies).

- If a firm goes into bankruptcy more than once during its existence, we only use the events where a bankruptcy is not followed by another bankruptcy within the window of the event (i.e., as long as a new bankruptcy does not happen in periods $t=1,2,3,4$, or 5 of the event under consideration).

- We eliminate outliers by filtering out the top $1 \%$ and the bottom $1 \%$ of each of the 
variables reported.

- Standard deviations reported correspond to the cross-section deviation for those firms under analysis.

\section{A2 Computational Algorithm}

In this section, we describe our computational algorithm.

1. Set grids for $k \in K, b \in B$, and $z \in Z$.

2. Guess initial wage rate $w^{0}$, price schedule $q^{0}\left(k^{\prime}, b^{\prime}, z\right)$, and recovery rate schedule $\phi^{0}\left(k^{\prime}, b^{\prime}, z\right)$.

3. Solve Firm Problem: Given the bond price schedule, recovery schedule, and wage rate, solve the firm problem to obtain capital, debt, exit, and bankruptcy decision rules as well as value functions.

4. Update Recovery Schedule: Using the value functions obtained in step 3, solve the renegotiation problem to obtain $\phi^{1}\left(k^{\prime}, b^{\prime}, z\right)$.

5. Update Bond Price Schedule: Using the exit and bankruptcy decision rules, obtain a price function that is consistent with them. Let it be $q^{1}\left(k^{\prime}, b^{\prime}, z\right)$.

6. If $\left\|\phi^{1}(k, b, z)-\phi^{0}(k, b, z)\right\|<\epsilon_{\phi}$ and $\left\|q^{1}\left(k^{\prime}, b^{\prime}, z\right)-q^{0}\left(k^{\prime}, b^{\prime}, z\right)\right\|<\epsilon_{q}$, for small $\epsilon_{\phi}$ and $\epsilon_{q}$, then we have obtained the equilibrium price and recovery schedule (for a given price $\left.w^{0}\right)$, continue to the next step. If not, update the price and recovery schedule (i.e., set $\phi^{0}=\phi^{1}$ and $q^{0}=q^{1}$ ) and return to step 3 .

7. Update wage using free entry condition: Evaluate the free entry condition $V^{E}$ at $w^{0}$. If it holds with equality, continue. If it does not, proceed as follows:

- If $V^{E}$ is positive, increase $w^{0}$ and return to step 3 .

- If $V^{E}$ is negative, reduce $w^{0}$ and return to step 3.

\section{Derive Equilibrium Mass of Firms from Labor Market Clearing:}

- Set $M=1$ and compute the stationary distribution associated with the set of decision rules obtained above and this mass of entrants. Denote this distribution $\hat{\Gamma}(k, b, z ; M=1)$.

- Calculate labor demand $\hat{\Gamma}(k, b, z ; M=1)$, that is:

$$
\hat{N}(M=1)=\int n(z, k, b) d \hat{\Gamma}(z, k, b ; M=1) .
$$

- Set $M^{0}$ to satisfy the labor market clearing condition. That is, set $M^{0}$ as follows:

$$
M^{0}=1 / \hat{N}(M=1) .
$$


- The equilibrium prices and distribution are: $w^{*}=w^{0}, M^{*}=M^{0}, \Gamma^{*}=M^{*} \hat{\Gamma}(k, b, z ; M=$ 1), $q^{*}=q^{0}, \phi^{*}=\phi^{0}$.

- Aggregates and Taxes: Compute aggregate consumption and taxes.

\section{A3 Sensitivity Analysis}

\section{A3.1 Entry Costs Measured in Labor Units}

We study a version of the model where entry costs are measured in labor units. The value of an entrant is:

$$
V_{E}=\max _{k^{\prime} \geq 0, b^{\prime}}\left\{d_{E}+(1+r)^{-1} \sum_{z^{\prime}} V\left(z^{\prime}, k^{\prime}, b^{\prime}\right) \bar{G}\left(z^{\prime}\right)\right\}
$$

where

$$
d_{E}=-k_{E}^{\prime}+q\left(k_{E}^{\prime}, b_{E}^{\prime}\right) b_{E}^{\prime}-w \kappa-\lambda_{E}\left(-k_{E}^{\prime}+q\left(k_{E}^{\prime}, b_{E}^{\prime}\right) b_{E}^{\prime}-w \kappa\right) .
$$

The aggregate labor demand is:

$$
N=\int n(z, k, b) d \Gamma(z, k, b)+M^{*} \kappa
$$


Table A4: Bankruptcy Reforms ( $\kappa$ in labor units): Balance Sheet and Firm Dynamics

\begin{tabular}{l|c|c|c}
\hline \hline Moments (\%) & Data & $\begin{array}{c}\text { Bench. } \\
\text { Model }\end{array}$ & $\begin{array}{c}\text { Bankruptcy } \\
\text { Reform }\end{array}$ \\
\hline Exit Rate & 1.10 & 1.19 & 1.14 \\
Frequency of All Bankdruptcy & 0.96 & 0.88 & 0.43 \\
Fraction of Bankruptcy Reorganization & 79.15 & 72.61 & 99.99 \\
Recovery Rate by Liquidation & 5.80 & 4.23 & 14.51 \\
Recovery Rate Reorganization & 49.09 & 57.91 & 88.04 \\
Med. Equity Issuance Non-Bankrupt & 0.06 & 0.00 & 0.00 \\
Med. Equity Issuance Reorganization & 0.01 & 0.01 & 0.25 \\
Debt to Assets Non-Bankrupt & 28.31 & 28.97 & 36.63 \\
Debt to Assets Reorganization & 41.99 & 43.15 & 89.06 \\
Net Investment/Assets Non-Bankrupt & 1.16 & 0.89 & 1.06 \\
Net Investment/Assets Reorganization & -2.94 & -6.22 & -13.55 \\
\hline Fraction of Exit by Liquidation & 19.83 & 20.18 & 0.00 \\
Frac. Firms Issuing Equity Non-Bankrupt & 22.04 & 26.72 & 25.71 \\
Frac. Firms Issuing Equity Reorganization & 13.14 & 9.75 & 50.88 \\
Dividend to Asset Non-Bankrupt & 3.49 & 2.87 & 3.01 \\
Net Debt / Assets Non-Bankrupt & 9.11 & 22.82 & 32.99 \\
Net Debt / Assets Reorganization & 29.61 & 43.15 & 89.06 \\
Spread All firms & 1.300 & 0.50 & 0.051 \\
Spread Non-Bankrupt & & 0.43 & 0.052 \\
Spread Reorganization & & 13.86 & 0.000 \\
\hline Avg Size $(k)$ / Prod. $z$ Non-Bankrupt & & $0.642 / 1.015$ & $0.633 / 1.021$ \\
Avg Size $(k)$ / Prod. $z$ Ch 11 & $1.978 / 1.561$ & $0.433 / 0.6187$ \\
Avg Size $(k)$ / Prod. $z$ Ch 7 & $0.010 / 0.645$ & $0.010 / 0.589$ \\
Avg Size $(k)$ / Debt $b$ Entrant & & $0.674 / 0.475$ & $0.729 / 0.649$ \\
\hline \hline
\end{tabular}

Notes: In the benchmark, liquidation (Chapter 7 ) refers to $(\Delta=1, x=1)$, while reorganization (Chapter 11) refers to $(\Delta=1, x=0)$. In the reform, liquidation refers to $\Delta=1$ and $V(z, k, 0)<s k$, while reorganization refers to $\Delta=1$ and $W^{0}(z, k, 0) \geq s k$.

Table A4 shows that the changes in firm dynamics and the capital structure of firms after the reform in this case, where the entry cost is measured in labor units, are similar to our benchmark economy, where the entry cost is a resource cost to the economy. Table A5 shows that the aggregate results are robust to this change in the environment. 
Table A5: Bankruptcy Reforms ( $\kappa$ in labor units): Welfare and Aggregates (percent deviation)

\begin{tabular}{l|c||c}
\hline \hline & $\begin{array}{c}\text { Bench. } \\
\text { Model }\end{array}$ & $\begin{array}{c}\text { Bankruptcy } \\
\text { Reform }\end{array}$ \\
\hline Aggregate Consumption $C$ & 1.13 & 0.54 \\
Aggregate Output $Y$ & 1.76 & -0.01 \\
Fixed Cost $C F$ & 0.20 & 1.89 \\
Investment $I$ & 0.36 & -0.82 \\
Adjustment Costs $\Psi$ & 0.03 & -5.46 \\
Equity Issuance $\Lambda$ & 0.002 & -84.78 \\
Bankruptcy Costs $B C^{c}$ & 0.004 & -99.75 \\
Bankruptcy Costs $B C^{s}$ & 0.0001 & -100.00 \\
Exit Value $X$ & 0.01 & 26.47 \\
Entry Costs $E$ & 0.04 & 5.27 \\
\hline Equilibrium Wage & 1.00 & 0.00 \\
Capital to Output Ratio $K / Y$ & 1.46 & -1.35 \\
Measured TFP $\left(=Y / K^{1 / 3}\right)$ & 1.28 & 0.44 \\
Avg. Productivity $\bar{z}$ & 1.02 & 0.04 \\
Avg. (output weighted) Prod. $\hat{z}$ & 1.24 & 0.44 \\
Cov $(z, \omega)$ & 0.22 & 2.29 \\
Mass Entrants & 0.05 & -2.71 \\
Total Mass Firms & 3.97 & 1.83 \\
\hline \hline
\end{tabular}

Note: Benchmark in levels; all other columns present the percent deviation from the benchmark model. $\bar{z}$ is average firm productivity, $\widehat{z}$ is the (output weighted) average

firm level productivity, and $\omega$ is the output share of each firm.

As in our benchmark economy, after the bankruptcy reform output declines slightly but consumption increases due to the reduction in adjustment costs, equity issuance costs and bankruptcy costs.

\section{A3.2 Alternative Bankruptcy Costs}

In this appendix, we compare our benchmark with the results of our main bankruptcy reform where $\left\{c_{B}, s_{B}\right\}=\left\{c_{7}, s_{7}\right\}$ and those that arise if bankruptcy costs are set as $\left\{c_{B}, s_{B}\right\}=$ $\left\{c_{11}, s_{7}\right\}$ as well as $\left\{c_{B}, s_{B}\right\}=\left\{c_{11}, s_{11}\right\}$. Tables A6 and A7 present the comparison across the equilibria. 
Table A6: Bankruptcy Reforms: Balance Sheet and Firm Dynamics

\begin{tabular}{|c|c|c|c|c|c|}
\hline Moments (\%) & Data & $\begin{array}{l}\text { Bench. } \\
\text { Model }\end{array}$ & $\begin{array}{c}\text { Bankruptcy } \\
\text { Reform }^{\dagger} \\
c_{B}=c_{7} \\
s_{B}=s_{7}\end{array}$ & $\begin{array}{c}\text { Bankruptcy } \\
\text { Reform } \\
c_{B}=c_{11} \\
s_{B}=s_{7}\end{array}$ & $\begin{array}{c}\text { Bankruptcy } \\
\text { Reform } \\
c_{B}=c_{11} \\
s_{B}=s_{11}\end{array}$ \\
\hline Exit Rate & 1.10 & 1.19 & 1.14 & 1.16 & 1.20 \\
\hline Frequency of All Bankruptcy & 0.96 & 0.88 & 0.43 & 0.00 & 0.02 \\
\hline Fraction of Bankruptcy Reorganization & 79.15 & 72.61 & 99.99 & 99.61 & 0.00 \\
\hline Recovery Rate by Liquidation & 5.80 & 4.23 & 14.51 & 0.00 & 80.73 \\
\hline Recovery Rate Reorganization & 49.09 & 57.91 & 88.04 & 41.74 & n.a. \\
\hline Equity Issuance Non-Bankrupt & 0.06 & 0.00 & 0.00 & 0.00 & 0.00 \\
\hline Equity Issuance Reorganization & 0.01 & 0.01 & 0.65 & 0.30 & n.a. \\
\hline Debt to Assets Non-Bankrupt & 28.31 & 28.97 & 36.63 & 32.69 & 33.87 \\
\hline Debt to Assets Reorganization & 41.99 & 43.15 & 89.06 & 74.32 & n.a. \\
\hline Net Investment/Assets Non-Bankrupt & 1.16 & 0.89 & 1.06 & 0.919 & 0.90 \\
\hline Net Investment/Assets Reorganization & -2.94 & -6.22 & -13.55 & -21.64 & n.a. \\
\hline Fraction of Exit by Liquidation & 19.83 & 20.18 & 0.00 & 0.00 & 1.99 \\
\hline Frac. Firms Issuing Equity Non-Bankrupt & 22.04 & 26.72 & 25.70 & 25.86 & 26.53 \\
\hline Frac. Firms Issuing Equity Reorganization & 13.14 & 9.75 & 50.88 & 2.85 & n.a. \\
\hline Dividend to Asset Non-Bankrupt & 3.49 & 2.87 & 3.00 & 3.02 & 3.01 \\
\hline Dividend to Asset Reorganization & 1.80 & 0.00 & 0.00 & 0.00 & n.a. \\
\hline Net Debt / Assets Non-Bankrupt & 9.11 & 22.82 & 32.98 & 28.35 & 29.75 \\
\hline Net Debt / Assets Reorganization & 29.61 & 43.15 & 89.06 & 74.32 & n.a. \\
\hline Spread All Firms & 1.300 & 0.50 & 0.051 & 0.003 & 0.005 \\
\hline Spread Non-Bankrupt & & 0.43 & 0.052 & 0.004 & 0.005 \\
\hline Spread Reorganization & & 13.86 & 0.000 & 0.000 & n.a. \\
\hline Avg Size $(k) /$ Prod. $z$ Non-Bankrupt & & $0.642 / 1.015$ & $0.633 / 1.021$ & $0.635 / 1.020$ & $0.635 / 1.020$ \\
\hline Avg Size $(k) /$ Prod. $z$ Ch 11 & & $1.978 / 1.561$ & $0.433 / 0.619$ & $0.460 / 0.510$ & n.a. \\
\hline Avg Size $(k) /$ Prod. $z$ Ch 7 & & $0.010 / 0.645$ & $0.010 / 0.589$ & $0.284 / 0.438$ & $0.723 / 0.499$ \\
\hline Avg Size $(k) /$ Debt $b$ Entrant & & $0.674 / 0.475$ & $0.729 / 0.649$ & $0.729 / 0.523$ & $0.729 / 0.586$ \\
\hline
\end{tabular}

Notes: In the benchmark, liquidation (Chapter 7) refers to $(\Delta=1, x=1)$, while reorganization (Chapter 11) refers to $(\Delta=1, x=0)$. In the reform, liquidation refers to $\Delta=1$ and $V(z, k, 0)<s k$, while reorganization refers to $\Delta=1$ and $W^{0}(z, k, 0) \geq s k .{ }^{\dagger}$ refers to Main Reform. 
Table A7: Bankruptcy Reforms: Welfare and Aggregates (percent deviation)

\begin{tabular}{|c|c|c|c|c|}
\hline & $\begin{array}{l}\text { Bench. } \\
\text { Model }\end{array}$ & $\begin{array}{c}\text { Bankruptcy } \\
\text { Reform }^{\dagger} \\
c_{B}=c_{7} \\
s_{B}=s_{7}\end{array}$ & $\begin{array}{c}\text { Bankruptcy } \\
\text { Reform } \\
c_{B}=c_{11} \\
s_{B}=s_{7}\end{array}$ & $\begin{array}{c}\text { Bankruptcy } \\
\text { Reform } \\
c_{B}=c_{11} \\
s_{B}=s_{11}\end{array}$ \\
\hline & & \multicolumn{3}{|c|}{$(\Delta \%)$} \\
\hline Aggregate Consumption $C$ & 1.13 & 0.54 & 0.55 & 0.55 \\
\hline Aggregate Output $Y$ & 1.76 & -0.04 & -0.08 & -0.06 \\
\hline Fixed Cost $C F$ & 0.20 & 1.87 & 1.38 & 1.34 \\
\hline Investment $I$ & 0.36 & -0.83 & -0.81 & -0.95 \\
\hline Adjustment Costs $\Psi$ & 0.03 & -5.49 & -5.86 & -6.02 \\
\hline Equity Issuance $\Lambda$ & 0.002 & -84.32 & -84.86 & -83.78 \\
\hline Bankruptcy Costs $B C^{c}$ & 0.004 & -99.75 & -100.00 & -96.28 \\
\hline Bankruptcy Costs $B C^{s}$ & 0.0001 & -100.00 & -100.00 & -100.00 \\
\hline Exit Value $X$ & 0.01 & 26.38 & 30.76 & 39.21 \\
\hline Entry Costs $E$ & 0.04 & 3.52 & 4.68 & 8.21 \\
\hline Equilibrium Wage & 1.00 & 0.02 & -0.06 & -0.04 \\
\hline Capital to Output Ratio $K / Y$ & 1.46 & -1.35 & -1.29 & -1.35 \\
\hline Measured TFP $\left(=Y / K^{1 / 3}\right)$ & 1.28 & 0.43 & 0.38 & 0.41 \\
\hline Avg. Productivity $\bar{z}$ & 1.02 & -0.02 & 0.00 & 0.06 \\
\hline Avg. (output weighted) Prod. $\hat{z}$ & 1.24 & 0.44 & 0.44 & 0.46 \\
\hline $\operatorname{Cov}(z, \omega)$ & 0.22 & 2.58 & 2.49 & 2.32 \\
\hline Mass Entrants & 0.05 & -2.78 & -1.54 & 1.76 \\
\hline Total Mass Firms & 3.97 & 1.80 & 1.34 & 1.33 \\
\hline
\end{tabular}

Note: Benchmark in levels, all other columns present the percent deviation from the benchmark model. $\bar{z}$ is average firm productivity, $\widehat{z}$ is the (output weighted) average

firm level productivity, and $\omega$ is the output share of each firm. ${ }^{\dagger}$ Main Reform.

Table A6 shows that the exit rate is barely affected by changes in the value of bankruptcy costs. However, the bankruptcy rate is significant smaller after reforms where the cost is set to $c_{B}=c_{11}$ (this is also reflected in the sharp reduction in spreads). Under all reforms, the debt-to-asset ratio of non-bankrupt firms increase. Table A7 makes evident that the variation in bankruptcy rates does not affect the aggregate results. After all reforms, output decreases slightly but consumption increases due to the reduction in adjustment costs, equity issuance costs, and bankruptcy costs. Allocative efficiency also increases in all experiments.

\section{A3.3 Reform No Chapter 11}

In this appendix, we compare our benchmark with the results of our main bankruptcy reform and those that arise after a reform that eliminates Chapter 11 reorganization. We imple- 
ment this experiment by increasing the cost of Chapter 11 in our benchmark economy to a prohibitively high number. Tables A8 and A9 present the comparison across the equilibria.

Table A8: Bankruptcy Reforms: Balance Sheet and Firm Dynamics

\begin{tabular}{l|c|c|c|c}
\hline \hline & & Bench. & Bankruptcy & Reform \\
Moments (\%) & Data & Model & Reform & No Ch $11\left(c_{11}=\infty\right)$ \\
\hline Exit Rate & 1.10 & 1.19 & 1.14 & 1.24 \\
Frequency of All Bankruptcy & 0.96 & 0.88 & 0.43 & 0.25 \\
Fraction of Bankruptcy Reorganization & 79.15 & 72.61 & 99.99 & n.a. \\
Recovery Rate by Liquidation & 5.80 & 4.23 & 14.51 & 4.33 \\
Recovery Rate Reorganization & 49.09 & 57.91 & 88.04 & n.a. \\
Equity Issuance Non-Bankrupt & 0.06 & 0.00 & 0.00 & 0.00 \\
Equity Issuance Reorganization & 0.01 & 0.01 & 0.65 & n.a. \\
Debt to Assets Non-bankrupt & 28.31 & 28.97 & 36.63 & 32.37 \\
Debt to Assets Reorganization & 41.99 & 43.15 & 89.06 & n.a. \\
Net Investment/Assets Non-Bankrupt & 1.16 & 0.89 & 1.06 & 0.71 \\
Net Investment/Assets Reorganization & -2.94 & -6.22 & -13.55 & n.a. \\
\hline Fraction of Exit by Liquidation & 19.83 & 20.18 & 0.00 & 20.55 \\
Frac. Firms Issuing Equity Non-Bankrupt & 22.04 & 26.72 & 25.70 & 26.42 \\
Frac. Firms Issuing Equity Reorganization & 13.14 & 9.75 & 50.88 & n.a. \\
Dividend to Asset Non-Bankrupt & 3.49 & 2.87 & 3.00 & 3.08 \\
Dividend to Asset Reorganization & 1.80 & 0.00 & 0.00 & n.a. \\
Net Debt / Assets Non-Bankrupt & 9.11 & 22.82 & 32.98 & 27.38 \\
Net Debt / Assets Reorganization & 29.61 & 43.15 & 89.06 & n.a. \\
Spread All Firms & 1.300 & 0.50 & 0.051 & 0.160 \\
Spread Non-Bankrupt & & 0.43 & 0.052 & 0.160 \\
Spread Reorganization & & 13.86 & 0.000 & n.a. \\
\hline Avg Size $(k) /$ Prod. $z$ Non-Bankrupt & & $0.642 / 1.015$ & $0.633 / 1.021$ & $0.648 / 1.019$ \\
Avg Size $(k)$ / Prod. $z$ Ch 11 & & $1.978 / 1.561$ & $0.433 / 0.619$ & n.a. \\
Avg Size $(k)$ / Prod. $z$ Ch 7 & & $0.010 / 0.645$ & $0.010 / 0.589$ & $0.011 / 0.645$ \\
Avg Size $(k) /$ Debt $b$ Entrant & & $0.674 / 0.475$ & $0.729 / 0.649$ & $0.707 / 0.519$ \\
\hline \hline
\end{tabular}

Notes: In the benchmark, liquidation (Chapter 7 ) refers to $(\Delta=1, x=1)$, while reorganization (Chapter 11) refers to $(\Delta=1, x=0)$. In the reform, liquidation refers to $\Delta=1$ and $V(z, k, 0)<s k$, while reorganization refers to $\Delta=1$ and $W^{0}(z, k, 0) \geq s k$. 
Table A9: Bankruptcy Reforms: Welfare and Aggregates (percent deviation)

\begin{tabular}{l|c||c|c}
\hline \hline & $\begin{array}{c}\text { Bench. } \\
\text { Model }\end{array}$ & $\begin{array}{c}\text { Bankruptcy } \\
\text { Reform }\end{array}$ & $\begin{array}{c}\text { Reform } \\
\text { No Ch } 11\left(c_{11=\infty}\right)\end{array}$ \\
\hline & & \multicolumn{2}{|c}{$(\Delta \%)$} \\
\hline Aggregate Consumption $C$ & 1.13 & 0.54 & 0.48 \\
Aggregate Output $Y$ & 1.76 & -0.04 & -0.20 \\
Fixed Cost $C F$ & 0.20 & 1.87 & -0.19 \\
Investment $I$ & 0.36 & -0.83 & -1.36 \\
Adjustment Costs $\Psi$ & 0.03 & -5.49 & -2.91 \\
Equity Issuance $\Lambda$ & 0.002 & -84.32 & -83.78 \\
Bankruptcy Costs $B C^{c}$ & 0.004 & -99.75 & -99.75 \\
Bankruptcy Costs $B C^{s}$ & 0.0001 & -100.00 & -81.25 \\
Exit Value $X$ & 0.01 & 26.38 & 2.48 \\
Entry Costs $E$ & 0.04 & 3.52 & 7.37 \\
\hline Equilibrium Wage & 1.00 & 0.02 & -0.21 \\
Capital to Output Ratio $K / Y$ & 1.46 & -1.35 & -0.43 \\
Measured TFP $\left(=Y / K^{1 / 3}\right)$ & 1.28 & 0.43 & 0.01 \\
Avg. Productivity $\bar{z}$ & 1.02 & -0.02 & -0.01 \\
Avg. (output weighted) Prod. $\hat{z}$ & 1.24 & 0.44 & 0.48 \\
Cov $(z, \omega)$ & 0.22 & 2.58 & 2.76 \\
Mass Entrants & 0.05 & -2.78 & 3.50 \\
Total Mass Firms & 3.97 & 1.80 & -0.15 \\
\hline \hline
\end{tabular}

Note: Benchmark in levels, all other columns present the percent deviation from the benchmark model. $\bar{z}$ is average firm productivity, $\widehat{z}$ is the (output weighted) average

firm level productivity, and $\omega$ is the output share of each firm.

Table A8 shows that when Chapter 11 reorganization is not available the exit rate increases and the bankruptcy rate is largely reduced. The fraction of firms that is liquidated after bankruptcy (Chapter 7 ) is barely affected ( 0.241 in the benchmark versus 0.25 after the reform). The debt-to-asset ratio increases (as was the case under our main bankruptcy reform analyzed). Table A9 makes evident that eliminating Chapter 11 results in lower output $(-0.20 \%$, also consistent with the reduction in wages) but higher consumption $(+0.48 \%)$ due to lower adjustment costs, equity issuance costs, and bankruptcy costs.

\section{A3.4 Sensitivity Analysis: Bargaining Weights}

In this section, we present a sensitivity analysis with respect to the parameter controlling the bargaining weight $(\theta)$. By moving this parameter, we can also understand how the bankruptcy reform compares with reforms that would give the borrower more or less bargaining power than the benchmark value. Tables A10 and A11 present the comparison across the equilibria. 


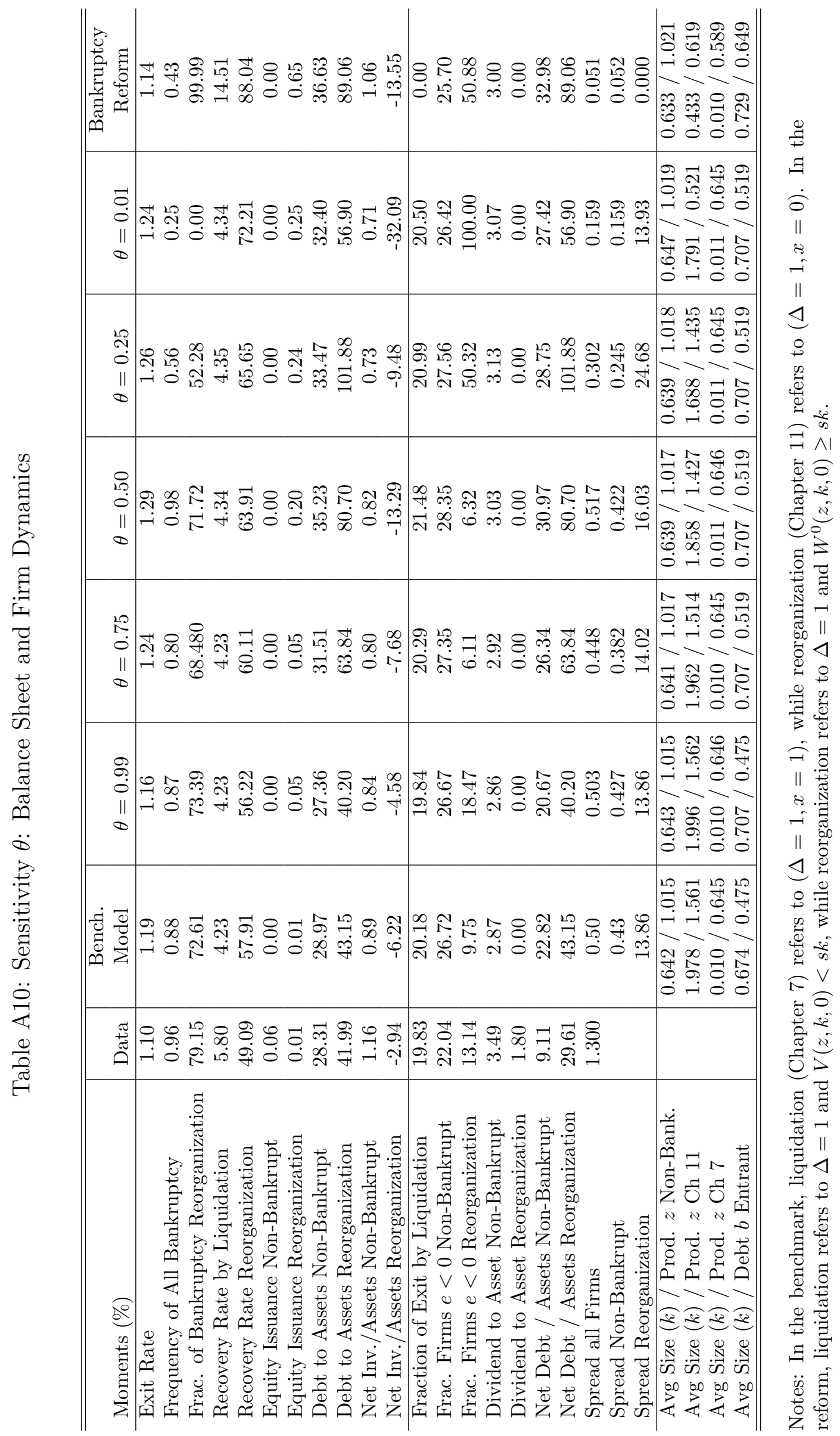


Table A11: Sensitivity $\theta$ : Welfare and Aggregates (percent deviation)

\begin{tabular}{|c|c|c|c|c|c|c|c|}
\hline & $\begin{array}{c}\text { Bench. } \\
\text { Model } \\
\theta=0.96\end{array}$ & $\theta=0.99$ & $\theta=0.75$ & $\theta=0.50$ & $\theta=0.25$ & $\theta=0.01$ & $\begin{array}{c}\text { Bankruptcy } \\
\text { Reform }\end{array}$ \\
\hline & & \multicolumn{6}{|c|}{$(\Delta \%)$} \\
\hline Aggregate Consumption $C$ & 1.13 & 0.00 & 0.00 & -0.26 & 0.10 & 0.48 & 0.54 \\
\hline Aggregate Output $Y$ & 1.76 & -0.04 & 0.03 & 0.01 & -0.16 & -0.20 & -0.04 \\
\hline Fixed Cost $C F$ & 0.20 & -0.10 & 0.29 & 0.21 & 0.47 & -0.20 & 1.87 \\
\hline Investment $I$ & 0.36 & -0.16 & -0.84 & -1.32 & -1.66 & -1.36 & -0.83 \\
\hline Adjustment Costs $\Psi$ & 0.03 & -0.77 & -1.05 & -0.57 & -3.96 & -2.87 & -5.49 \\
\hline Equity Issuance $\Lambda$ & 0.002 & -10.27 & 45.95 & 124.86 & 24.86 & -83.78 & -84.32 \\
\hline Bankruptcy Costs $B C^{c}$ & 0.004 & -0.74 & -14.14 & 10.42 & -54.34 & -99.75 & -99.75 \\
\hline Bankruptcy Costs $B C^{s}$ & 0.0001 & -6.25 & -12.50 & 137.50 & 18.75 & -81.25 & -100.00 \\
\hline Exit Value $X$ & 0.01 & -2.48 & 3.50 & 6.27 & 4.96 & 2.62 & 26.38 \\
\hline Entry Costs $E$ & 0.04 & 0.91 & 8.18 & 12.53 & 10.37 & 7.43 & 3.52 \\
\hline Equilibrium Wage & 1.00 & -0.03 & 0.03 & 0.00 & -0.16 & -0.20 & 0.02 \\
\hline Capital to Output Ratio $K / Y$ & 1.46 & 0.10 & -0.14 & -0.26 & -0.56 & -0.43 & -1.35 \\
\hline Measured TFP $\left(=Y / K^{1 / 3}\right)$ & 1.28 & -0.06 & 0.07 & 0.09 & 0.08 & 0.01 & 0.43 \\
\hline Avg. Productivity $\bar{z}$ & 1.02 & -0.10 & 0.00 & 0.05 & 0.02 & -0.01 & -0.02 \\
\hline Avg. (output weighted) Prod. $\hat{z}$ & 1.24 & 0.48 & 0.47 & 0.45 & 0.34 & 0.48 & 0.44 \\
\hline $\operatorname{Cov}(z, \omega)$ & 0.22 & 3.15 & 2.67 & 2.30 & 1.79 & 2.76 & 2.58 \\
\hline Mass Entrants & 0.05 & -2.74 & 2.20 & 23.13 & 6.38 & 3.55 & -2.78 \\
\hline Total Mass Firms & 3.97 & -0.14 & -0.47 & 0.30 & 0.53 & -0.16 & 1.80 \\
\hline
\end{tabular}

Note: Benchmark in levels; all other columns present the percent deviation from the benchmark model. $\bar{z}$ is average firm productivity, $\widehat{z}$ is the (output weighted) average

firm level productivity, and $\omega$ is the output share of each firm.

\section{A3.5 Decomposition: General Equilibrium vs Partial Equilibrium}

This section presents the results of the counterfactual experiments absent general equilibrium effects (i.e., the wage rate stays constant and does not adjust to satisfy the free entry condition). Table A12 shows the comparison of the effects of the reform under general equilibrium (GE) and partial equilibrium (PE). 
Table A12: Bankruptcy Reform: General Equilibrium vs Partial Equilibrium

\begin{tabular}{l|c|c|c}
\hline \hline & Bench. & $\begin{array}{c}\text { G.E. } \\
\text { Bankruptcy } \\
\text { Reform }\end{array}$ & $\begin{array}{c}\text { P.E. } \\
\text { Bankruptcy } \\
\text { Reform }\end{array}$ \\
\hline Exit Rate & 1.19 & 1.14 & 1.14 \\
Frequency of All Bankruptcy & 0.88 & 0.43 & 0.47 \\
Fraction of Bankruptcy Reorganization & 72.61 & 99.99 & 99.99 \\
Recovery Rate by Liquidation & 4.23 & 14.51 & 14.51 \\
Recovery Rate Reorganization & 57.91 & 88.04 & 87.87 \\
Equity Issuance Non-Bankrupt & 0.00 & 0.00 & 0.00 \\
Equity Issuance Reorganization & 0.01 & 0.65 & 0.61 \\
Debt to Assets Non-bankrupt & 28.97 & 36.63 & 36.69 \\
Debt to Assets Reorganization & 43.15 & 89.06 & 90.03 \\
Net Investment/Assets Non-Bankrupt & 0.89 & 1.06 & 1.06 \\
Net Investment/Assets Reorganization & -6.22 & -13.55 & -13.05 \\
\hline Fraction of Exit by Liquidation & 20.18 & 0.00 & 0.00 \\
Frac. Firms Issuing Equity Non-Bankrupt & 26.72 & 25.70 & 25.46 \\
Frac. Firms Issuing Equity Reorganization & 9.75 & 50.88 & 49.38 \\
Dividend to Asset Non-Bankrupt & 2.87 & 3.00 & 3.01 \\
Dividend to Asset Reorganization & 0.00 & 0.00 & 0.00 \\
Net Debt / Assets Non-Bankrupt & 22.82 & 32.98 & 33.05 \\
Net Debt / Assets Reorganization & 43.15 & 89.06 & 90.03 \\
Spread All Firms & 0.50 & 0.051 & 0.058 \\
Spread Non-Bankrupt & 0.43 & 0.052 & 0.058 \\
Spread Reorganization & 13.86 & 0.000 & 0.000 \\
\hline Avg Size $(k) /$ Prod. $z$ Non-Bankrupt & $0.642 / 1.015$ & $0.633 / 1.021$ & $0.633 / 1.021$ \\
Avg Size $(k)$ / Prod. $z$ Ch 11 & $1.978 / 1.561$ & $0.433 / 0.619$ & $0.425 / 0.625$ \\
Avg Size $(k)$ / Prod. $z$ Ch 7 & $0.010 / 0.645$ & $0.010 / 0.589$ & $0.010 / 0.584$ \\
Avg Size $(k)$ / Debt $b$ Entrant & $0.674 / 0.475$ & $0.729 / 0.649$ & $0.729 / 0.649$ \\
Avg. Prod. $z$ & 1.020 & 1.019 & 1.019 \\
Avg. (weighted) Prod. $\hat{z}$ & 1.240 & 1.246 & 1.246 \\
Cov( $z, \omega)$ Non-Bankrupt & 0.221 & 0.227 & 0.227 \\
\hline \hline
\end{tabular}

Notes: GE correspond to solution of general equilibrium model (i.e., the wage rate adjusts to clear the labor market). $\mathrm{PE}$ corresponds to the solution of the partial equilibrium model (i.e., wage rate stays constant). Liquidation (Chapter 7 ) refers to $(\Delta=1, x=1)$ while reorganization (Chapter 11) refers to $(\Delta=1, x=0)$. 